\title{
E-aprendizaje en bibliotecología: perspectivas globales
}

FILIBERTO FELIPE MARTÍNEZ ARELLANO (comp.)

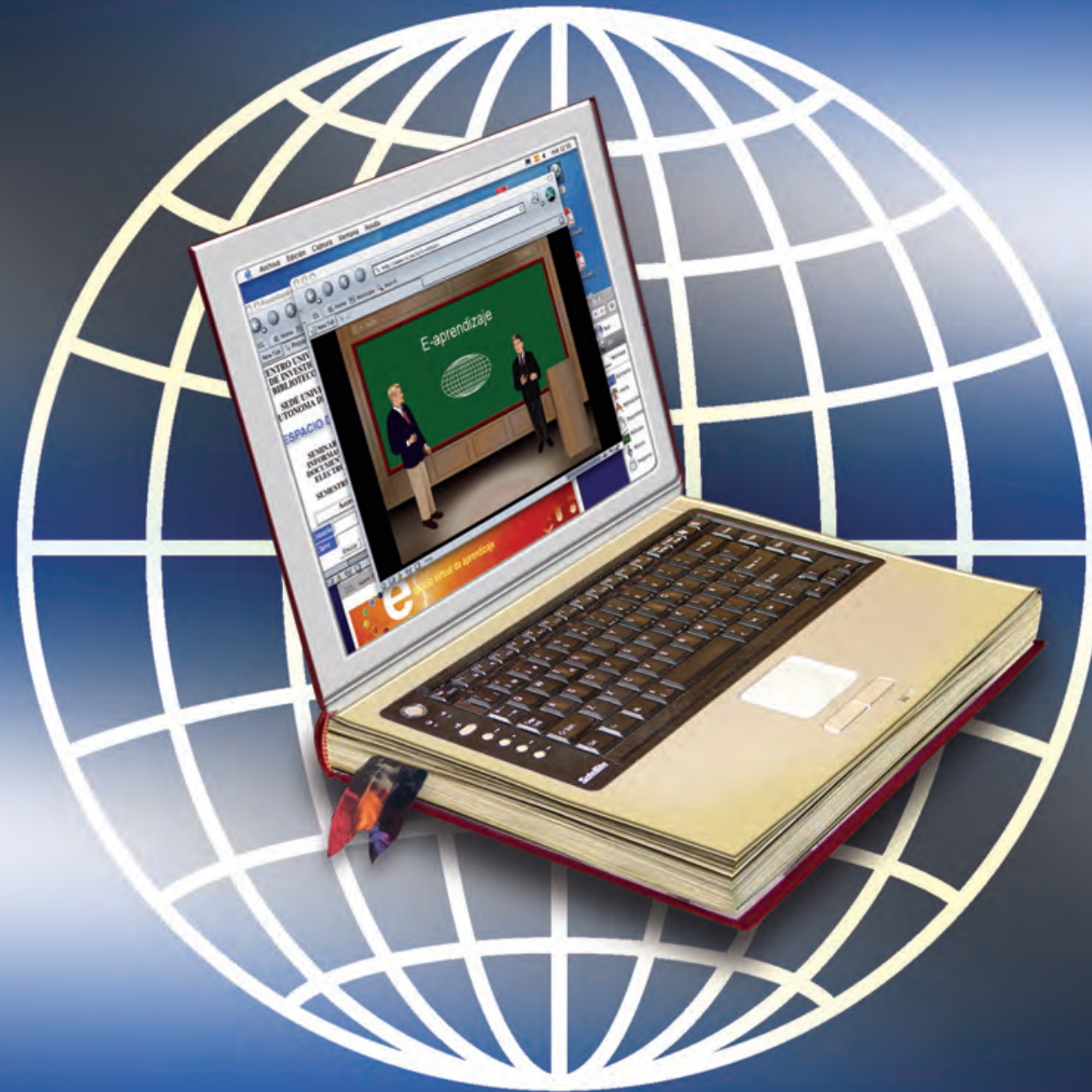

PEt

(1)

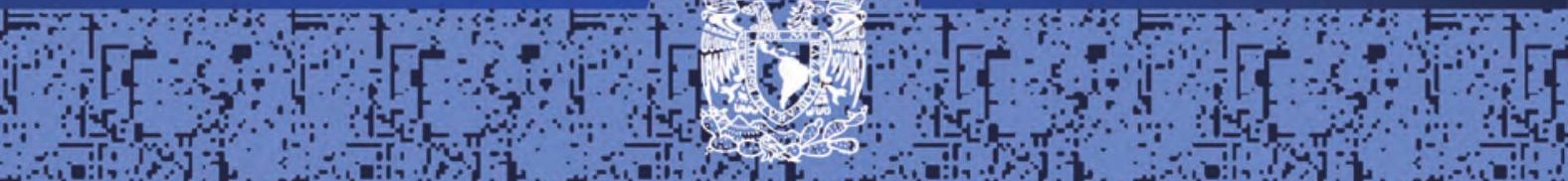
ons 


\section{La presente obra está bajo una licencia de:}

\section{http://creativecommons.org/licenses/by-nc-sa/3.0/deed.es MX}

\section{Atribución-No Comercial-Licenciamiento Reciproco 3.0 Unported}

Eres libre de:

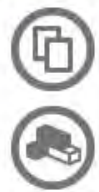

copiar, distribuir y comunicar públicamente la obra

hacer obras derivadas

Bajo las condiciones siguientes:

Atribución - Debes reconocer la autoría de la obra en los términos

especificados por el propio autor o licenciante.

No comercial - No puedes utilizar esta obra para fines comerciales.

Licenciamiento Reciproco - Si alteras, transformas o creas una obra a

partir de esta obra, solo podrás distribuir la obra resultante bajo una licencia

igual a ésta.

\section{Esto es un resumen fácilmente legible del: texto legal (de la licencia completa)}

\section{En los casos que sea usada la presente} obra, deben respetarse los términos especificados en esta licencia.

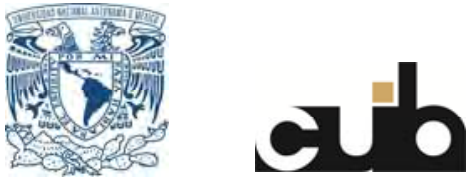


E-aprendizaje en bibliotecología: perspectivas globales 


\section{COLECCIÓN}

TECNOLOGíAS DE LA INFORMACIÓN

Centro Universitario de Investigaciones Bibliotecológicas 


\title{
E-aprendizaje en bibliotecología: perspectivas globales
}

\author{
Compilador \\ Filiberto Felipe Martínez Arellano
}

Universidad Nacional Autónoma de México 2005 


\section{LC5803}

C65E36 E-aprendizaje en bibliotecología : perspectivas globales / Comp. Filiberto Felipe Martínez Arellano. - México : UNAM, Centro Universitario de Investigaciones Bibliotecológicas, 2005.

xi, 155 p. - (Tecnologías de la Información)

ISBN: 970-32-2741-4

1. Enseñanza Asistida por Computadora - Bibliotecología 2. Educación a Distancia - Bibliotecología 3. Tecnologías de la Información y las Comunicaciones I. Martínez Arellano Filiberto Felipe, comp. II. ser.

Diseño de portada: Mario Ocampo Chávez

Primera Edición 2005

DR @ UNIVERSIDAd NACIONAL AUTÓNOMA DE MÉXICO

Ciudad Universitaria, 04510, México D.F.

Impreso y hecho en México

ISBN: 970-32-2741-4 


\section{Contenido}

INTRODUCCIÓN . . . . . . . . . . . . . . . . . vii

Filiberto Felipe Martínez Arellano

SITUACIÓN ACTUAL Y PERSPECTIVAS DEL E-APRENDIZAJE EN

MÉXICO Y SUS REPERCUSIONES EN EL ÁMBITO

DE LA BIBLIOTECOLOGÍA . . . . . . . . . . . . . . . . . . 1

Roberto Garduño Vera

SOPORTE AL E-LEARNING: UN NUEVO DESAFÍO PARA

LOS BIBLIOTECARIOS . . . . . . . . . . . . . . . . . . . . 61

Regina Santos Silva Tonini

CALIDAD Y E-LEARNING $\ldots \ldots \ldots \ldots$

Viviana Fernández Marcial

PRINCIPLES OF CLASSIFICATION FOR WRITING

HYPERDOCUMENTS . . . . . . . . . . . . . . . . . . . . . . . 92

Maria Luiza de Almeida Campos

Hagar Espanha Gomez

InTERoperability With E-LEARNING Process: CAPABILITIES

OF Digital LIBRARIES IN SUPPORTING COURSE WEBSITES

AS A NeW DOMAIN OF E-SERVICES . . . . . . . . . . . . . . . . 104

Ahmed Taha

E-APRENDiZAJE EN El Posgrado EN Bibliotecología Y

ESTUDIOS DE LA INFORMACIÓN DE LA UNIVERSIDAD

NACIONAL AUTÓNOMA DE MÉXICO . . . . . . . . . . . . . . . . 120

Filiberto Felipe Martínez Arellano

Adolfo Rodríguez Gallardo

AUTORES . . . . . . . . . . . . . . . . . . . . . . . . . 154 



\title{
Introducción
}

\author{
Filiberto Felipe Martínez Arellano
}

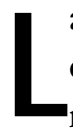

a integración de las tecnologías de la información y la comunicación (TICs) en diversos campos y actividades de la sociedad actual muestra una gran expansión y la educación no podía ser la excepción. Las formas en las cuales la enseñanza es proporcionada y el aprendizaje es adquirido han cambiado notablemente las peculiaridades de la educación debido a un incremento en la utilización de las computadoras, la comunicación basada en Internet y la existencia de nuevas opciones de comunicación, distribución y recuperación de la información, tales como las listas de discusión, el correo electrónico, el chat y los recursos electrónicos de la web. Como producto de la integración de las TICs dentro de la educación, particularmente la Internet, ha surgido el e-aprendizaje, el cual ha sido visto como una oportunidad para eliminar las barreras de espacio, tiempo y distancia, facilitando además este proceso educativo.

Un estudio llevado a cabo por el National Center for Education Statistics (2004) de los Estados Unidos de Norteamérica para estimar el número de instituciones que impartían educación a distancia, considerando a ésta como los cursos ofrecidos en forma remota fuera del campus a través de audio, video (en vivo o pregrabado) o con tecnologías de cómputo (en forma síncrona o asíncrona), encontró que durante el año académico 2000-2001, un 56 por ciento $(2,320)$ de las instituciones de educación superior de ese país ofrecían este modalidad educativa y otro 12 por ciento (510) estaban planeando ofrecerla 
en los próximos tres años. Por otro lado, actualmente más de 70 millones de personas ya reciben educación a través de Internet y en un futuro próximo, la formación de profesionales en distintas disciplinas será efectuada de ese modo. (El e-aprendizaje, 2004).

Al igual que en otras disciplinas, dentro de la bibliotecología, la educación a distancia y el e-aprendizaje representan nuevas alternativas para la formación profesional. El número de programas de educación a distancia basados en las TICs se ha incrementado notablemente en los últimos años. En un reporte estadístico de la Asociación de Educación en Bibliotecología y Ciencias de la Información (Association for Library and Information Science Education), correspondiente a 1990, se mostraba que 38 escuelas de los Estados Unidos de Norteamérica ofrecían alrededor de 408 cursos fuera de las instalaciones de sus campus, cerca del doble de los que habían sido ofrecidos el año anterior. Asimismo, solamente diez escuelas utilizaron alguna forma de telecomunicaciones para impartirlos. Por otro lado, en el reporte correspondiente al año 2000, cuarenta y cuatro escuelas ofrecían 489 cursos fuera de sus instalaciones y en veintiocho de ellos se había utilizado alguna forma de telecomunicaciones. En 1990, catorce escuelas indicaban cambios en sus ofertas educativas, principalmente en el incremento de sus contenidos y en el 2000, veintiocho escuelas indicaron cambios, particularmente en el número de cursos ofrecidos a través de Internet (Barron, 2002).

Por otro lado, en el Directorio 2004-2005 de Programas de Maestría en Bibliotecología y Estudios de la Información acreditados por la American Library Association (2005), se incluyeron diez instituciones que ofrecían programas totalmente en línea, ocho que ofrecían programas en línea complementados con algunos cursos presenciales, diecisiete instituciones que utilizaban satélite y televisión para impartir sus programas y otras diecisiete con programas presenciales pero que incluían algunos cursos en línea.

Los datos anteriormente mencionados son algunas de las evidencias que permiten afirmar que actualmente la educación en línea y el 
e-aprendizaje son fenómenos que forman parte del entorno educativo del siglo XXI. Asimismo, que dentro de la bibliotecología, estos fenómenos también se encuentran presentes. Por otro lado, es posible afirmar que a nivel mundial, la educación en línea y el e-aprendizaje también son utilizados para la formación de bibliotecólogos. Considerando que podría ser de interés para la disciplina conjuntar y presentar los puntos de vista sobre la educación en línea y el e-aprendizaje en bibliotecología de especialistas provenientes de distintas partes del mundo, se ha elaborado el presente trabajo. En éste se han incluido trabajos de especialistas de México, Brasil, España y los Emiratos Árabes Unidos, lo cual es ilustrativo del interés que este tema ha despertado a nivel mundial. Sin duda alguna, en muchos casos es difícil separar lo local de lo global y la práctica de la teoría por lo que todos estos aspectos se encuentran de alguna $u$ otra forma entrelazados dentro de los trabajos incluidos.

Roberto Garduño Vera en su documento "Situación actual y perspectivas del e-aprendizaje en México y sus repercusiones en el ámbito de la bibliotecología" reflexiona sobre los siguientes asuntos: la educación a distancia y las tecnologías de información y comunicación como referentes del e-aprendizaje; la tendencia emergente del e-aprendizaje; el panorama del e-aprendizaje empresarial en México; el panorama de la educación a distancia y su vínculo con el e-aprendizaje en la educación superior en México; la industria tecnológica en México; las instituciones mexicanas relevantes que ofrecen programas educativos a distancia; el programa del gobierno federal sobre e-aprendizaje; el e-aprendizaje que existe sobre bibliotecología en México; las instituciones en México que ofrecen programas a distancia en bibliotecología y las ciencias de la información; y las perspectivas del e-aprendizaje en el campo de la bibliotecología y los estudios de la Información en México.

En el texto de Regina Santos Silva Tonini, "Soporte al e-learning: un nuevo desafío para los bibliotecarios", se presentan una serie de consideraciones sobre las ventajas del aprovechamiento de las tecnologías 
que hacen posible esta forma de aprendizaje y la importante posibilidad de desarrollo para las personas de todo el mundo, particularmente para las de los países en vías de desarrollo, donde los recursos educativos, muchas veces escasos, impiden que los alumnos asistan a las clases presenciales. Adicionalmente se considera la relevancia de los portales que presentan textos en más de dos idiomas, los cuales superan las barreras lingüísticas, especialmente en los países en desarrollo. También se presenta una reflexión sobre el rol del bibliotecario en la sociedad actual y su condición de profesional responsable de investigar, organizar y facilitar la información y que puede contribuir a lograr resultados positivos en el proceso del e-aprendizaje. Se expone, en líneas generales, un proyecto para la utilización de bibliotecas digitales como herramienta de apoyo al trabajo de los e-estudiantes.

Viviana Fernández Marcial en su trabajo, "Calidad y e-learning", aborda el establecimiento de criterios, indicadores, estándares y sistemas de calidad en el e-aprendizaje. Asimismo, los procesos de acreditación de la calidad y su tendencia en la gestión de la calidad en esta modalidad educativa. Revisa una amplia gama de iniciativas orientadas al establecimiento de estándares de calidad y de guías de recomendaciones y/o evaluación de la calidad en el contexto de la formación virtual, particularmente las iniciativas relacionadas con la calidad en el e-aprendizaje desarrolladas, fundamentalmente, en el ámbito de la Comunidad Europea.

En el documento, "Principles of classification for writing hyperdocuments", Maria Luiza de Almeida Campos y Hagar Espanha Gomes resaltan la importancia de la clasificación facetada y la teoría de conceptos como las bases teóricas y metodológicas para la planeación y la escritura de hiperdocumentos con propósitos educativos. Estas dos teorías proporcionan las condiciones para la elaboración de nodos coherentes y evitar la sobrecarga cognoscitiva.

Ahmed Taja en su documento, "Interoperability with e-learning process: capabilities of digital libraries in supporting course websites as a 
new domain of e-services", esboza las líneas generales de un plan de la Universidad de los Emiratos Arabes Unidos para enfrentar los retos que el nuevo paradigma del e-aprendizaje posee y explora algunas formas para apoyar la integración de los e-recursos con los programas de estudio en la web. Sus beneficios y potenciales son discutidos y ubicados dentro de una gama de oportunidades para una colaboración fructífera dentro de la sociedad basada en el conocimiento.

Finalmente, en el documento de Filiberto Felipe Martínez Arellano y Adolfo Rodríguez Gallardo, "E-aprendizaje en el Posgrado en Bibliotecología y Estudios de la Información de la Universidad Nacional Autónoma de México", se exponen las ventajas y retos que presenta esta nueva opción educativa. Asimismo, se presentan las principales características de la plataforma de e-aprendizaje utilizada para impartir este posgrado a distancia y como el uso de las TICs ha apoyado los roles y actividades de los alumnos y del profesor en un ambiente de e-aprendizaje, reproduciendo el ambiente de aprendizaje del salón de clases tradicional dentro de un entorno virtual.

\section{REFERENCIAS}

American Library Association (2005). 2004-2005 Directory of institutions offering ALA-accredited Master's Programs in Library and Information Studies.

http://www.ala.org/ala/accreditation/lisdirb/lisdirectory.htm (Consultado, 25 de enero de 2005).

Barron, Dan (2002). Distance education in Library and Information Science: a long road traveled. Journal of Education for Library and Information Science, 43(1), 3-5

El e-aprendizaje (2004).

http://tecnologia.monster.es/articulos/e_aprend/

(Consultado, 25 de enero de 2005).

National Center for Education Statistics (2004). Distance education at degree-granting postsecondary institutions: 2000-2001. http://nces.ed.gov/surveys/peqis/publications/2003017/ (Consultado, 25 de enero de 2005). 



\title{
Situación actual y perspectivas del e-aprendizaje en México y sus repercusiones en el ámbito de la bibliotecología
}

\author{
ROBERTO GARDUÑO VERA
}

\section{RESUMEN}

En la génesis del siglo XXI se evidencia con mucha certeza que la educación en todos sus niveles ha sido afectada por los progresos derivados de la investigación científica y tecnológica. El control, en cuanto al desarrollo de las tecnologías de la información y la comunicación, la privatización y comercialización de conocimiento, a la vez que la demanda creciente de propuestas educativas por parte de la sociedad, lleva a las universidades a incidir en programas que faciliten el avance hacia un desarrollo sostenible relacionado con la prestación de servicios educativos. En este contexto, el e-aprendizaje como modelo de interacción social educativa plantea novedosas formas de aprendizaje basado en la convergencia tecnológica y en los objetos de aprendizaje. El valor de dicha convergencia radica en que las TICs (Tecnologías de Información y Comunicación) no reconocen fronteras geopolíticas y en que junto con los objetos de aprendizaje y los actores educativos prometen transformaciones culturales en los entornos educativos en donde se desarrolle el e-aprendizaje.

En este documento se reflexiona principalmente a partir de los siguiente asuntos: la educación a distancia y las tecnologías de información y comunicación como referentes del e-aprendizaje; la tendencia emergente del e-aprendizaje; el panorama del e-aprendizaje empresarial en México; el panorama de la educación a distancia y su vínculo con el e-aprendizaje en la educación superior en México; la industria tecnológica en México; las instituciones mexicanas relevantes que ofrecen programas educativos a distancia; el programa 
del gobierno federal sobre e-aprendizaje; el e-aprendizaje que existe sobre bibliotecología en México; las instituciones en México que ofrecen programas a distancia en bibliotecología y ciencias de la información; y las perspectivas del e-aprendizaje en el campo de la bibliotecología y los estudios de la información en México.

\section{INTRODUCCIÓN}

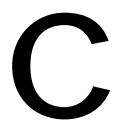

iertamente, la educación a distancia de finales del siglo XX y los inicios del XXI, se ha posicionado como modalidad alternativa debido, entre otros aspectos, a los avances pedagógicos y a la incorporación de tecnologías de información y comunicación. Lo anterior ha requerido modernizar la educación a través de programas que evidencien las políticas de gobierno dirigidas a efectuar cambios culturales, económicos y constitucionales; respondan y le den coherencia a la incorporación de los individuos a programas educativos que propician la democratización educativa; y disminuyan los rezagos de preparación existentes en los distintos niveles educativos.

En la actualidad se ha dado un incremento exponencial de propuestas educativas a distancia debido a la influencia de la globalización y el aumento en cuanto al uso de tecnologías para la prestación de servicios educativos. Por ello, la enseñanza a distancia representa un fenómeno de estudio permanente porque son aún escasas las propuestas sólidas sobre la educación vía Internet, lo cual convierte este fenómeno en objeto de investigación en todas las áreas disciplinares.

No obstante las diversas connotaciones generadas principalmente por las tecnologías de información y comunicación, tales como educación virtual, educación en línea, e-learning, entre otras, existe una tendencia a incorporar estas particularidades en la educación a distancia porque su trayectoria histórica permite identificar las dimensiones de estas formas de enseñanza-aprendizaje. Respecto al e-learning, se puede mencionar lo siguiente: 
El aprendizaje a través de medios electrónicos se caracteriza por ser "[...] un conjunto de métodos, tecnologías, aplicaciones y servicios orientados a facilitar el aprendizaje a distancia a través de Internet." 1 Para ello, la industria del e-learning considera como fundamentales los siguientes aspectos: el desarrollo de contenido, el software de apoyo a la generación de contenidos y su distribución, el uso de plataformas tecnológicas en el aprendizaje por medios electrónicos, la venta de contenidos generados por autores individuales o institucionales, la venta de software educativo como soporte en el desarrollo de contenidos y la venta de servicios en los que se pueden involucrar centros virtuales para la formación.

Al parecer, el e-aprendizaje llama cada vez más la atención de empresas de distinta naturaleza debido a los aspectos mencionados y también porque promete una baja inversión que redundaría en costo-beneficio en la formación de grupos en los diversos sectores. También es evidente que el e-learning tiene como intención penetrar el mercado de la educación en todos sus niveles, y es esto lo que suscita la reflexión sobre sus posibles repercusiones en la sociedad y en la educación del presente siglo.

\section{LA EDUCACIÓN A DISTANCIA Y LAS TECNOLOGÍAS DE INFORMACIÓN Y COMUNICACIÓN COMO REFERENTES DEL E-APRENDIZAJE}

En la actualidad se observa que la reciente aparición de la industria relacionada con el aprendizaje por medios electrónicos está posicionándose globalmente. No obstante que en sus inicios manifestó una orientación hacia el desarrollo de contenidos y la capacitación empresarial, en la actualidad se perfila como una propuesta educativa vinculada con las nuevas modalidades del aprendizaje virtual en

1 Cornella, Alfonso. E-learning: de la formación de los empleados al conocimiento en toda la cadena de valor. En El Profesional de la Información, vol. 11, núm. 1, ene-feb. 2002, p. 65. 
distintos niveles educativos. Por ello, su orientación reciente remite necesariamente a la convergencia tecnológica y sus repercusiones en la educación a distancia, la educación en línea, la tele-enseñanza y el tele-aprendizaje, entre otras denominaciones.

A partir de la última década del siglo XX, la educación a distancia se ha visto afectada con mayor énfasis por el uso de Tecnologías de Información y Comunicación (TICs) debido a que éstas han propiciado el desarrollo de escenarios virtuales de aprendizaje donde el estudio individual y la colaboración del grupo determinan dinámicas para la construcción de aprendizajes. Así, en la génesis del siglo XXI se ha hecho patente que este tipo de aprendizaje exige de los participantes un compromiso de colaboración activa y planificada que tome en cuenta intenciones educativas específicas y marcos pedagógicos compartidos.

Por lo anterior, los elementos que precisa la educación a distancia para poder llegar a la educación virtual y aprovechar las TICs son los análisis necesarios que permitan comprender con mayor certeza las posibilidades del aprendizaje electrónico en la formación del presente siglo. En este sentido hay que partir del hecho de que el estudio de los conceptos y los elementos teóricos fundamentales de la educación a distancia puede explicar la importancia del e-aprendizaje, valorar su utilidad y abrir interrogantes que motiven investigación en temas relacionados con este fenómeno emergente, como pueden ser: "[...] el rol de factorías de contenidos en la industria del e-learning, desarrollo y diseño de contenidos: tendencias a considerar en el proceso de terciarización, tendencias e innovaciones en los contenidos de e-learning [...] el aspecto lúdico del e-learning: el juego en entornos virtuales, fuentes de contenido para el diseño de propuestas de aprendizaje virtuales a medida". ${ }^{2}$

2 Contenidos e-learning. En e-learning América Latina. La Revista Digital de Elearnig en América Latina, año1, núm. 8, nov. 2004. [En línea]

http://www.elearnigamericalatina.com/edicion/noviembre/index.php

[Consultada: 05/1104]

Para una mayor información al respecto, también se puede consultar:

http://www.elearningamericalatina.com/encuestas/latinoamerica_4.php 
El creciente interés generado por el estudio y aplicación de la educación a distancia, la educación virtual y el e-aprendizaje ha suscitado que en los últimos años abunde la literatura generada en formatos impresos y digitales. Mucha de esta literatura evidencia el intento de consolidar los conceptos apropiados que agrupen la esencia de estas formas de educar y de aprender.

Así, diversos autores coinciden al señalar que el término educación a distancia involucra desde el campo de estudio de la educación por correspondencia, fundamentada en impresos, hasta la educación virtual, denominada también educación en línea, la cual se apoya en las TICs. En ambas situaciones, la noción de la separación del tutor y del alumno es una constante. Sin embargo, muchos autores e instituciones prefieren utilizar el término aprendizaje a distancia porque aquí el énfasis radica en el alumno, más que en el proceso educativo. "Se puede señalar que la diferencia entre educación a distancia y aprender a distancia es un asunto de énfasis debido a que no existe hasta nuestros días, consenso en los medios académico sobre cual término es el más apropiado". ${ }^{3}$

Con la aplicación de las TICs en la educación a distancia y en el e-aprendizaje, la situación conceptual se ha complicado aún más, por lo que se ha intentado generar conceptos que expliquen de manera apropiada el uso que se hace de estas tecnologías en estas nuevas formas de enseñar y aprender. En la actualidad existe una amplia gama de conceptos que buscan explicar y fundamentar las características relacionadas con la separación de los actores del aprendizaje, el desarrollo de contenidos, la entrega de materiales didácticos, los procesos de la comunicación, etcétera. Quizá, la novedad más significativa de algunas definiciones consista en destacar las facilidades que estas tecnologías les otorga a los actores del aprendizaje para interactuar y navegar en entornos virtuales y entregar materiales didácticos en línea. Algunos de los términos más frecuentemente utilizados para explicar dichos aspectos son los siguientes: aprendizaje distribuido,

3 Ibídem, p. 11. 
aprendizaje síncrono, aprendizaje asíncrono, tele-aprendizaje, teleenseñanza, tele-formación, educación virtual, educación vía Internet y aprendizaje electrónico (e-learning).

El aprendizaje distribuido parece tener características en común con el aprendizaje abierto y flexible, pero al mismo tiempo implica el uso de tecnologías de información y comunicación para desarrollar y entregar los cursos. El aprendizaje síncrono se refiere a la interacción en tiempo real entre los actores del aprendizaje. En cambio el aprendizaje asíncrono implica la comunicación en tiempo diferido, lo que determina la obtención de respuestas en tiempos diferidos. En ambos casos, las interacciones con el aprendizaje se realizan por lo general a través de la comunicación asistida por computadora.

Collins define al tele-aprendizaje como: "[...]la conexión entre personas y recursos a través de las tecnologías de la comunicación con un propósito de aprendizaje". ${ }^{4}$ En cuanto a la tele-enseñanza, Tiffin la define como "[...] la posibilidad de simular la presencia física sin que ésta exista realmente y de facilitar la interacción entre estudiantes y profesores". ${ }^{5}$ Con relación a la tele-formación, FUNDESCO manifiesta que "[...] es un sistema de impartición de formación a distancia, apoyada en TIC, que combina distintos elementos pedagógi$\cos [\ldots] " .{ }^{6}$ Se puede observar que es común a todas ellas "el componente 'tele' como prefijo, el cual determina un sentido de distancia a la palabra [a la que está unida], aunque en la actualidad casi siempre implica el uso de redes telemáticas". ${ }^{7}$ Por su parte Urdan y Weggan definen e-learning como "[...] el desarrollo de contenidos a través de cualquier medio electrónico, incluyendo Internet, Intranet,

4 Collis, B. Tele-learning in a digital world: the future of distance learning. London : International Thompson Computers Press, 1996. p. 9.

5 Tiffin, John y Lalita Rajasingham. En busca de la clase virtual: la educación en la sociedad de la información. Barcelona: Paidós, 1997. p. 235.

6 FUNDESCO. Teleformación: un paso más en el camino de la formación continua. Madrid : FUNDESCO, 1998. p. 56.

7 Sanz Prieto, Mariano. Teleeducación entornos de aula virtual. En Temas [2002], p.12. 
extranet, satélites, cintas de audio y video, televisión interactiva y CD-ROM". ${ }^{8}$ A mayor abundamiento, Rosenberg afirma lo siguiente: “[...] 1. el e-learning consiste en una red cuyo propósito es lograr en forma ágil el almacenamiento, la recuperación, la distribución y la conexión con el instructor o con la información. 2. éste es liberado al usuario final vía computadora utilizando estándares tecnológicos internacionales. El propósito principal está referido a soluciones de aprendizaje-aprendizaje apoyado por paradigmas tradicionales de formación". 9

Se puede señalar que las definiciones más recientes coinciden al señalar que las constantes invariables se refieren a la separación física de los sujetos del aprendizaje, los contenidos didácticos y los medios de comunicación. Asimismo, diversos especialista en educación han señalado que la denominación educación a distancia puede ser considerado como el término más amplio que puede integrar, entre otros, los mencionados con anterioridad, los cuales son utilizados de acuerdo con la oferta educativa que se persiga. En el presente trabajo el término núcleo a utilizar será e-aprendizaje o aprendizaje electrónico, debido al enfoque del propio documento; sin embargo, también se hace referencia a las modalidades de educación a distancia, virtual y en línea.

Como corolario se puede señalar que en los últimos años, un asunto que ha suscitado mucha discusión en los medios académicos especializados se refiere a la aplicación de tecnologías de información y comunicación en el aprendizaje electrónico; la reflexión se ha orientado, entre otros aspectos, a su implantación en la sociedad debido a que "[...] sus efectos y alcance, no sólo se sitúan en el terreno

8 Urdan, T. y C. Weggan. Citados por Carlos Marcelo [et al.]. Formando teleformadores: diseño y desarrollo de un curso online utilizando WebCT. [En línea] http://s.es/idea/mie/pub/marcelo/Formando\%20Teleformadores.pdf

9 Cfr. Rosenberg, Marc J. e-learning for delivering knowledge in the digital age, 2001. Citado en Introducción al e-learnig. [En línea] http://www.mailxmail.com/curso/empresa/elearnig/capitulo1.htm [Consultada: 06/11/04] 
de la información y comunicación, sino que lo sobrepasan para llegar a provocar y proponer cambios en la estructura social, económica, jurídica, política, [educativa]. Y ello es debido a que; no sólo se centran en la captación de la información, sino también, y es lo verdaderamente significativo, a las posibilidades que tienen para manipularla, almacenarla y distribuirla”. ${ }^{10}$

\section{TENDENCIA EMERGENTE DEL E-APRENDIZAJE}

Los orígenes del e-aprendizaje se sitúan en las tecnologías de información y comunicación y su principal objetivo ha sido la formación de grupos que hagan uso de las tecnologías emergentes; sin embargo, “[...] en el 2005, 58.8\% del mercado de e-aprendizaje está concentrado en el desarrollo de habilidades para negocios y en otras habilidades no relacionadas con tecnologías de información". ${ }^{11}$

Asimismo, "[...] los sistemas de administración de contenidos para el aprendizaje (LCMS por sus siglas en inglés) son la última tendencia en el mercado de e-aprendizaje. Expertos de la industria aseguran que los LCMS que han aparecido en los últimos 12 meses les permiten a las empresas crear pequeñas unidades de contenido educativo llamadas [objetos de aprendizaje], que les representan ahorros en tiempo y costos asociados con el desarrollo de contenidos". ${ }^{12}$

Sin embargo habrá que tomar en cuenta que aunque el e-aprendizaje enfatiza como propósitos principales la administración y el desarrollo de contenidos, los hechos muestran que el aprendizaje electrónico se propone avanzar con mayor fuerza en los próximos años hacia el desarrollo de contenidos, apoyados en el uso creciente

10 Cabrero Almenara, Julio. Nuevas Tecnologías, comunicación y educación. En EDUTEC. Revista electrónica de tecnología educativa, núm.1, feb. 1996. [En línea] www.http://uib.es/depart/gte/revelec1.html/ [Consultada: 20/10/03

11 Hechos y estadísticas del e-aprendizaje. [En línea] http://www.dr-zippie.net/?elearnig_/ [Consultada: 06/11/04]

12 Ibídem. 
de las TICs y la interacción académica efectiva entre tutor-alumno, alumno-tutor, la cual utiliza diversos canales de comunicación que implican el fomento del estudio independiente y al aprendizaje en colaboración y en escenarios virtuales.

Lo anterior determina el uso creciente de redes de teleproceso donde los sistemas tecnológicos de comunicación e información transformen con mayor énfasis los procesos y las prácticas tradicionales del aprendizaje y la socialización de conocimiento en tareas como: producción, distribución, apropiación, representación, significación e interpretación de la información y el conocimiento. Cabe señalar que estos aspectos son inherentes a la educación a distancia.

En este sentido se ha mencionado que "[...] la convergencia tecnológica de las redes telemáticas en la tele-enseñanza y el tele-aprendizaje induce a la integración de diversas tecnologías de información, la diversificación de los sistemas de comunicación y la apertura de fuentes de información". ${ }^{13}$ Así, la convergencia radica en la posibilidad de realizar comunicaciones y diálogos remotos entre individuos y grupos, la facilidad para distribuir información y conocimiento, y la capacidad para generar ciberespacios y espacios virtuales orientados a la interactividad entre computadoras y actores del aprendizaje. De esta forma, la universidad virtual atiende el reto que plantea la globalización a partir del abordaje en los cambios que requieren los modelos de aprendizaje. "[...] las ventajas de la universidad virtual son amplias y variadas, y se consolidan cada vez más a partir del crecimiento de Internet". ${ }^{14}$

El uso en el aumento de tecnologías en el e-aprendizaje es complejo, por lo que los resultados que se esperan de ellas deben ser

13 UNESCO. Rapport mondial sur la communication. Citado por Rocío Amador Bautista. Nuevos procesos educativos en el medio digital. En El medio digital en el siglo XXI: retos y perspectivas para los bibliotecólogos, investigadores, educadores y editores. México : UNAM, CUIB, [Editado en CD-ROM]. Trabajo presentado en el XVIII Coloquio Internacional de Investigación Bibliotecológica.

14 Contreras M. Rita. Reflexiones en torno al uso de la tecnología de la información en el terreno educativo. En Soluciones Avanzadas: tecnologías de información y estrategias de negocios, vol. 5, no. 46, jun. 1997, p. 12. 
considerados a largo plazo y en el marco de la revolución tecnológica que ha incidido en la sociedad de la información y del conocimiento. Con relación a esta idea, Loyo ha señalado que " [...] con la utilización de agentes cooperativos implantados en computadoras, multimedios y utilizando sistemas de enseñanza asistida por computadora, se incrementará la participación interactiva y la interacción directa de los actores del proceso de enseñanza-aprendizaje". ${ }^{15}$ A mayor abundamiento sobre los diversos aspectos del e-aprendizaje, Cornella hace una serie de señalamientos al respecto, de los cuales se destacan los siguientes:

1. Los cursos monolíticos de larga duración sobre un determinado tema, serán sustituidos por pastillas de conocimiento que vengan a responder inmediatamente a las necesidades de los usuarios. [...] habrá que construir los contenidos en términos de RLO (Reusable Learning Objects), pequeñas experiencias independientes de aprendizaje, que contienen un objetivo, una actividad de aprendizaje y una forma de evaluación

2. Los momentos de aprendizaje podrán realizarse mediante contenidos en una amplia gama de formatos (texto, audio, vídeo o una combinación de ellos en forma de simulaciones realistas), para tener en cuenta tanto el momento (la situación) en la que se encuentre el usuario (en el coche, en su casa, etc.), como sus estilos personales de aprendizaje (aprendo viendo, escuchando, hacien$d o$, etc.). La clave de esta nueva visión sobre la formación residirá en facilitar a los usuarios la identificación de sus objetivos de aprendizaje, así como la navegación por los materiales disponibles.

3. La elaboración de los contenidos no se realizará de manera centralizada, sino que cualquier persona podrá estructurar sus conocimientos en un curso, mediante herramientas simples, en forma de plantilla. Cualquiera tendrá entre sus funciones principales aprender (para hacer mejor su trabajo, pero también para contribuir con ideas a generar productos que respondan a los ciclos de vida más cortos de los mercados), y también enseñar (transmitir lo que sabe a los demás, y no sólo almacenando lo que lleva en su cabeza, sino

15 Loyo Varela, C. y V.G. Sánchez. La telemática y la educación a distancia [En línea]. En Soluciones Avanzadas, vol. 4, núm. 24, ago., 1995.

http://www.lania.mx/nivel2/divulgacion.html 
haciendo un esfuerzo por hacerlo comprensible, es decir, con una orientación pedagógica).

4. El e-learning no se limitará a la formación de los empleados, sino que se extenderá a toda la cadena de valor. Así, con frecuencia se deberá proveer de contenidos organizados tanto a los proveedores como a los clientes. 16

No obstante que el e-aprendizaje surge con el propósito principal de generar y vender contenidos, en la actualidad se advierte una tendencia a elaborar propuestas educativas integrales que respondan a los requerimientos de empresas e instituciones de distinta naturaleza. Algunos aspectos de dicha tendencia se hacen evidentes en los rubros que siguen.

\section{PANORAMA DEL E-APRENDIZAJE EMPRESARIAL EN MÉXICO}

Tomando en consideración los diversos aspectos mencionados con anterioridad, así como las posibilidades del aprendizaje por medios electrónicos, conviene enfatizar que la tecnología del e-learning presenta opciones que pueden ser aprovechadas para la capacitación y la formación continua en diversos niveles educativos.

Para muchos expertos de la industria de la información, la próxima aplicación dominante de Internet será el e-learning. Este instrumento de educación y cooperación [...] permitirá a los empleados de una empresa concluir una licenciatura y trabajar con otro equipo en cualquier parte del mundo. ${ }^{17}$

Debido a que en nuestros días el impacto más notorio del e-aprendizaje se da en el sector empresarial, se hace referencia a información relevante emanada de una encuesta orientada a identificar diversos aspectos de la situación del e-learning corporativo en América Latina.

16 Cornella, Alfonso. E-learning: de la formación de los empleados al conocimiento en toda la cadena de valor. En El Profesional de la Información, Vol. 11, núm. 1, ene-feb. 2002, p. 68.

17 E-learning en México. En Reforma, el independiente. [En línea] Eduterra.com [Consultado: 1811/04] 
"La encuesta se realizó [...] en México, Perú, Brasil, Chile, Argentina, olombia y Ecuador, sobre un universo de 480 grandes y medianas empresas de la región. Del conjunto de consultas efectuadas, 140 se realizaron en México, 100 en Brasil, 90 en Argentina, 50 en Chile, 40 en Colombia, 32 en Perú y 28 en Ecuador". ${ }^{18}$ Por la orientación de este documento sólo se citan algunos resultados relevantes relacionados con México; no obstante, es importante hacer notar que este artículo puede ser de mucho interés para los estudiosos del e-learning.

Con relación al uso de tecnologías (gráfica 1), la gran mayoría de los ejecutivos de las compañías consultadas le asignaron importancia al uso de la tecnología digital como herramienta de negocios. El $82,14 \%$ opinó que las TICs son esenciales para lograr un mayor éxito y productividad, mientras que el $10 \%$ les asignó una moderada relevancia, sólo el 2,85\% de los entrevistados le restó importancia y descartó su influencia en el crecimiento de una empresa. El 5\% restante no precisó respuestas a esta requisitoria.

En la actualidad, sólo el 22,14\% de las compañías mexicanas se encuentran implementando una solución de e-learning (gráfica 2) para la capacitación y formación de su personal y un $45 \%$ de los empresarios indagados manifestó tener planes tendientes a incorporar esta metodología en un futuro. El 18,57\% aseguró no considerar la posibilidad de adoptarla. Así, el porcentaje de quienes no tienen una opinión formada sobre el particular asciende a 14,28\%.

De esta forma, de las 140 empresas consultadas, $94(67,14 \%)$ manifestaron estar implementando soluciones de e-learning, o considerando su aplicación en los procesos de capacitación corporativos en un futuro próximo.

18 Encuesta panorámica e-learning corporativo en América Latina 2003 [Resultados México] / Tecnonexo. En e-learning América Latina, Revista Digital de E-learnig de América Latina, año 2, núm. 46, nov. 2004. [En línea]

http://www.elearningamericalatina.com/encuestas/latinoamerica.php [Consultada: 20/11/04] 


\section{Gráfica 1.}

Uso de tecnologías

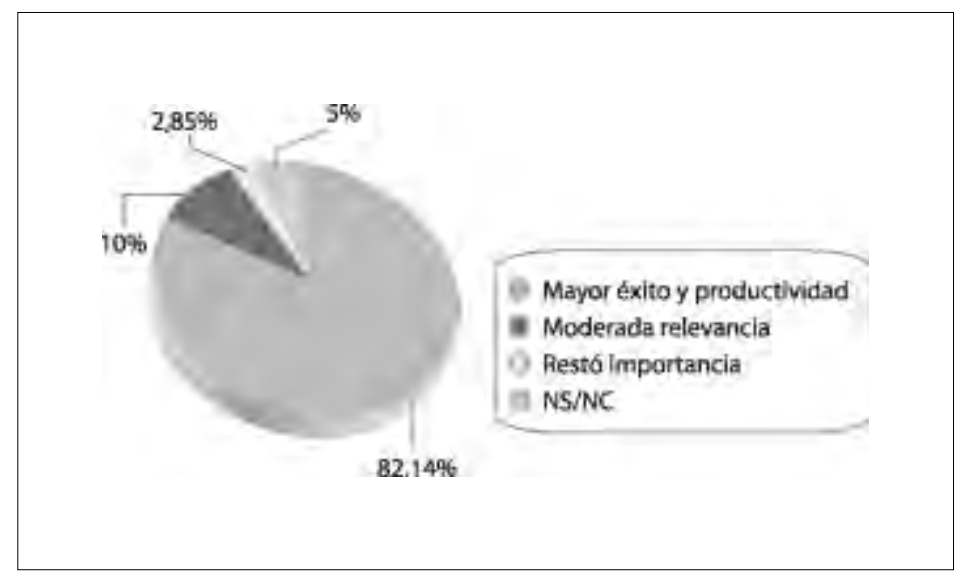

Fuente: Encuesta panorámica e-learning corporativo en América Latina 2003 [Resultados México] [En línea] http://www.elearningamericalatina.com/encuestas/latinoamerica.php

\section{Gráfica 2.}

Implementación de soluciones de e-learning

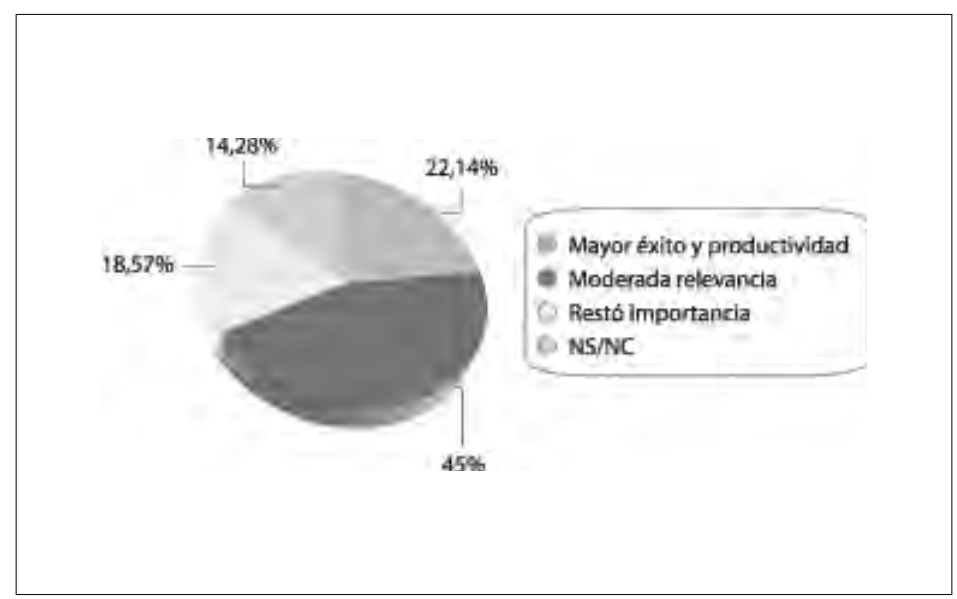

Fuente: Encuesta panorámica e-learning corporativo en América Latina 2003 [Resultados México] [En línea] http://www.elearningamericalatina.com/encuestas/latinoamerica.php 
Respecto a los motivos por los que cada compañía decidió implementar o piensa adoptar una solución de e-learning para cubrir las necesidades de capacitación de su empresa, el 87,23\% se inclinó por la posibilidad de optimización del tiempo que presenta la modalidad virtual. El 90,42\% identificó como la razón principal a la mejora en la calidad de la capacitación y un 55,31\% a la reducción de costos a mediano o largo plazo [...]. El 35,10\% prefirió alternativas no ofrecidas entre las opciones propuestas, mientras que el 76,59\% señaló como razón de su decisión el querer lograr una mayor motivación del personal y el 45,74\% el lograr una mejor administración.

Por otra parte, en cuanto a las oportunidades de formación (gráfica 3), el 64,51\% de las 23 empresas que actualmente incluyen soluciones de e-learning admitió haber mejorado en gran medida las oportunidades de formación profesional y personal de los empleados, mientras que el $25,80 \%$ reconoció un incremento en este sentido, pero no tan determinante. Apenas el 3,22\% consideró que esta modalidad no había aportado mejoras a la capacitación de sus recursos humanos. El 6,45\% de los consultados no respondió.

Gráfica 3.

Oportunidades de formación con e-learning

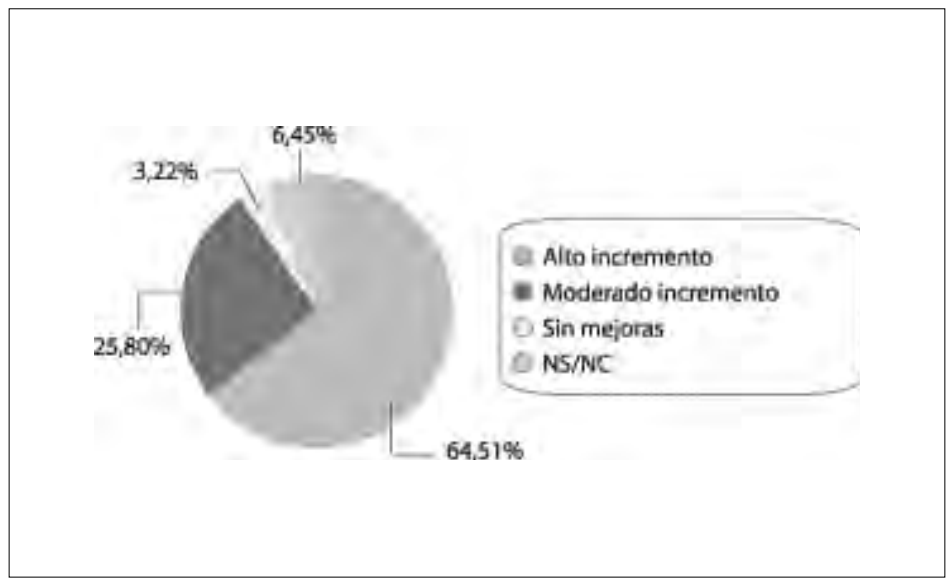

Fuente: Encuesta panorámica e-learning corporativo en América Latina 2003 [Resultados México] [En línea] http://www.elearningamericalatina.com/encuestas/latinoamerica.php 
De las 140 empresas consultadas, el 67,14\% considera que contar con una estrategia de aprendizaje corporativo es muy importante, mientras que para el $22,85 \%$ esta importancia es moderada y el $3,57 \%$ le resta relevancia. El $6,42 \%$ no tiene una posición tomada al respecto.

Con base en la información precedente, se puede señalar que en la actualidad los avances del aprendizaje electrónico son indiscutibles en el sentido de que ofrece posibilidades novedosas de capacitación empresarial, tomando en consideración las particularidades de los sectores que lo soliciten. Con el desarrollo de objetos de aprendizaje, la capacitación de formadores acreditados y el uso de tecnologías de información y comunicación, se pretende identificar con mayor certeza las soluciones y los servicios para el aprendizaje que más convengan a una determinada organización. Sin embargo, se requiere fomentar con mayor energía la cultura del e-aprendizaje empresarial con el propósito de que se comprenda cabalmente que la formación de empleados debe ser constante si se busca aumentar el valor agregado de sus productos.

\section{PANORAMA DE LA EDUCACIÓN A DISTANCIA Y SU VÍNCULO CON EL E-APRENDIZAJE EN LA EDUCACIÓN SUPERIOR EN MÉXICO}

Hacia la década de los setenta, a partir del desarrollo de la radio y la televisión, la enseñanza a distancia se convirtió en una alternativa para facilitar el acceso a la educación secundaria y tecnológica de las poblaciones dispersas y alejadas de las instituciones educativas. Por ello, el uso de los medios de comunicación era concebido como la panacea para abordar las desigualdades sociales y resolver los problemas educativos de México.

En la década de los ochenta, con el desarrollo y la expansión de los sistemas de televisión vía satélite, se pretendió resolver la crisis económica y alcanzar la competitividad en los mercados laborales nacionales e internacionales. Las estrategias de expansión de las telecomunicaciones tenían el propósito de crear redes que articularan a las universidades e instituciones de educación superior líderes 
en el marco nacional con las instituciones locales y regionales que disponían de menores recursos. Los programas académicos ofrecían conocimientos orientados a capacitar a ciertos sectores de la población para realizar las nuevas prácticas y actividades que demandaban los campos laborales; crear nuevos perfiles profesionales; diversificar la gama de actividades industriales; enfrentar la creciente internacionalización educativa así como la movilidad política y económica; e innovar los conocimientos científicos.

En este contexto, en la década de los noventa, las redes telemáticas configuran el nuevo escenario mundial de la educación a distancia debido a que representan la estrategia tecnológica fundamental para establecer la comunicación entre investigadores, docentes y estudiantes, sin importar el lugar del mundo en que se encuentren. En este entorno, el fenómeno educación a distancia ha sido puesto en constante debate en las instituciones mexicanas que tienen responsabilidad en los programas educativos, debido a que esta educación puede ser una estrategia para avanzar hacia el desarrollo social, el crecimiento económico y la competitividad laboral en los nuevos mercados mundiales.

Si se acepta que el e-aprendizaje se ha vinculado en forma directa con la aparición y el desarrollo de tecnologías de información y comunicación, y con el uso de redes de teleproceso, entonces su ubicación natural estaría situada en la educación a distancia y en línea. En este sentido, “[...] para delimitar cronológicamente a la educación en línea en México, debemos recordar que fue [...] en junio de 1987 cuando por primera ocasión en el país se estableció una conexión permanente a Internet [del] Instituto Tecnológico de Estudios Superiores de Monterrey, ${ }^{19}$ [...] en octubre, se hizo lo correspondiente en la Universidad Nacional Autónoma de México, cuando se efectuó, desde Ciudad Universitaria hasta el ITESM, y de ahí hasta San Antonio, Texas, el acceso a la red BITnet, y con ello se estableció

$19 \mathrm{Al}$ respecto se puede consultar la semblanza histórica de este proceso de incorporación del Internet al ITESM, en: histórico http://tyr.mty.itesm.mx/Historia/historia.html 
el servicio de correo electrónico, la transferencia de archivos y el acceso remoto". 20

El desarrollo de propuestas educativas institucionales vía Internet propiciaron la creación de la Red-Mex, "[...] la que dio origen en 1992 a la Asociación Mexnet con el propósito de coordinar las estrategias de desarrollo de Internet en el país. La proliferación de redes y la coincidencia de objetivos, obligó a un replanteamiento de estrategias de colaboración interinstitucional que facilitara la operación de los accesos a Internet, por ello se planteó la fusión entre MEXnet y la red de CONACYT, con lo cual se constituyó en 1994 la Red Tecnológica Nacional, RTN". ${ }^{21}$

El uso de tecnologías de información y comunicación en las instituciones de educación superior de México se evidencia con mayor certeza hacia finales del siglo XX, debido a los cambios sociales producidos en lo económico y la tendencia hacia lo global. Como consecuencia de ello se genera un incremento de la oferta y la demanda de propuestas educativas a distancia, en línea, e-aprendizaje, etcétera, aspecto que le da una nueva fisonomía a las instituciones otorgantes de servicios educativos. Por lo tanto, con el propósito de conocer el estado que guardan los sistemas telemáticos de las instituciones de educación superior, la ANUIES realizó el "Diagnóstico de Telecomunicaciones e Informática”, ${ }^{22}$ el cual enfatiza lo siguiente: “[...] con el amplio desarrollo de la informática y las telecomunicaciones, las instituciones de educación superior han reconocido la posibilidad de reforzar los programas abiertos y a distancia, mediante procesos de planeación integral de esta modalidad, ejemplo de ello son las diversas redes

20 Barrón Soto, Héctor S. La educación en Línea y el texto didáctico. México: UNAM, Coordinación de Universidad Abierta y Educación a Distancia: Facultad de Filosofía y Letras,2004. p. 59

21 Ibidem, p.62.

22 Ibidem. 
interinstitucionales constituidas en las regiones noreste (REUNE) y noroeste (READIN), así como la Red Nacional de Videoconferencias". ${ }^{23}$

Hoy, las instituciones educativas públicas y privadas de México que ofrecen programas de educación abierta y a distancia cuentan con modelos escolarizados y modelos flexibles para propiciar espacios de aprendizaje independiente. "Entre estos dos extremos, se encuentra una gama amplia de desarrollos académicos abiertos y a distancia que tratan de cubrir las necesidades de su entorno en relación con la formación, la actualización y la capacitación". ${ }^{24}$ Con el propósito de ilustrar algunos aspectos de la educación superior abierta y a distancia en México, a continuación se presenta información relevante al respecto.

En la gráfica $4^{25}$ se puede observar el número de instituciones mexicanas que ofrecen programas de licenciatura en las modalidades "semiescolarizada" y abierta. ${ }^{26}$ Se aprecia que en el sistema abierto se ubica el mayor número de instituciones.

\section{Ibídem.}

24 Ibidem.

25 Las gráficas de este rubro fueron tomadas de ANUIES (Asociación Nacional de Universidades e Institutos de Educación Superior). Plan Maestro de Educación Superior Abierta y a Distancia: líneas estratégicas para su desarrollo.

26 En el diagnóstico citado se define a la modalidad semiescolarizada como aquella caracterizada por ser flexible en tiempo y espacio y adaptable a los alumnos. Éstos pueden estudiar de acuerdo con su ritmo de aprendizaje o su interés personal y con mayor libertad respecto a lugar, horario y calendario de estudio. La modalidad abierta o no escolarizada se define como aquella que forma parte de un sistema destinado a proporcionar la educación correspondiente a un tipo y nivel educativos, a través de asesorías periódicas a los alumnos, sin concurrir diariamente a la escuela; el educando se sujeta a una serie de exámenes para certificar el adelanto en el cumplimiento del programa. Con base en este planteamiento se puede señalar que dichos propósitos coinciden con los objetivos de la educación abierta y a distancia en el marco mundial. 
Gráfica 4.

Instituciones que ofrecen programas de licenciatura

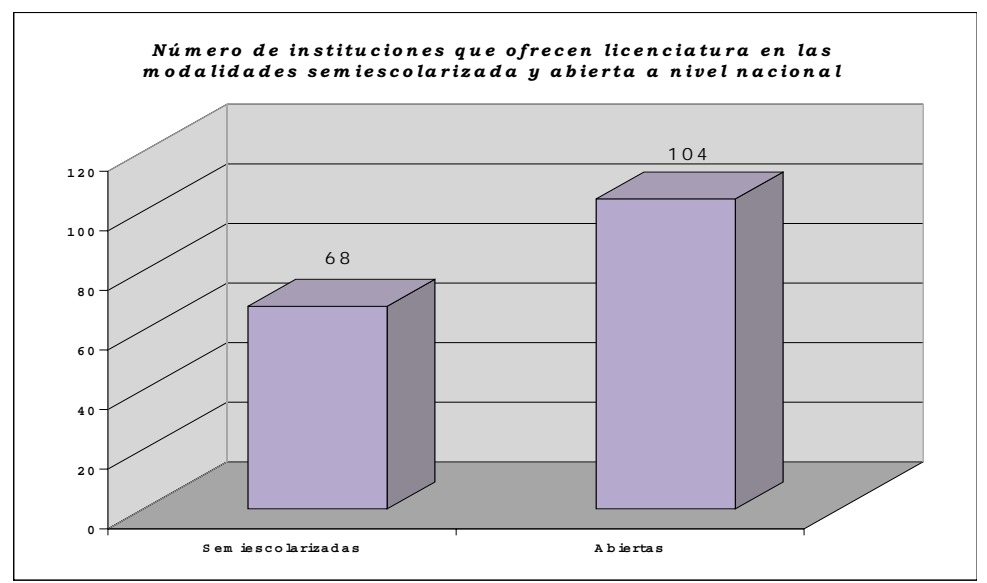

Fuente: ANUIES. Plan Maestro de Educación Superior Abierta y a Distancia: líneas estratégicas para su desarrollo. [En línea] http://www.anuies.mx/pdf/Plan\%20Maestro1.pdf

En la gráfica 5 se reflejan datos en cuanto a la población por áreas de conocimiento en la modalidad semi-escolarizada del nivel licenciatura, cuya matrícula nacional asciende a 127,368 estudiantes y en el nivel de postgrado a 8,842. Destaca, en primer término, el área de educación y humanidades con el $70.07 \%$ en licenciatura, a la cual sigue en orden de importancia el área de ciencias naturales y exactas, con una población del $27.14 \%$ y las agropecuarias con un porcentaje poco significativo.

En la gráfica 6 se aprecia que en las instituciones de educación superior (IES) afiliadas a la ANUIES, oferentes de programas semi-escolarizados y abiertos, la modalidad abierta rebasa en forma notable a los programas semi-escolarizados.

En la gráfica 7 se ilustra la situación del nivel de postgrado y en ella se puede apreciar que la modalidad semi-escolarizada presenta mayor número de programas que la modalidad abierta. 


\section{Gráfica 5.}

\section{Población por área de conocimiento}

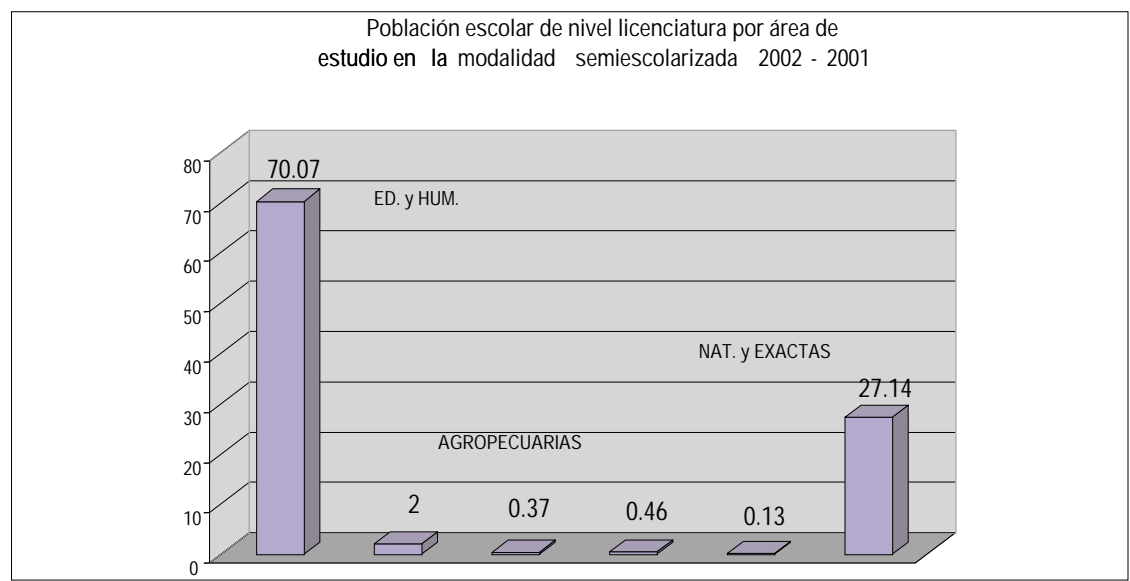

Fuente: ANUIES. Plan Maestro de Educación Superior Abierta y a Distancia: líneas estratégicas para su desarrollo. [En línea] http://www.anuies.mx/pdf/Plan\%20Maestro1.pdf

\section{Gráfica 6. \\ Instituciones afiliadas a la ANUIES}

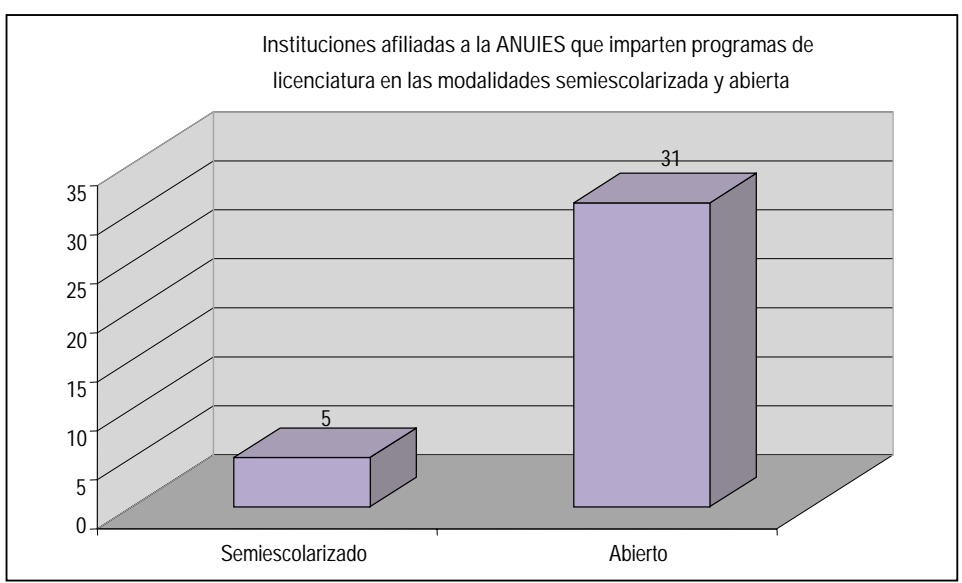

Fuente: ANUIES. Plan Maestro de Educación Superior Abierta y a Distancia: líneas estratégicas para su desarrollo. [En línea] http://www.anuies.mx/pdf/Plan\%20Maestro1.pdf 
Gráfica 7.

Programas de postgrado por nivel

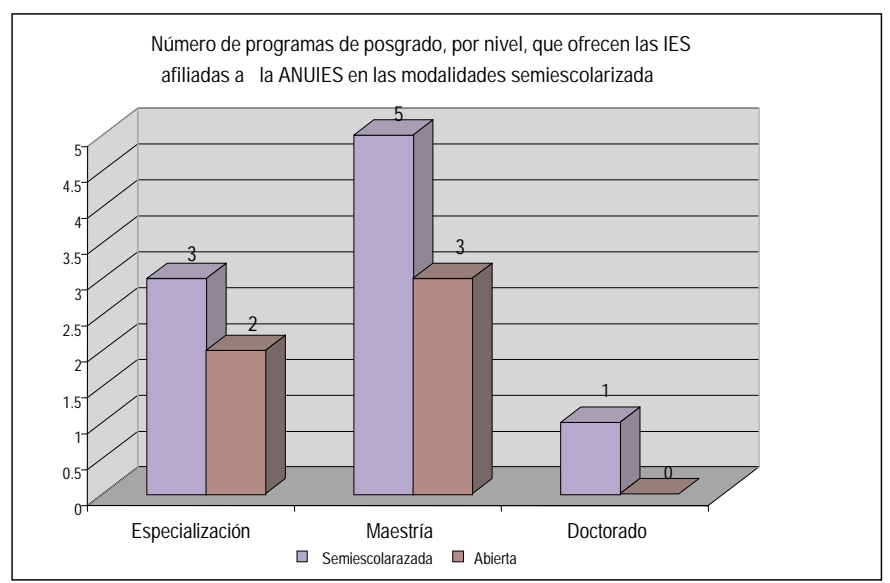

Fuente: ANUIES. Plan Maestro de Educación Superior Abierta y a Distancia: líneas estratégicas para su desarrollo. [En línea] http://www.anuies.mx/pdf/Plan\%20Maestro1.pdf

Respecto al nivel de doctorado, sólo se presentan cuatro instituciones que ofrecen programas en estas modalidades; el estudio referido señala que esto se debe probablemente a una deficiencia en cuanto al llenado del instrumento o a dificultades en la recopilación de los datos. Esas instituciones son las siguientes: Colegio de Profesionistas de la Educación José Vasconcelos (Puebla), Escuela Normal de Sinaloa, Universidad Multicultural, A. C. (Tamaulipas) y la Universidad Pedagógica Veracruzana.

Por otra parte se registra un incremento en el número de instituciones que utilizan redes de teleproceso como medio de comunicación; en este sentido, la gráfica 8 muestra que el $42 \%$ del total de las instituciones encuestadas participa en redes satelitales; que el segundo lugar lo ocupan las redes de videoconferencia con un $26 \%$; que un porcentaje muy similar pertenece a las redes informáticas (25\%), y que en cuanto a las radiofónicas, la gráfica revela apenas un $7 \%$. 
Gráfica 8.

Participación en redes

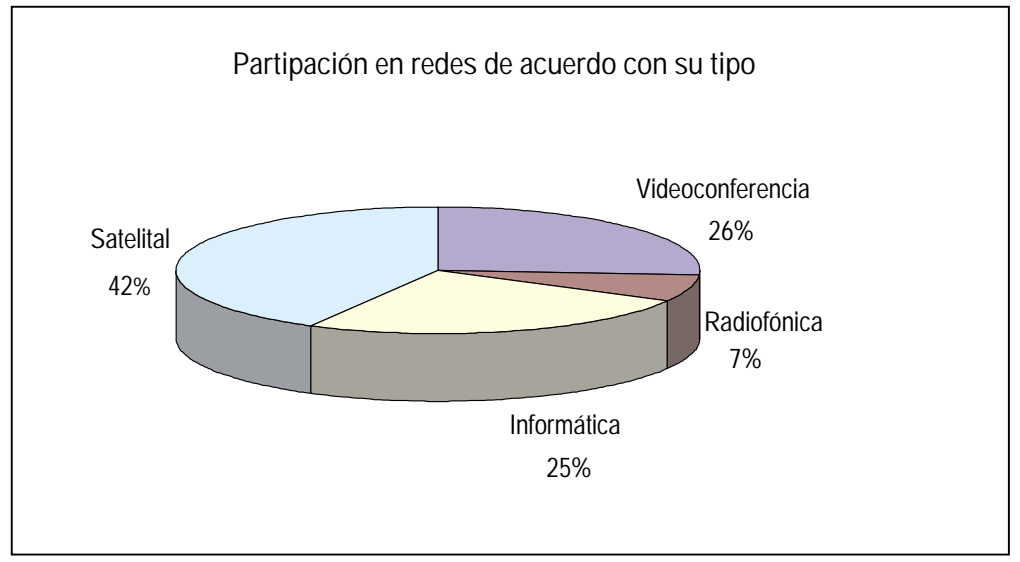

Fuente: ANUIES. Plan Maestro de Educación Superior Abierta y a Distancia: líneas estratégicas para su desarrollo. [En línea] http://www.anuies.mx/pdf/Plan\%20Maestro1.pdf

Se puede observar que la participación en redes satelitales ocupa el primer lugar; ello permite inferir el importante papel que tiene la instalación de equipos para la recepción de la señal EDUSAT en el desarrollo de proyectos educativos en la modalidad a distancia. Las instituciones que reportan un mayor uso por diversos organismos educativos, en cuanto a distribución de la señal satelital, son la Red EDUSAT y la Universidad Nacional Autónoma de México.

Por otra parte, resulta de mucho interés el hecho de que las redes de videoconferencia ocupen el segundo lugar en importancia como infraestructura. No obstante, las instituciones de educación superior reconocen que su participación en este tipo de redes ha sido insuficiente.

Se puede afirmar que los avances en infraestructura tecnológica han requerido de esfuerzos importantes por parte de las universidades públicas mexicanas, los institutos tecnológicos y los organismos educativos privados. Por otro lado, cabe resaltar la importante labor realizada por la Red Satelital de Televisión Educativa (EDUSAT) a través de la 
Dirección General de Televisión Educativa de la SEP y del Instituto Latinoamericano de la Comunicación Educativa (ILCE). Este último facilita la recepción de la señal en un número importante de instituciones educativas de México y en otros países latinoamericanos.

\section{LA INDUSTRIA TECNOLÓGICA EN MÉXICO}

En la actualidad, es evidente, que tanto el sector educativo como la iniciativa privada, se ocupan de perfilar diversas estrategias educativas y de mercado con el apoyo de las tecnologías de información y comunicación. En este sentido, es conveniente analizar las repercusiones producidas por el cambio del modelo empresarial del cómputo en México, cuyo propósito consiste en afrontar los retos que amenazan la supervivencia de mayoristas y distribuidores.

Por ello, la industria de software en México revela el interés de organismos educativos y del gobierno federal por atender aspectos relacionados con esta industria. En la actualidad, "[...] la industria del software se conforma por 110 mil profesionales y dos mil 95 empresas de TI [Tecnologías de Información]; cuenta con una producción anual de 600 millones de dólares. [...] Las metas que el Prosoft se ha propuesto alcanzar para el año 2013 son: Lograr una producción anual de software de cinco millones de dólares, alcanzar el promedio mundial de gastos en tecnología de información y convertir a México en líder latinoamericano de desarrollo de software y contenidos digitales en español". ${ }^{27}$

Sin duda, la industria tecnológica y las instituciones que generan productos tecnológicos de apoyo al aprendizaje se han percatado de que su aplicación en la educación a distancia les exige favorecer la convergencia tecnológica para propiciar la interacción entre los actores

27 Carrera Riva Palacios, Sergio. Programa para el Desarrollo de la Industria del Software. En Política Digital, núm. 15, feb. 2004, p.8. (El PROSOFT. Programa para el Desarrollo de la Industria del Software, se enmarca en la coordinación de Comercio Interior y Economía Digital de la Secretaría de Economía). 
del proceso de enseñanza-aprendizaje con el fin de reflexionar, preguntar, opinar o discutir. En resumen, redes, aulas virtuales, software educativo, etcétera, se complementan para cumplir con su propósito de facilitar la creación de escenarios educativos virtuales que faciliten la realización de aprendizajes para los usuarios de propuestas educativas de esta naturaleza.

Los logros relacionados con el uso de tecnología de red en la educación a distancia en México y la estandarización de estructuras para el desarrollo de contenidos y plataformas de apoyo a la educación con la finalidad de facilitar la colaboración empresarial e institucional en materia de intercambio local, nacional e internacional de contenidos de aprendizaje, han influido los propósitos del e-aprendizaje y por ello conviene estar atentos al respecto, pues se espera que la incorporación a corto plazo de estándares en el desarrollo de herramientas tecnológicas para el aprendizaje electrónico traerá consigo beneficios como los siguientes:

Permitirá a los instructores y estudiantes crear, encontrar, evaluar y compartir contenido electrónico; motivará la creación de grupos multidisciplinarios de técnicos y pedagogos como productores de medios tecnológicos; garantizará el intercambio de contenidos entre diferentes entornos virtuales de formación; el uso de metadatos ayudará a la indexación de materiales que podrán ser buscados por toda la red; los usuarios finales tendrán cursos de calidad a menos costo y adaptados a sus necesidades; la reingeniería, interoperabilidad e independencia de la plataforma disminuirá el costo de los cursos; los usuarios de $e$ learning podrán comprar contenidos y componentes de sistemas de diferentes vendedores con la confianza de que funcionarán juntos de forma correcta; los productores de soluciones competirán por la calidad y valor de sus productos; el amplio mercado de contenidos aumentará la producción de materiales incluso en áreas especializadas; fomentará la profesionalización en la elaboración de contenidos y; facilitará la actualización y mantenimiento de unidades didácticas. ${ }^{28}$

28 Castellanos Coutiño, Carlos Alberto. Panorama general de los sistemas de educación a distancia. En Primer Congreso Virtual Latinoamericano de Educación a Distancia. [En línea] LatinEduca2004.com [Consultada: 18/11/2004 
No obstante el hecho de que en la actualidad el e-learning en México se ubica principalmente en el sector empresarial y de negocios, la educación a distancia vía Internet ha hecho patente diversos de los aspectos mencionados con anterioridad, a través de la importante labor emprendida por distintos organismos mexicanos como: universidades públicas y privadas, institutos tecnológicos y el gobierno federal, los cuales tienen presente la relevancia social de la educación de esta naturaleza; por ello, han dedicado esfuerzos para generar proyectos y plataformas tecnológicas cuyos frutos ya son muy visibles. Algunos ejemplos representativos son los siguientes:

\section{Universidad Nacional Autónoma de México}

\section{Coordinación de Universidad Abierta y Educación a Distancia}

Entre las actividades relevantes de esta Coordinación se encuentran las siguientes:

[...] divulgación de las prácticas educativas del Sistema Universidad Abierta (SUA), Continua y a Distancia más adecuadas, así como el impulso a los mejores usos educativos de la tecnología que resultan de su actividad de prospección y producción de materiales. Su tarea también radica en difundir los métodos de evaluación, acreditación y certificación de conocimientos; colaborar con las entidades universitarias para su óptima integración en Educación Abierta, Continua y a Distancia y, responder a las necesidades de educación y capacitación de instituciones educativas, sociales, gubernamentales y empresas privadas a fin de llevar la Universidad a las diferentes organizaciones que la requieran, sean éstas nacionales o internacionales. ${ }^{29}$

El SUA ha incidido en:

[...] extender la educación universitaria a grandes sectores de la población por medio de métodos teórico-prácticos de transmisión y evaluación de conocimientos y la creación de grupos de aprendizaje[...]. Su principal objetivo es facilitar a los estudiantes [...] la posibilidad de

29 CUAED. [En línea] http://www.cuaed.unam.mx/contenido/notices.htm [Consultada: 10/10/04] 
combinar el estudio con el trabajo, mediante la flexibilidad de horarios y la adaptación personal a ritmos y métodos de aprendizaje. 30

Con el desarrollo tecnológico tales propósitos se perfilan con mucho éxito. Muestra de ello se advierte en el "Programa Universidad en Línea (PUEL),"31 el cual se apoya en una plataforma desarrollada ex profeso. Con base en ella se pretende que cualquier institución de México y de América Latina tenga la posibilidad de instalar cursos en línea; por lo tanto se busca “[...] contar con un sistema de cómputo integrado [...] que sea sencillo, eficiente, y que permita crear, adaptar, mantener, administrar y dar seguimiento a [diversos cursos en línea]". ${ }^{2}$ Así, "[...] el tutor tiene la posibilidad de revisar el grado de avance, dar seguimiento a cada uno de los alumnos y permitir una evaluación completa de todas las partes que conforman el curso en línea". 33

Asimismo, el PUEL incorpora foros de discusión que buscan crear comunidades de aprendizaje en las que intervengan los diversos actores del aprendizaje. "De igual manera, con este programa se pretende reducir los altos costos que implican las licencias actuales que tienen las plataformas comerciales para e-learning." 34 Uno de los atractivos de esta plataforma estriba en que la licencia de uso que otorgará la UNAM será gratuita.

En la actualidad, con el uso de dicha plataforma se incide en la formación de tutores para la educación abierta y a distancia. De este modo, los docentes desarrollan habilidades para el manejo de herramientas digitales y para participar en foros de discusión, y cuentan con asesoría vía correo electrónico. Después de adquirir los conocimientos fundamentales, el docente puede preparar cursos en línea

30 SUA [En línea] http://fcasua.contad.unam.mx/sua/que_sua.htm [Consultada:09/10/04]

31 Para una mayor información sobre el PUEL se puede consultar:

http://www.puel.unam.mx.

32 Programa Universidad en Línea. En Gaceta UNAM, 23 de junio de 2003. p.7.

33 Ibidem.

34 Ibidem. 
apoyado por el Taller Planeación Didáctica para Cursos en Línea, ${ }^{35}$ cuya función es: "[...] proporcionar a los participantes los elementos didácticos que les permitan planear, diseñar y poner en marcha programas educativos en línea, apoyados en las principales herramientas de Internet". 36

Centro de Alta Tecnología de Educación a Distancia (CATED)

Por su parte, el Centro de Alta Tecnología de Educación a Distancia (CATED) pretende ser un polo educativo continental y cuenta con tecnología de punta, lo cual abre oportunidades educativas para un país como México. El Centro, "[...] será sede del observatorio UNAM-UNESCO, del Campus virtual y del Centro de Investigación de Tecnología Educativa [...] tiene un potencial extraordinario que permitirá llegar a una ilimitada cantidad de lugares, con sus mejores exponentes de la ciencia y la cultura". ${ }^{37}$ Asimismo, se abordarán temas de interés local, regional y universal; se crearán cursos flexibles y se elaborarán materiales didácticos que apoyen la educación de la sociedad mexicana.

El Centro fue creado con el objetivo de promover la tecnología más avanzada en el ámbito de la educación abierta, continua y a distancia, recogiendo así los tres sistemas que han de integrar una educación de calidad. La idea del CATED es ofrecer este tipo de estudios a los alumnos de la UNAM, pero se ha pensado desde un primer momento en ampliarlo a otras instituciones de educación superior. A mayor abundamiento, Rosaura Ruiz Gutiérrez ${ }^{38}$ afirma que con este Centro se avanza en la creación de la universidad en línea, a la que

35 PUEL. [En línea] http://www.puel.unam.mx/cursos/t_planeacion/index.htm\# [Consultada: $10 / 09 / 04]$

36 Ibídem.

37 En función el Centro de Alta Tecnología en Tlaxcala. Declaración hecha por Juan Ramón de la Fuente. En Gaceta UNAM, 28 de agosto de 2003. p.6.

38 Cfr. Álvarez, M. Inaugura el Rector trascendente Centro de Alta Tecnología de Educación a Distancia (CATED) [En línea] http://www.elearningworkshops.com/modules.php?name $=$ News $\&$ file $=$ article $\&$ sid $=106$ [Consultada: $10 / \mathbf{1 1} / 04]$ 
habrá que añadirle el mayor número posible de licenciaturas y postgrados. Los primeros esfuerzos se dirigen hacia las carreras y programas de posgrado en humanidades y ciencias sociales [...] ya que el alumno puede completar sus estudios en línea, mientras que las carreras técnicas que necesitan prácticas de laboratorio entrarán en una segunda fase.

Un aspecto significativo de las carreras experimentales pasa por colocar la teoría en línea, pero las prácticas se harán en otras universidades mexicanas o fuera del país; por eso, la Secretaria de Desarrolló entiende que se trata de un modelo de formación conjunta que se ejecutará entre varias universidades. Aquí se refleja un aspecto fundamental de los estudios a distancia: los recursos se comparten y los exámenes prácticos se pueden tomar en una universidad alejada físicamente de la ciudad o el país en el que vive el estudiante y los títulos serán impartidos por una, dos o varias universidades. Ésta es la gran aportación al mundo globalizado.

En la actualidad se han liberado en línea cinco licenciaturas y diversas asignaturas en distintas disciplinas; sin embargo, en el 2005, la oferta educativa en dicha modalidad irá en aumento. Al respecto ha mencionado Ruiz Gutiérrez:

[...] se pretende que el ciclo de educación a distancia sea completo. El proyecto permitirá que el alumno pueda realizar desde su propia inscripción en la computadora. Tomará clases en casa o donde tenga acceso a la red; presentará los exámenes por la misma vía y tendrá el apoyo de un tutor, con el cual se comunicará por medio de la página electrónica. 39

Por otra parte, cabe destacar que en el 2004, la Coordinación de Universidad Abierta y Educación a Distancia inició un proceso de reestructuración dirigido, entre otros aspectos, a generar su reglamento, la normatividad requerida por la educación abierta y a distancia que ofrecerá la UNAM, la definición de las figuras académicas necesarias en dichas modalidades y los lineamientos que requiere el desarrollo de materiales didácticos. Lo anterior pretende sustentar las asesorías a las

39 Ibídem. 
dependencias universitarias que la requieran y evaluar las propuestas educativas fundamentadas en las modalidades abierta y a distancia. El desarrollo de dichas tareas se apoya en un Comité Asesor que se formó considerando el Acuerdo por el que se Reorganiza la Coordinación de Universidad Abierta y Educación a Distancia, el cual destaca que "[...] para el correcto desarrollo de sus funciones la Coordinación contará con la siguiente estructura: Dirección de Desarrollo Educativo, Dirección de Tecnologías de la Información; Dirección de Proyectos y Vinculación, Centro de Alta Tecnología de educación a Distancia (CATED, Tlaxcala y, la Secretaría Académica". ${ }^{40}$

Asimismo, se enfatiza que "[...] los programas de Educación Abierta (licenciatura y posgrado) serán responsabilidad de las entidades académicas que los impartan, los cuales deben ser autorizados por los respectivos Consejos Técnicos. [...] en los casos en que los programas sean a distancia se deberá contar con la opinión favorable del Consejo Asesor de la Coordinación de Universidad Abierta y Educación a Distancia, a fin de revisar el cumplimiento normativo de las modalidades educativas". ${ }^{41}$ Sin duda, la labor de dicho Comité redundará al interior de la Universidad y con toda seguridad en el marco nacional y latinoamericano.

La visibilidad y el impacto actuales que tiene la CUAED en el marco internacional propicia la cooperación con diversos organismos de distintos países. Uno de estos reconocimientos se hace visible con la responsabilidad de organizar el congreso internacional denominado Virtual Educa 2005, el cual se llevará a efecto en la UNAM bajo la responsabilidad de la Coordinación. En suma, la educación abierta y a distancia es actualmente uno de los proyectos de mayor importancia de la UNAM por los beneficios que traerá consigo a la sociedad mexicana.

Por su parte, la Dirección General de Cómputo Académico, también dependencia de la UNAM, tiene una importante participación en

40 Acuerdo por el que se reorganiza la Coordinación de Universidad Abierta y Educación a Distancia. (Signado por el Rector de la UNAM: Juan Ramón de la Fuente, el 19 de septiembre de 2003. En Gaceta UNAM, Septiembre de 2003, p.24

41 Ibídem. 
el desarrollo de Internet 2 . Con relación al e-aprendizaje se ha conformado la Comisión Académica Especializada en Objetos de Aprendizaje, en la cual tienen participación, entre otras, las siguientes universidades: Universidad de Colima, Universidad de Guadalajara y, la Universidad Virtual del Instituto Tecnológico y de Estudios Superiores de Monterrey. Con el propósito de sustentar los fundamentos de los objetos de aprendizaje para el e-learning, esta Comisión entiende que dicho objeto " [...] es una entidad informativa digital desarrollada para la generación de conocimiento, habilidades y actitudes que tienen sentido en función de las necesidades del sujeto y que corresponden con una realidad concreta, $[\ldots]$ ". ${ }^{42}$ Sin duda, los logros de dicha Comisión serán de suma importancia porque abordan un fenómeno de estudio de mucha actualidad y enfrentan los muy pocos resultados hasta ahora emanados de investigaciones de alto impacto. Por ello, la educación en todos sus niveles requiere de contenidos de alta calidad para poder incidir en aprendizajes innovadores, aspecto que se intenta inducir a partir del e-aprendizaje.

\section{Universidad Pedagógica Nacional (UPN)}

La Universidad Pedagógica Nacional (UPN) ${ }^{43}$ cuenta con un programa de educación a distancia denominado Sistema de Educación a Distancia (SEAD) que tiene una sede central en la ciudad de México y 74 unidades ubicadas a lo largo del territorio nacional. El sistema de la UPN dispone de un conjunto de métodos, técnicas, procedimientos y dispositivos para guiar el aprendizaje a distancia, que incluye la enseñanza oral y el trabajo en grupos, además de una buena cantidad de materiales impresos y televisivos. El proyecto de la UPN se divide en dos grandes rubros: la elaboración de materiales y apoyos y el

42 Reunión de la Comisión Académica de Objetos de Aprendizaje. [En línea] (Guadalajara, Jal. 4 de julio 2002) http://www.cudi.org/ob_ap.html [Consultada: 10/10/03]

43 Para mayor información sobre la UPN se puede consultar: Zetina Aguirre, Ignacio. Experiencias del sistema de educación a distancia de la Universidad Pedagógica Nacional. En Divulgación Científica, vol. 1, núm. 1, 1989, p. 21. 
servicio que ofrecen los asesores académicos. El SEAD pretende que los tutores se familiaricen de manera profunda con los contenidos de los materiales didácticos, conozcan las actividades que conducen al cumplimiento de los objetivos de los diversos cursos y se familiaricen con las TICs utilizadas en los procesos de interacción con los actores del aprendizaje.

\section{Instituto Politécnico Nacional (IPN)}

El Instituto Politécnico Nacional ${ }^{44}$ es un proveedor importante del sistema de los institutos tecnológicos de México y por ello realiza también diversas actividades asociadas con la educación a distancia. Entre ellas se destaca el proyecto denominado Espacios Virtuales de Aprendizaje (EVA), cuyo enfoque se orienta a la utilización de tecnologías de información y comunicación para el desarrollo y la implantación de ambientes integrados de aprendizaje. Dicha propuesta se coordina en el Laboratorio de Agentes del Centro de Investigación en Computación del Instituto (CIC-IPN).

Los ambientes virtuales de aprendizaje se conciben como modelos educativos apoyados en herramientas tecnológicas para facilitar la operación de programas académicos que trascienden el espacio del aula tradicional. Con ello se pretende dar cabida a diversas modalidades educativas, entre ellas la educación en línea. A este respecto, Sheremetov ha señalado que "[...] los Ambientes Virtuales de Aprendizaje (AVA) se consideran actualmente como una generalización de diferentes enfoques de aplicación de la computación en educación que han surgido durante las tres décadas de desarrollo de sistemas de software educativo." 45

44 Para mayor información sobre el Instituto Politécnico Nacional se puede consultar el sitio: http://www.ipn.mx.

45 Sheremetov, L. Espacios virtuales de aprendizaje: experiencia y prospectiva. En El medio digital en el siglo XXI: retos y perspectivas para los bibliotecólogos, investigadores. educadores y editores. México : UNAM, CUIB, [En CD-ROM]. 


\section{Instituto Tecnológico y de Estudios Superiores de Monterrey (ITESM)}

El Instituto Tecnológico y de Estudios Superiores de Monterrey (ITESM) es una institución privada fundada en 1943 por un grupo de importantes empresarios de la ciudad de Monterrey, México. Desde 1951, el sistema educativo del ITESM fue acreditado en Estados Unidos por la Asociación de Universidades y Escuelas del Sur (Southern Association of Colleges and Schools, SACS) para otorgar títulos profesionales y grados académicos.

En 1996, el ITESM ${ }^{46}$ crea la Universidad Virtual basada en una infraestructura de telecomunicaciones integradas a través de televisión satelital y una red de cómputo e informática. En la actualidad, el Instituto cuenta con una red nacional conformada por sedes transmisoras ubicadas en los campus de la ciudad de México-Monterrey, Morelos, Toluca, Chihuahua y Guadalajara, además de sedes receptoras en todo el territorio nacional. Asimismo, el ITESM se apoya en una red de aulas remotas para difundir programas de doctorados, maestrías, licenciaturas y educación continua en países como Estados Unidos, Colombia, Ecuador, Honduras, Perú, Costa Rica y Venezuela.

El ITESM, con una matrícula actual que suma alrededor de 80,000 alumnos, es la institución privada con mayor interés en el desarrollo de programas de educación a distancia. Uno de sus proyectos iniciales fue denominado SEIS, el cual se basó en un circuito cerrado de televisión que contaba con cuatro puntos de emisión en cuatro de sus seis campus universitarios.

Posteriormente el sistema creció en varias direcciones y cuenta, por ejemplo, con una red de videoconferencia y ha desarrollado redes de televisión (sobre todo hacia el exterior del Tecnológico, hasta hace muy poco por medio de la renta de canales privados a la empresa

46 Amador Bautista, Rocío. Educación y formación a distancia en México. Crónica de una historia no escrita. En Educación y formación a distancia. Prácticas, propuestas y reflexiones / coord. Rocío Amador Bautista. México: Universidad de Guadalajara, 2001. p. 34 
Multivisión), pero actualmente renta la señal de dos satélites para apoyar el Aula Virtual Empresarial (AVE) y la Universidad Virtual Empresarial.

Las estadísticas que el ITESM presenta para su organización de universidad virtual mencionan alrededor de 5000 estudiantes en cursos regulares de licenciatura; 5000 en cursos regulares de maestrías y algunos de doctorado, y 30000 en los del canal empresarial. Asimismo ha formado 30000 maestros de la Secretaría de Educación Pública en su programa de habilidades docentes.

\section{Instituto Latinoamericano de la Comunicación Educativa (ILCE)}

El Instituto de Comunicación Educativa fue creado en 1956 con el propósito de formar profesionales en el campo de la tecnología educativa, mediante un acuerdo firmado por la Organización de las Naciones Unidas para la Educación, la Ciencia y la Cultura (UNESCO) y el Gobierno de México. Su objetivo inicial fue contribuir al mejoramiento de la educación a través del uso de medios y recursos audiovisuales, principalmente películas y filminas.

A este respecto, Amador Bautista afirma que “[...] en 1969 el Instituto cambia su nombre a Instituto Latinoamericano de la Comunicación Educativa (ILCE) su finalidad es atender las demandas en materia de comunicación educativa de los diferentes países miembros de América Latina y el Caribe. En 1972 inicia programas de cooperación con otras instancias tanto nacionales como internacionales y en la actualidad cuenta con una maestría en tecnología educativa, así como con un centro de información automatizado sobre temas, educación de adultos, tecnología educativa y educación a distancia”. ${ }^{47}$

47 Amador Bautista, Rocío. Op. cit. p. 39-40. 
En búsqueda de alternativas que apoyen a la educación, el ILCE extiende sus actividades a la región latinoamericana por medio de acuerdos bilaterales con instituciones afines como organismos internacionales y ministerios de educación. Se puede señalar que la evolución del ILCE "[...] ha pasado de la producción de filminas a la de video y la televisión educativa vía satélite; de cursos breves a posgrados; de reuniones de trabajo a seminarios y congresos; de la acumulación de información a la creación de un Centro de Documentación para América Latina; de la publicación de folletos a la edición de libros; del diseño de programas de cómputo al multimedio interactivo". 48

Los principales objetivos de este Instituto son los siguientes:

- Cooperar regionalmente en la investigación y experimentación del contenido de los materiales audiovisuales.

- Producir, difundir y recopilar materiales audiovisuales como programas televisivos, diaporamas, cassettes, disquets, multimedia, y actualmente con apoyo en Internet, la Red Escolar.

- Formar y capacitar recursos humanos en el área de la tecnología educativa, a través del otorgamiento de becas, la transmisión vía satélite de diplomados y la organización de simposios y maestrías.

- Recopilar materiales y documentos.

Algunas instituciones nacionales e internacionales con las cuales el ILCE sostiene actividades de intercambio de información y experiencias son las siguientes: Organización de las Naciones Unidas para la Educación, la Ciencia y la Cultura (UNESCO); Organización de los

48 La información sobre el ILCE se apoyó principalmente en las fuentes siguientes:

Freixas Flores, R. SEP e ILCE en la educación a distancia [En línea].

http://www.ciberhabitat.com.mx/escuela/sep_ilce/textos/texto_sepilce.htm

[Consultada:28/08/01]

ILCE [En línea]. 2000. http://members.tripod.com/ ILCE/ilce.htm

ILCE [En línea]. 2000. http://www.ilce.edu.mx/ 
Estados Americanos (OEA); Centro Regional para la Educación de Adultos en América Latina y el Caribe (CREFAL); Fondo de las Naciones Unidas para la Infancia (UNICEF); Centro de Tecnología Educativa (CTE); Departamento de Investigaciones Educativas (DIE); Centro Internacional de Estudios Superiores de Comunicación para América Latina (CIESPAL); y con las Universidades latinoamericanas de Argentina, Costa Rica, Ecuador, Panamá, Trinidad \& Tobago, Colombia, Haití y Venezuela.

Las actividades de cooperación del ILCE con México son muy extensas y se centran fundamentalmente en la SEP mediante el Convenio de Colaboración en Materia Educativa a Distancia, particularmente a través del PROED (Programa de Educación a Distancia). El ILCE también mantiene importantes relaciones de cooperación orientadas al desarrollo de los programas del Sistema Educativo Nacional con diversas dependencias gubernamentales, estatales e instituciones de educación superior a lo largo de todo el territorio mexicano.

En el campo de la informática educativa, además de haber equipado miles de escuelas con computadoras, el ILCE ha desarrollado y opera la RED ESCOLAR, que conecta a las escuelas públicas del país con Internet y ofrece un conjunto de materiales y servicios en línea en formato multimedia, dirigidos a maestros y alumnos. Asimismo, desarrolla investigación en campos como diseño curricular, educación formal, educación no formal, educación a distancia, uso de medios, y estrategias de enseñanza y aprendizaje

Como se observa, la educación a distancia es vista en el ILCE como una modalidad educativa planificada, administrada, controlada y evaluada sistemáticamente para responder a la característica fundamental de esta modalidad; flexibilidad tanto en espacio como en tiempo, pues ofrecer una educación a la medida de las posibilidades del estudiante exige una vinculación entre los diferentes elementos del proceso educativo, tales como el material didáctico, la tutoría y la evaluación del aprendizaje, así como la aplicación de medios y métodos que tratan de enseñar a aprender y, a su vez, dotan de cierta autonomía al individuo que busca un desarrollo integral, al estimular sus intereses formativos y sus habilidades creativas. 


\section{Programa del Gobierno Federal sobre e-aprendizaje}

Por su parte, el Gobierno Federal liberó recientemente el Sistema Nacional e-México cuyo propósito es "[...] eliminar las barreras que actualmente existen para obtener información y servicios públicos [...] reducir las brechas tecnológicas al interior del país y entre la población mexicana con el resto del mundo. Con el proyecto e-México, el gobierno mexicano espera trasformar el país a través de la aplicación de tecnología moderna [...] iniciando una reforma de educación para crear un México digital e inaugurar una nueva era" ${ }^{49}$ En el contexto de este proyecto, la misión del e-aprendizaje es fomentar "[...] nuevas opciones de acceso a la educación y capacitación, que estimulen el aprendizaje como un medio para el desarrollo integral de los mexicanos. Un sistema de aprendizaje en línea que integre los esfuerzos hechos por las instituciones en materia educativa, para el desarrollo equitativo de nuestro país". ${ }^{50}$ Las líneas estratégicas del programa sobre e-aprendizaje tienen el siguiente propósito:

[...] impulsar e integrar esfuerzos hechos por las diversas instituciones

del sector de la educación, principalmente con tres grandes grupos:

1. Academia

2. Organización

3. Iniciativa Privada. 51

El Gobierno Federal también se ha comprometido a impulsar el desarrollo de la industria mexicana de software a través de la Fundación México Digital, cuyo objetivo es promover acciones que reduzcan la brecha digital y el rezago tecnológico en México. La Fundación "[...] es un proyecto que buscará impulsar la adopción de tecnologías en las empresas mexicanas para estimular su desarrollo mediante

49 E-México. Hacia la sociedad e la información. En http://www.emexico.gob.mx/wb2/eMex_faq [Consultada: 10/09/04]

50 Ibídem.

51 Portal e-México. Hacia la sociedad de la información. (e-aprendizaje) [En línea] http://www.e-mexico.gob.mx/wb2/eMex/eMex_Acerca_del_programa [Consultada: 06/11/04] 
soluciones digitales, con el fin de ayudarlas a alcanzar niveles óptimos de competitividad en el mercado global a través de tecnología informática".52 Tales propósitos necesariamente incidirán en el aprendizaje electrónico.

\section{E-APRENDIZAJE SOBRE BIBLIOTECOLOGÍA EN MÉXICO}

Se asume que las dimensiones de la educación a distancia le son inherentes a la enseñanza en esta modalidad de la bibliotecología. Sin embargo, es conveniente tener presente que las propuestas a distancia en este campo exigen un indispensable acercamiento teórico de la bibliotecología, que tome en cuenta su vínculo con los requerimientos sociales y culturales de México. Dicha tarea debe comprender una investigación científica de calidad sustentada en la enseñanza interdisciplinaria y multidisciplinaria.

Es notorio que los fenómenos generados por las tecnologías de información y comunicación le plantean nuevos retos a la bibliotecología y, en consecuencia, a los sectores bibliotecarios y las unidades de información documental. Tales transformaciones tecnológicas han provocado cambios en la sociedad modificando las formas de trabajo y el modo de interacción y comunicación entre los diversos sectores sociales. Asimismo, las redes de telecomunicación facilitan cada vez más el acceso a la información en un entorno global, su alta velocidad reduce los límites de fronteras, espacio y tiempo y facilita la recuperación de información requerida por los procesos de enseñanzaaprendizaje.

Sin embargo, la bibliotecología habrá de tomar en cuenta que en sí mismo el uso de TICs no es garantía de éxito de los programas educativos a distancia. Las propuestas de calidad exigen el desarrollo de tareas de gestión educativa que incluyan: el aprendizaje innovador, la formación de tutores académicos, la preparación de autores de

52 Fundación México Digital. [En línea]

http//:www.todito.com/paginas/noticias/129874.html [Consultada:28/08/03] 
contenido y la participación de tutores pedagógicos, expertos en diseño gráfico, desarrolladores y administradores de aulas virtuales de aprendizaje.

El proceso de enseñanza-aprendizaje a distancia de fenómenos relacionados con la bibliotecología, exige del tutor académico ser un experto en la materia que imparta, conocer los fundamentos del diseño instruccional y el perfil de sus alumnos a distancia, ser diestro en la planeación curricular y hábil en los procesos de comunicación con los alumnos virtuales. De ahí que una de las actividades sobresalientes del tutor académico deberá estar dirigida a lograr que los alumnos estudien y reflexionen, tanto en escenarios físicos como en virtuales, a los cuales es posible que nunca se hayan enfrentado. En este sentido, el tutor académico tendrá que involucrarse con funciones como las siguientes:

- Propiciar la comunicación del aprendizaje.

- Participar en la elaboración de materiales didácticos que respondan a las necesidades de los estudiantes tomando en consideración las particularidades de operación social de los sistemas bibliotecarios, bibliográficos y de información.

- Colaborar en la creación de escenarios virtuales de aprendizaje basados en dinámicas de construcción sobre el conocimiento individual y de grupo. Comprometer a los alumnos a distancia con su participación activa y planificada atendiendo a los objetivos educativos específicos y a los marcos pedagógicos planeados.

La interactividad y la navegación en red son fenómenos de gran interés para la bibliotecología debido a su novedad y a los pocos avances que se han logrado al respecto hasta nuestros días. Por lo tanto, los diseñadores de propuestas educativas para escenarios virtuales deberán analizar detenidamente los problemas que sigue causando la interactividad y la navegación en los procesos de aprendizaje vía redes de teleproceso. Al mismo tiempo, la bibliotecología debe considerar la innovación educativa a largo plazo para insertar a sus egresados en la competitividad que exige la internacionalización de la educación superior y la movilidad de profesionales tomando en consideración, entre otros aspectos, el desarrollo cultural y la cooperación en un mundo global. 


\section{INSTITUCIONES EN MéXICO QUE OFRECEN PROGRAMAS A DISTANCIA EN BIBLIOTECOLOGÍA Y CIENCIAS DE LA INFORMACIÓN}

En México, la oferta de programas de educación a distancia y de e-aprendizaje en bibliotecología y ciencias de la información es hasta el momento muy limitada. Sin embargo, se percibe un interés creciente en el desarrollo de propuestas educativas a distancia vía Internet. En cuanto a estudios oficiales, existen dos instituciones de educación superior que ofrecen programas a distancia y en línea. Asimismo, las escuelas que se han caracterizado por ser de orientación presencial han adoptado en la actualidad diversas tecnologías de información y comunicación y ofrecen materias específicas en la modalidad mixta que implica el uso de Internet y sesiones cara a cara. Para efectos de este trabajo se presenta información relevante de la Escuela Nacional de Biblioteconomía y Archivonomía (ENBA) de la Secretaría de Educación Pública, del Instituto Tecnológico y de Estudios Superiores de Monterrey (ITESM), y algunos aportes en educación a distancia del Centro Universitario de Investigaciones Bibliotecológicas (CUIB) de la UNAM.

\section{Escuela Nacional de Biblioteconomía y Archivonomía (ENBA)}

La ENBA, dependencia de la Secretaría de Educación Pública, tiene como propósito formar bibliotecarios y archivista en el nivel de licenciatura. Dichas carreras se ofrecen en la modalidad presencial y a distancia. A través de ésta última se persigue:

[...] la vinculación con instituciones de carácter público y privado que demanden servicios especializados de bibliotecarios y archivistas para instrumentar programas de prácticas de campo, de servicio e investigaciones aplicadas para resolver problemas disciplinarios en los propios escenarios de trabajo de estos profesionales. 53

53 Pérez Paz, Nahúm. La modalidad de educación abierta y a distancia de la Escuela Nacional de Biblioteconomía y Archivonomía. En Jornadas Mexicanas de Biblioteconomía (28: 1997: Cocoyoc, Mor.). México: AMBAC, 1998. p. 126 
Este modelo educativo contempla diversas estrategias de aprendizaje encaminadas a fortalecer en los alumnos la adquisición de habilidades cognoscitivas, la valoración de experiencias profesionales y la producción de conocimientos significativos. El hecho de buscar que el estudiante se asuma como sujeto activo de su aprendizaje implica dedicarle tiempo al estudio, ejercitar sus habilidades de estudio independiente, tener capacidad para organizar sus actividades de aprendizaje y hacer un seguimiento del avance de su proceso formativo. Desde el punto de vista administrativo, el modelo cuenta con los siguientes subsistemas académicos: Experiencias de aprendizaje, Asesoría y Evaluación.

Una de las intenciones relevantes de dicha modalidad es la búsqueda de la profesionalización a través de la experiencia adquirida por bibliotecarios y archivistas en ejercicio, en las diferentes instituciones mexicanas. En este sentido el programa sobre educación abierta y a distancia permite realizar las siguientes acciones:

- Impulsar la descentralización y ampliar la cobertura en la formación de recursos en el campo de la Biblioteconomía y de la Archivonomía.

- Disminuir el rezago de recursos humanos profesionales en las bibliotecas y archivos.

- Impulsar el liderazgo nacional de la ENBA en la docencia, investigación y difusión en el campo de la Archivonomía y la Biblioteconomía. 54

En cuanto a materiales y medios didácticos, la Escuela dispone de guías de autoaprendizaje y de lecturas en forma impresa, asesorías en línea y telefónica, fax, correo electrónico y sesiones de chat. "El proceso de formación es flexible, pues cada estudiante se inscribe en cualquier momento, avanza a su propio ritmo y se evalúa cuando considera que domina los objetivos de aprendizaje". 55

En abril de 1997 se inició el proceso de inscripción y en junio de 1999 la Escuela contaba con 420 estudiantes, 59 inscritos en la licenciatura en archivonomía y 361 en biblioteconomía; los alumnos se

54 Ibídem. p. 128

55 Ibidem. p. 129 
ubican a todo lo largo del país. Hasta el 20 de febrero de 2002 se reportó una matrícula de 836 alumnos, de los cuales 100 han solicitado su baja. Por tanto, permanecen 736 alumnos de los cuales a 238 se les aplicará el nuevo reglamento de inscripciones que señala lo siguiente: para ser un estudiante regular en la Modalidad Abierta y a Distancia se requiere aprobar un mínimo de 8 asignaturas por año. Con esta medida se pretende disminuir la deserción y fomentar en los estudiantes la regularización en sus estudios. Los logros de estas normas se observan en los datos recolectados hasta el 19 de noviembre de 2004: estudiantes de biblioteconomía 334, estudiantes de archivonomía 73, número de estudiantes que fueron dados de baja 150 , estudiantes que solicitaron su baja definitiva 195, egresados de biblioteconomía 5 y de archivonomía 4. Número de estudiantes que están condicionados a aprobar materias 389.

García Olvera $^{56}$ resume los logros de mayor relevancia que hasta el 2004 ha tenido la modalidad a distancia de la ENBA, los que a continuación se describen:

1. Haber diseñado material didáctico inédito para un área donde la información se produce en forma dispersa y heterogénea.

2. Haber creado un sistema de asesoría interactiva donde predomina la comunicación bidireccional. El uso del correo electrónico, por ejemplo, ha facilitado el intercambio de tareas, actividades de aprendizaje, exámenes, etcétera.

3. Haber constituido un sistema de evaluación flexible. Se le aplica al estudiante una evaluación diagnóstica y si la aprueba estará en condiciones de que se le aplique una evaluación sumativa. La flexibilidad se basa en reconocer que los bibliotecarios cuentan con conocimientos previos sobre materias específicas, por ejemplo, publicaciones seriadas.

56 Guillermo García Olvera, Coordinador de la modalidad a distancia de la ENBA, proporcionó en entrevista la información estadística, así como diversos aspectos de índole normativo y de resultados. (10 de noviembre de 2004) 
4. Haber permitido un mejor conocimiento de la realidad nacional, ya que en algunos casos se ha visitado a los estudiantes en sus lugares de residencia y tomado en cuenta su entorno laboral y profesional.

5. Impulsar el reconocimiento de estas dos licenciaturas en provincia.

\section{Instituto Tecnológico y de Estudios Superiores de Monterrey}

El programa del Instituto denominado "Maestría en Bibliotecología y Ciencias de la Información", ${ }^{57}$ se instauró en 1999 bajo la tutela de la Escuela de Graduados en Educación de la Universidad Virtual y desde entonces se ofrece en ella. Este programa es conducido de manera conjunta con la Escuela de Bibliotecología y Ciencias de la Información de la Universidad de Texas, en Austin (Graduate School of Library and Information Science).

Algunos aspectos que fueron considerados para instaurar esta maestría fueron, entre otros, los siguientes:

1. Los altos costos y problemas logísticos asociados al mantenimiento de una colección tradicional y de servicios bibliotecarios orientados al uso exclusivo de medios impresos han propiciado que muchas bibliotecas universitarias, públicas y privadas se encuentren en un periodo de estancamiento.

2. El uso cada vez más generalizado de las nuevas tecnologías de información representa una oportunidad para las bibliotecas tradicionales de renovarse y lograr rápidamente una actualización sostenida de sus colecciones.

La Maestría en Bibliotecología y Ciencias de la Información (MBCI) surge entonces para apoyar a las bibliotecas que atraviesan por un proceso de transformación que les exige diversificar sus funciones y adoptar nuevas plataformas tecnológicas para el manejo de información.

57 La Maestría en Bibliotecología y Ciencias de la Información del ITESM, descrita en este rubro se fundamentó en: http://www.itesm.mx/programas/maestría/mbci. 
El objetivo de este programa es tener impacto en al menos dos ámbitos: el académico y el empresarial. En el ámbito académico, las tecnologías de información representan una oportunidad para las bibliotecas tradicionales de renovarse, mejorar su productividad y ofrecer mejores servicios para sus usuarios. En el ámbito empresarial, el conocimiento y su generación, administración y aplicación se ha convertido en uno de los activos más importantes. La maestría proporciona las herramientas para organizar la información de toda institución.

El perfil del egresado especifica que el graduado será capaz de:

- Comprender el impacto causado por las tecnologías electrónicas de información y las redes computacionales en el manejo de la información.

- Planear, administrar e implantar los sistemas de información necesarios para la creación, organización y diseminación de la información.

- Comprender las teorías, principios y habilidades relacionados con las funciones de selección, adquisición, organización, catalogación, almacenamiento, recuperación, uso y evaluación de la información en todos sus ámbitos.

- Conocer y aplicar las teorías de administración de sistemas de información y servicios relacionados con las bibliotecas.

- Desarrollar empatía y sensibilidad hacia los usuarios y conocer sus procesos de búsqueda de información para diseñar, organizar e implantar mejores sistemas, servicios y programas de capacitación que cumplan con sus necesidades y expectativas.

- Adquirir y aplicar los conocimientos y habilidades especializados que se adecuen a los objetivos, intereses y alternativas del desarrollo profesional individual.

- Lograr un mejor desarrollo profesional al promover la necesidad de un aprendizaje y capacitación continuos y al incrementar la participación en organizaciones profesionales. 
Cabe señalar que dicha maestría ya ha generado profesionales a quienes conviene hacer un seguimiento con el propósito de medir el impacto tanto del programa como de los egresados en el mercado laboral. Asimismo, sería enriquecedor evaluar la efectividad de la maestría en relación con las coordenadas de costo beneficio.

\section{Centro Universitario de Investigaciones Bibliotecológicas (CUIB)}

La línea de investigación del Centro Universitario de Investigaciones Bibliotecológicas (CUIB) ${ }^{58}$ denominada Educar para informar, tiene como propósito, estudiar los problemas inherentes a la educación bibliotecológica y de la información con el fin de generar propuestas educativas acordes a los contextos sociales en que éstas se inserten. En este sentido, la investigación se amplía hasta incluir aspectos aplicados como sucedió con la primera experiencia en materia de educación virtual a partir del Diplomado en Línea sobre Biblioteca Digital el cual constituyó el primer esfuerzo realizado en la región latinoamericana en el campo de la bibliotecología.

El diplomado exigió la creación de un aula virtual para facilitar, por ejemplo, la interactividad entre estudiantes y tutores, la administración escolar, la disponibilidad en línea de material didáctico y el control de la evaluación, así como el diseño de una biblioteca digital de apoyo. Este diplomado surgió como respuesta a la necesidad, por un lado, de planear nuevos servicios que han empezado a exigir los usuarios a partir de las posibilidades que ofrece Internet y con el desarrollo de programas e interfaces para acceder de manera remota a servicios documentales; por el otro, a la urgencia de adecuar los servicios bibliotecarios y de información a la educación en línea en ambiente digital, donde el acceso a la información se convierte en la columna vertebral del proceso de enseñanza-aprendizaje. Por lo anterior, se consideró conveniente que el diplomado se ofreciera en un

58 Para mayor información sobre las actividades de investigación y producción editorial del CUIB puede consultar la siguiente dirección: http://cuib.unam.mx 
ambiente propicio para el desarrollo de la biblioteca digital con base en las siguientes razones:

- Darles oportunidad a los diversos actores del proceso enseñanza-aprendizaje de interactuar con la dinámica propia de ese tipo de modalidad educativa y comprender las necesidades informativas que implica esta forma de aprendizaje.

- Experimentar con los elementos teóricos y aplicados en torno a la educación a distancia y con el diseño y desarrollo de la biblioteca digital.

- Brindar la posibilidad de asumir el lugar del usuario ubicado en un ambiente digital a fin de comprender dicha situación y de este modo reducir las complejidades de la interacción entre la información y los servicios de la biblioteca digital.

Así, el grupo de trabajo para el diseño del modelo tecnológico en ambiente de red que comprende el aula virtual y la biblioteca digital, tomó en consideración algunos resultados preliminares emanados de las investigaciones que se realizan en el CUIB sobre Educación a Distancia y Biblioteca Digital. La complejidad del diseño y el desarrollo de tales herramientas requirió la concurrencia de un grupo interdisciplinario que debió tomar en cuenta que para sustentar el diseño del aula virtual y de la biblioteca digital en un entorno de red era primero necesario analizar diversos fenómenos relacionados con Internet y de manera principal aquellos vinculados con la educación en línea y la biblioteca digital. Los resultados preliminares, emanados de las investigaciones mencionadas, permitieron integrar un documento que sirvió de base para la discusión del grupo y ayudaron a desarrollar las diversas tareas que requería tal proyecto.

En consecuencia, para efectos del Diplomado en Biblioteca Digital, se acudió a diversos parámetros teóricos sustentados principalmente en el aprovechamiento de las tecnologías de información y comunicación que nos orientaran en lo siguiente:

- Los procesos y servicios interrelacionados.

- Una organización y administración flexible orientada a controlar la calidad de la información y de los servicios. 
- Los sistemas de comunicación entre biblioteca y comunidades académicas que especifican perfiles de interés y medios de aprovechar la información y las colecciones digitales disponibles.

- Los métodos de análisis de los procesos involucrados en la utilización de las tecnologías de información y telecomunicaciones, con el fin de desarrollar estrategias que ofrezcan servicios bibliotecarios y de información documental por medio de sistemas específicamente concebidos para tal fin.

- Un cuidadoso diseño de una interfaz para el usuario, intuitiva, normalizada y de fácil aprendizaje para la operación de los servicios.

- Los sistemas de información dirigidos al análisis interactivo de la información mediante sistemas de metadatos a modo de potenciar y facilitar los procesos de consulta documental.

- La capacidad para diseñar sistemas sobre el manejo de tecnologías como el hipertexto, los multimedia y la construcción de la arquitectura de comunicaciones dirigida tanto al manejo de enlaces dinámicos internos (intranet), como externos (Internet).

En suma, el Diplomado permitió, entre otros aspectos, experimentar e incidir, con los elementos teóricos y aplicados relacionados con la educación en línea y el diseño y desarrollo de una aula virtual; de esta manera pudimos adquirir conocimiento especializado y actual, así como propiciar que los diversos actores del proceso de ensenanza-aprendizaje interactuaran con la dinámica propia de la educación en línea y comprendieran los requerimientos informativos y la necesidad de apropiarse del conocimiento teórico, tecnológico y aplicado que implica esta forma de aprendizaje.

\section{Cooperación institucional del Centro Universitario de} Investigaciones Bibliotecológicas

A partir de 1998, el Centro es corresponsable, junto con la Facultad de Filosofía y Letras de la UNAM, del Posgrado en Bibliotecología y Estudios de la Información. El Centro también proporciona asesoría a instituciones nacionales e internacionales y en la actualidad forma parte del Comité Asesor de la Coordinación de Universidad 
Abierta y Educación a Distancia de la UNAM. Una de las aportaciones principales del Centro, en cuanto a educación a distancia (e-aprendizaje) radica en que a partir de 2002 ofrece, dentro del Postgrado mencionado, diversas materias en la modalidad a distancia, tanto del programa de maestría inserto en la UNAM, como de los que se imparten en Mérida, Yucatán y en San Luis Potosí.

Para ello, el CUIB utiliza como soporte tecnológico el "Espacio de Aprendizaje", 59 desarrollado por el propio Centro. El espacio es una aplicación sustentada en tecnología de redes en donde Internet es el medio fundamental como vía de comunicación e interacción con los actores del aprendizaje. Dicho espacio virtual contempla diversas aplicaciones e incluye dos ejes fundamentales: el alumno a distancia y el tutor responsable del curso. En este entorno, el tutor cuenta con una estructura fundamental a través de la cual les muestra a los alumnos los diversos elementos del curso como son: título de la materia, presentación de la misma, objetivos, temario, actividades de aprendizaje y evaluaciones. Por su parte, el alumno accede a las diversas opciones del curso y se comunica con el tutor a través de correo electrónico; las sesiones de conocimiento colaborativo se fundamentan en foros de discusión y el alumno obtiene el material didáctico del curso y puede consultar el historial de sus evaluaciones.

El diseño del espacio de aprendizaje es flexible debido a que ha sido dispuesto para apoyar la impartición en línea de cursos en diversos niveles académicos, los cuales pueden formar parte del plan de estudios de la Maestría en Bibliotecología y Estudios de la Información, como es el caso actual, o en su momento, sustentar el currículum integro, tanto de la maestría como de la licenciatura en bibliotecología y estudios de la información. El desarrollo tecnológico del espacio contempla compatibilidad de instalación y de uso en plataformas UNÍX, Linux y Windows.

59 La información tecnológica fue proporcionada por René Pérez Espinosa, responsable de la programación, actualización y funcionamiento del Espacio de Aprendizaje (10 de noviembre de 2004) 
No obstante las aportaciones logradas por el Centro, el panorama actual indica que le queda mucho que aprender y proponer en materia de e-aprendizaje con base en la investigación en educación que está realizando el CUIB. Algunos fenómenos investigativos deberían orientarse hacia los avances del software educativo, el desarrollo de plataformas para e-learning, los recursos informáticos de memoria y velocidad para la presentación de información gráfica de todo tipo, la producción de imágenes estáticas o animadas, el desarrollo de multimedia, y las tendencias de los objetos de aprendizaje en el $e$ learning, las comunidades virtuales de aprendizaje y las interfaces usuario-máquina.

PERSPECTIVAS DEL E-APRENDIZAJE EN EL CAMPO DE LA BIBLIOTECOLOGÍA Y LOS ESTUDIOS DE LA INFORMACIÓN EN MÉXICO

Con base en lo expuesto a lo largo de este trabajo y con la información existente en diversas fuentes de información que tratan el tema, se puede señalar que México es uno de los países de América Latina que se encuentra a la vanguardia en materia de programas educativos basados en la educación a distancia y, en consecuencia, en las propuestas sobre la tecnología del aprendizaje electrónico. La oferta de universidades públicas y privadas respecto a cursos basados en el e-aprendizaje brinda conocimientos básicos para el manejo de diversas tecnologías y distintos paquetes de software, incluida la enseñanza en e-aprendizaje de materias que corresponden a una determinada carrera, y programas completos de licenciatura, maestría y doctorado. Son todavía pocas las instituciones que han lanzado una oferta sustentada en un modelo de universidad virtual.

En el campo de la bibliotecología y estudios de la información, la oferta de estas formas educativas es escasa debido, entre otros aspectos, a que no se han comprendido cabalmente los beneficios que aportan estas formas de enseñanza-aprendizaje. Sin embargo, las pocas experiencias en operación ya han aportado resultados de mucho valor que pueden ser de gran utilidad para los diseñadores de propuestas 
educativas en línea. Las implicaciones del e-aprendizaje en la profesión bibliotecológica en México se evidencian a partir del aumento de alumnos que aprenden a distancia, lo cual ha generado el aumento de servicios de información acordes a su situación de lejanía, aspectos que propician nuevas oportunidades para el desarrollo de la profesión bibliotecaria, pues se proyectan novedosos escenarios laborales para los egresados de ésta. En consecuencia, se perfilan como fenómenos de aprendizaje en el campo de la bibliotecología las siguientes áreas: las teorías y metodologías de la educación en línea; el diseño y desarrollo de propuestas de e-aprendizaje en el campo de la bibliotecología; el establecimiento de centros e-learning; los perfiles temáticos que presentan los alumnos a distancia; la generación de nuevos servicios de información dirigidos a la e-tutoría basados en bibliotecas digitales y sitios web que contengan objetos informativos digitales acordes con las temáticas de las propuestas educativas basadas en aprendizaje electrónico; los servicios especializados dirigidos a los autores de contenido; la asesoría relacionada con los derechos de autor de documentos digitales; el dominio de estándares para la organización de objetos de aprendizaje, con base en sistemas de metadatos; la potencialidad de los acervos abiertos como fuentes documentales de apoyo al e-aprendizaje; el estudio de las particularidades del acceso libre (open access) de documentos digitales y su utilidad para los programas de e-learning.

La World Wide Web de acceso múltiple a sistemas de información distribuida requerirá de investigación multidisciplinaria dirigida a la generación y organización de objetos de aprendizaje orientados al apoyo de programas de e-learning, lo cual implicará crear, desarrollar y normalizar los instrumentos necesarios para llegar a su implementación apropiada en cuanto al almacenamiento, la búsqueda y la recuperación de dichos objetos. La naciente línea de investigación denominada web semántica, cuyo propósito es incidir en el máximo aprovechamiento de los recursos informativos de calidad disponibles en Internet, conseguirá que las páginas web dejen de ser cadenas de caracteres para las computadoras y se conviertan en textos provistos de semántica e incidirá en el uso de tecnologías aún más flexibles. De hacerse realidad, dichos propósitos traerían consigo 
nuevos replanteamientos en el proceso de enseñanza-aprendizaje, en el desarrollo y reutilización de objetos de aprendizaje y en la forma de recuperar objetos digitales dirigidos a la educación virtual.

Para proyectar el estudio de fenómenos emergentes, como los descritos con anterioridad, se debe entender cabalmente que los objetos de aprendizaje y los metadatos no sólo pertenecen a un paradigma de producción y organización novedoso, sino que también pretenden ser parte de las estructuras de conocimiento de la educación en línea. El éxito de los objetos de aprendizaje en una infraestructura informativa vía Internet para el e-aprendizaje dependerá en gran medida de la evolución, estudio y aplicación correcta de los estándares orientados a dichos objetos, lo cual deberá contemplar el uso de tecnologías que faciliten la reutilización de tales objetos en diversas plataformas para beneficio de los sistemas de e-learning. Por lo tanto, la disciplina bibliotecológica se verá precisada a contemplar el estudio de estos asuntos. Asimismo, la tendencia hacia el desarrollo de planes y programas flexibles, la movilidad de alumnos entre programas de la propia disciplina y su vinculación con otras disciplinas en el marco local, nacional e internacional, también son aspectos que atañen a dicha disciplina.

Sin duda la bibliotecología es una de las disciplinas que más han sido afectadas por las tecnologías de información y comunicación; sin embargo, esto no es necesariamente una calamidad, más bien debe observarse como una posibilidad de enriquecer la profesión, articulándose con el conocimiento multidisciplinario. Por lo tanto, el e-aprendizaje en el campo de la bibliotecología es, sobre todo, una oportunidad para que la disciplina redefina su papel en el contexto de los paradigmas educativos emergentes frente a la sociedad de la información y la sociedad del conocimiento.

\section{CONCLUSIONES}

En este naciente siglo se advierte con mayor énfasis que la modernización de la educación es uno de los proyectos relevantes de las naciones, entre ellos hay lugar para programas globales en los que esté presente la aplicación de políticas gubernamentales orientadas a efectuar 
cambios estructurales, económicos y constitucionales que le den coherencia a la participación educativa en un mundo globalizado.

El interés de diversos organismos e instituciones nacionales e internacionales en relación con la educación a distancia ha sido permanente por las repercusiones de ésta en las sociedades. Sin embargo, el estudio dirigido a este fenómeno ha cobrado mayor fuerza a raíz de la incorporación de tecnologías de información y comunicación, lo cual representa nuevas exigencias para analizar diversos aspectos que atañen a la teoría de la educación en escenarios virtuales de aprendizaje, como es el caso del e-aprendizaje.

Con relación a México se puede decir que en principio existe interés del Gobierno Federal y los Gobiernos Estatales de atender la educación de la población mexicana, porque es éste un mandato constitucional. Así, el aprendizaje en escenarios virtuales se percibe como una de las posibilidades para hacerle llegar programas educativos a poblaciones que históricamente han estado marginadas de este derecho. Hoy se tiene la convicción de que educar a un pueblo es una inversión a largo plazo que ocasiona bienestar social.

Muestra de ello se refleja en algunos propósitos del Programa eMéxico en el que se sostiene que hay que:

Fomentar a través del Sistema Nacional e-México nuevas opciones de acceso a la educación y capacitación, que estimulen el aprendizaje como un medio para el desarrollo integral de los mexicanos, [para ello se alude a incidir en] un sistema de aprendizaje en línea que integra los esfuerzos hechos por las instituciones en materia educativa, para el desarrollo equitativo de nuestro país. 60

Algunos resultados visibles de dichos propósitos son la inversión que se ha realizado en tecnologías de información y comunicación para las escuelas de nivel medio y superior; sin embargo, se advierte una escasa planeación en la formación de los cuadros que manejarán y posteriormente enseñarán a utilizar de manera apropiada las

60 E-México. Hacia la sociedad e la información. [En línea]

http://www.emexico.gob.mx/wb2/eMex_faq [Consultada: 10/09/04] 
tecnologías de información y comunicación dirigidas al programa eaprendizaje.

En la actualidad es visible la existencia de una demanda generalizada respecto al uso de Internet en las diversas áreas del conocimiento, siendo la educación superior una de las que registran mayor grado de demanda. Asimismo, es perceptible el propósito gubernamental de consolidar infraestructuras tecnológicas que permitan la conexión a Internet, propósito para el cual ha dedicado importantes sumas monetarias.

Asimismo, conviene que las instituciones educativas asuman el compromiso de atender los requerimientos que conlleva el incidir en programas educativos a distancia, como una alternativa que favorece que se cumplan los objetivos de ampliar la cobertura de la educación para un mayor número de ciudadanos, sin importar el lugar geográfico donde se encuentren; en todo ello, las diversas disciplinas deberán también colaborar desde el lugar que les corresponde para asegurar la calidad del aprendizaje. Con relación a la bibliotecología se debe reconocer que hace falta incidir más en el medio bibliotecario mexicano con propuestas de e-aprendizaje que favorezcan una preparación permanente en distintos niveles educativos.

Al mismo tiempo, el e-aprendizaje y las tecnologías de información y comunicación le plantean nuevos fenómenos de estudio a la bibliotecología, debido a las transformaciones tecnológicas operadas en el campo de las telecomunicaciones y la informática, pues han propiciado grandes cambios en las disciplinas en cuanto a las formas de aprender y las maneras de interactuar y comunicarse con alumnos en línea y en los requerimientos necesarios para la diseminación y el uso de la información y el conocimiento en actividades de aprendizaje en línea.

Un asunto que merece toda nuestra atención se relaciona con la formación de diversos expertos en educación y en tecnologías, reto que plantea para los próximos años grandes expectativas de formación vía Internet, siendo la propuesta e-learning aquella que vaticina los mayores logros que redundarán en las disciplinas, las empresas y los gobiernos. 
En el 2004, la formación en línea arrojó 4.000 millones de dólares en Europa" [...] para EEUU [se estimaron] 20.000 millones de dólares. De hecho, las ventajas del e-learning ya están siendo probadas por numerosas empresas. ${ }^{61}$

Al mismo tiempo habrá que tomar en consideración que las propuestas educativas a distancia en bibliotecología, se deben pensar tomando en cuenta el fenómeno de globalización que ha generado toda una serie de situaciones que la afectan. Lo global se relaciona con las tendencias del mundo actual por eliminar barreras de comunicación para facilitar los flujos de información impulsados, principalmente, por la tecnología electrónica, la informática y las telecomunicaciones. A la vez, es factible señalar que al e-aprendizaje en bibliotecología le son inherentes los aspectos de globalización, por lo que la sociedad requiere el acceso y la recuperación de información almacenada en múltiples formatos.

Otro elemento importante lo representan los contenidos informativos digitales, debido a la orientación de diversos programas relacionados con la edición y la organización digital de datos, cuya intención es integrar globalmente a los actores de conocimiento publicado con las unidades de servicios informativos y las instituciones educativas. Lo anterior pretende reducir las barreras tecnológicas que pueden presentar las telecomunicaciones y facilitar el uso de normas internacionales en el campo de la comunicación de información digital. En este contexto, la posibilidad de generar y transmitir flujos de información en un marco global hace necesario contemplar la estandarización tecnológica que se requiere para acceder a Internet. Lo anterior se plantea como factor determinante para la educación virtual del presente siglo.

A lo anterior habría que agregar el fenómeno sociedad de la información y del conocimiento, en donde las denominadas TICs y la propia información han propiciado cambios muy significativos y que

61 Fernández Eva, I. E-learning: implantación de proyectos de formación on line. México: Alfaomega, 2004. p.6. 
constituyen la base material de ésta. En el caso de la educación virtual en bibliotecología, el uso apropiado de la información relevante para los aprendizajes orientará cada vez más a los educadores a modificar las formas de estudiar, analizar y recrear la información disponible en redes para fines docentes.

También es importante señalar que en el diseño de propuesta educativas en bibliotecología, el e-aprendizaje precisa de la necesaria concurrencia de especialistas en educación, pedagogía, psicología, tecnologías de información y comunicación, telecomunicaciones, medios de comunicación, diseñadores gráficos, etcétera y, naturalmente, de especialistas en el ámbito de la bibliotecología. Esto pone de manifiesto el carácter multidisciplinario que exige el diseño de propuestas educativas de esta naturaleza.

Es en este contexto donde la bibliotecología y los estudios de la información se encuentran frente al panorama y las oportunidades que ofrece el e-aprendizaje. Por lo tanto, conviene que la bibliotecología reflexione a partir de la investigación y proponga nuevas formas de comunicar los aprendizajes, tomando en cuenta las necesidades de la educación en escenarios virtuales y las funciones que deben cumplir los profesionistas que prepara dicha disciplina. Hay que atender, en primera instancia, las exigencias de la actual sociedad mexicana usuaria de información.

\section{BIBLIOGRAFÍA}

Acuerdo por el que se reorganiza la Coordinación de Universidad Abierta y Educación a Distancia. (Signado por el Rector de la UNAM el 19 de septiembre de 2003. En Gaceta UNAM, septiembre de 2003, p.24

Álvarez, M. Inaugura el Rector trascendente Centro de Alta Tecnología de Educación a Distancia (CATED) [En línea] http://www.elearningworkshops.com/modules.php? name $=$ News\&file $=$ article $\& s i d=106$ [Consultada: $10 / 11 / 04]$ 
ALVA SUÁREZ, María de las Nieves. Las tecnologías de la información y el nuevo paradigma educativo. En Contexto Educativo y Nueva Alejandría Internet [En línea] http://contexto-ducativo.com.ar/ [Consultada: 28/10/04]

AMADOR BAUTISTA, Rocío. Educación y formación a distancia en México. Crónica de una historia no escrita. En Educación y formación a distancia. Prácticas, propuestas y reflexiones / coord. Rocío Amador Bautista. México: Universidad de Guadalajara, 2001. pp. 15-49

--. Nuevos procesos educativos en el medio digital. En El medio digital en el siglo XXI: retos y perspectivas para los bibliotecólogos, investigadores, educadores y editores . México:UNAM, CUIB, 2001[Editado en CD-ROM]. TRABAJO PRESENTADO EN EL XVIII Coloquio Internacional de Investigación Bibliotecológica.

ANUIES. Plan Maestro de Educación Superior Abierta y a Distancia: líneas estratégicas para su desarrollo. México: ANUIES, 2001. 118 p. [En línea].

http://www.anuies.mx/pdf/Plan\%20Maestro1.pdf [Consultada: $02 / 10 / 04]$

BARRÓN SOTO, Héctor S. La educación en Línea y el texto didáctico. México: UNAM, Coordinación de Universidad Abierta y Educación a Distancia: Facultad de Filosofía y Letras, 2004. 100 p.

CABRERO A. Julio. Nuevas tecnologías, comunicación y educación. En EDUTEC. Revista Electrónica de Tecnología Educativa, núm. 1, feb. 1996. [En línea]

www.http://uib.es/depart/gte/revelec1.html/ [Consultada: 20/09/04]

CARDONA OSSA, Guillermo. “Tendencias educativas para el siglo XXI educación virtual, online y @learning, elementos para la discusión". En Edutec. [En línea]

http://edutec.rediris.es/Revelec2/revelec15/cardona.pdf [Consultada: $18 / 11 / 04]$ 
CARRERA RIVA PALACIOS, Sergio. Programa para el desarrollo de la industria del software. En Política Digital, núm. 15, feb. 2004, p. 8.

Castellanos COUTiNo, Carlos Alberto. Panorama general de los sistemas de educación a distancia. En Primer Congreso Virtual Latinoamericano de Educación a Distancia. [En línea] LatinEduca2004.com [Consultada: 18/11/2004.

COLLIS, B. Tele-learning in a digital world: the future of distance learning. London: International Thompson Computers Press, 1996. $651 \mathrm{p}$.

CONTRERAS M. Rita. Reflexiones en torno al uso de la tecnología de la información en el terreno educativo. En Soluciones Avanzadas: Tecnologías de Información y Estrategias de Negocios $\mathrm{j}$, vol. 5, núm. 46, jun. 1997 , p. 10-15

Contenidos e-learning. En E-learning América Latina. La Revista Digital de e-learning en América Latina. año 1, núm. 8, nov. 2004. [En línea]

http://www.elearnigamericalatina.com/edicion/noviembre/index.php [Consultada: 05/11/04]

CORNELLA, Alfonso. E-Learning: de la formación de los empleados al conocimiento en toda la cadena de valor. En El Profesional de la Información, vol. 11, núm. 1, ene-feb. 2002. p. 65-68.

Centro Universitario de Investigaciones Bibliotecológicas. [En línea]

http://cuib.unam.mx [Consultada: 09/10/04]

CUAED.[En línea]

http://www.cuaed.unam.mx/contenido/notices.htm [Consultada: $10 / 10 / 04]$

EDUCADIS. Materiales y medios didácticos. servicios asociados para la educación a distancia. Argentina, 2000. [En línea] http://www.educadis.com.ar/mymath.htm [Consultada: 15/09/04] 
E-learning: soluciones de e-learning. formación a distancia [En línea].

http://e-learning.bankhacker.com/ [Consultada: 08/05/04]

E-learning en México. En Reforma, el independiente. [En línea] Eduterra.com [Consultado: 18/11/04]

Encuesta panorámica e-learning corporativo en América Latina 2003 [resultados México] / Tecnonexo. En E-learning América Latina, Revista Digital de e-learning de América Latina, año 2, núm. 46, nov. 2004. [En línea]

http://www.elearningamericalatina.com/encuestas/latinoamerica.php [Consultada: 20/11/04]

En función el Centro de Alta Tecnología en Tlaxcala. Declaración hecha por Juan Ramón de la Fuente. En Gaceta UNAM, 28 de agosto de 2003. p. 6.

E-México. Hacia la sociedad e la información. [En línea] http://www.emexico.gob.mx/wb2/eMex_faq [Consultada: $10 / 09 / 04]$

Fernández Eva, I. E-learning: implantación de proyectos de formación on line. México: Alfaomega, 2004. p. 6.

Freixas Flores, R. SEP e ILCE en la educación a distancia [En línea]. http://www.ciberhabitat.com.mx/escuela/sep_ilce/textos/texto_ sepilce.htm [Consultada:28/08/04]

FORNACA, R. Componentes epistemológicos en la reconstrucción histórica de los modelos educativos y pedagógicos (primera parte). En Cero en conducta, vol. 6, núm. 26-27, jul.-oct. 1991, p. 64-73.

Fundación México Digital. [En línea] http//:www.todito.com/paginas/noticias/129874.html [Consultada:28/10/04]

FUNDESCO. Teleformación: un paso más en el camino de la formación continua. Madrid : FUNDESCO, 1998. 212 p. 
GARCÍA ARETIO, L. La educación a distancia: de la teoría a la práctica. Barcelona: Ariel, 2001. 328 p. (Ariel Educación)

Hechos y estadísticas del e aprendizaje. [En línea] http://www.dr-zippie.net/?elearnig_/ [Consultada: 06/11/04]

ILCE [En línea]. http://members.tripod.com/ ILCE/ilce.htm [Consultada: 09/10/04]

ILCE [En línea]. http://www.ilce.edu.mx/ [Consultada: 09/10/04]

Instituto Politécnico Nacional. [En línea] http://www.ipn.mx. [Consultada: 10/11/04]

ITESM. Maestría en Bibliotecología y Ciencias de la Información [En línea] http://www.itesm.mx/programas/maestría/mbci. [Consultada: 08/10/04]

ITESM. histórico [En línea]

http://tyr.mty.itesm.mx/Historia/historia.html [Consultada: $15 / 10 / 04]$

KERCKHOVE, Derrick de. Inteligencias en conexión: bacia una sociedad de la Web. España: Gedisa, 1999. 214 p.

LEVER-DUFFY, Judy. Teaching and learning with technology / Judy Lever-Duffy, Jean B. McDonald, Al P. Mizell. - Boston: Pearson Education, 2003. 439 p.

LOYO VARELA, C. y V. G. Sánchez. La telemática y la educación a distancia. En Soluciones Avanzadas, vol. 4, núm. 24, ago. 1995, [En línea] http://www.lania.mx/nivel2/divulgacion.html

MOREIRA AREA, Manuel. ¿Qué aporta Internet al cambio pedagógico en la educación superior? Universidad de la Laguna . [En línea] http://tecnologiaedu.us.es/bibliovir/pdf/a12.pdf [Consultada: 15/11/04] 
PÉREZ PAZ, Nahúm. La modalidad de educación abierta y a distancia de la Escuela Nacional de Biblioteconomía y Archivonomía. En Jornadas Mexicanas de Biblioteconomía (28: 1997: Cocoyoc, Mor.). México: AMBAC, 1998. p.122-131

Portal e-México. Hacia la sociedad de la información. (e-aprendizaje) [En línea]

http://www.e-mexico.gob.mx/wb2/eMex/eMex_Acerca_del_programa [Consultada: 06/11/04]

Programa Universidad en Línea (PUEL). [En línea]

www.puel.unam.mx). [Consultada: 15/10/04]

Programa Universidad en Línea. En Gaceta UNAM, 23 de junio de 2003, p.7.

PUEL.[En línea] http://www.puel.unam.mx/cursos/t_planeacion/index.htm\# [Consultada: 10/09/04]

PUEL. [En línea] http://www.puel.unam.mx. [Consultada: $10 / 09 / 04]$

ROSENBERG, Marc J. E-learning for delivering knowledge in the digital age, 2001. Citado en Introducción al e-learning. [En línea] http://www.mailxmail.com/curso/empresa/elearnig/capitulo1. htm [Consultada: 06/11/04]

SANZ PRIETO, Mariano. Teleeducación entornos de aula virtual. En Temas [2002], p.12-20

SHEREMETOV, L. Espacios virtuales de aprendizaje: experiencia y prospectiva. En El medio digital en el siglo XXI: retos y perspectivas para los bibliotecólogos, investigadores. educadores y editores. México : UNAM, CUIB, 2001 [editado en CD-ROM].

SIMPSON, Ormond. Supporting students in online, open and distance learning. - 2a. ed. - London: Kogan Page Limited, 2002. xiii, 226 p. ISBN 0-7494-3740-5 
SUA [en línea]

http://fcasua.contad.unam.mx/sua/que_sua.htm [Consultada:

09/10/04]

Tecnonexo-Revista Digital e-Learning América Latina. e-learning América Latina [En línea]

http://www.elearningamericalatina.com/edicion/junio2_2004 /index.php.

También existe información al respecto en: ¿Cómo ven los empresarios latinoamericanos al e-learning? [En línea]

http://www.elearningamericalatina.com/edicion/noviembre1/ na_1.php [consultada: 22/11/04]

Tele-learning: the challenge for the third millennium / Edited by Don Passey, Mike Kendall. - Norwell, Massachusett: Kluwer Academic Publishers, 2002. xxiii, 372 p.

TIFFIN, John y Lalita Rajasingham. En busca de la clase virtual: la educación en la sociedad de la información. Barcelona: Paidós, 1997. $312 \mathrm{p}$.

VAQUERO SÁNCHEZ, A. Las TIC para la enseñanza, la formación y el aprendizaje. En Novática 132: monografía sobre las TIC en la educación [En línea].

http://www.ati.es/PUBLICACIONES/novatica/1998/132.html [Consultada: 08/19/04]

ZETINA AGUIRRE, Ignacio. Experiencias del sistema de educación a distancia de la Universidad Pedagógica Nacional. En Divulgación Científica 1989, vol. 1, no. 1. 


\title{
Soporte al E-learning: un nuevo desafío para los bibliotecarios
}

\author{
Regina Santos Silva Tonini
}

Hoy, entre tanto, estamos asistiendo a una desterritorialización de

la biblioteca

Pierre Lévy ${ }^{1}$

\begin{abstract}
RESUMEN
El texto se refiere al concepto de e-learning, web based trainning, computer based training, e-reading, tipos de cursos síncronos, asíncronos, educación a distancia y temas afines. Presenta consideraciones sobre las ventajas del aprovechamiento de las tecnologías que hacen posible esta forma de aprendizaje y la posibilidad de desarrollo para las personas en todo el mundo, principalmente en los países en vías de desarrollo en donde los recursos educativos muchas veces son escasos e impiden que los alumnos asistan a las clases presenciales. Comenta el beneficio que representa la transferencia de conocimiento vía web, tanto para quien lo transfiere como para quien lo recibe. Considera la relevancia de los portales que presentan textos en más de dos idiomas, los cuales superan las barreras lingüísticas, especialmente en los países en vías de desarrollo donde constituyen un excelente mercado para el intercambio de
\end{abstract}

1 Palestra realizada en el Festival Usina de Arte y Cultura, promovido por el Ayuntamiento Municipal de Porto Alegre en Octubre de 1994. Traducción de Suely Rolnik. Revisión de la traducción transcrita: João Batista Francisco y Carmen Oliveira 
información. El tema conduce a una reflexión sobre el rol del bibliotecario en la sociedad y su condición de profesional responsable de investigar, organizar y facilitar la información. Intenta mostrar las diversas formas mediante las cuales este profesional puede contribuir para lograr resultados positivos en el proceso del e-learning. Expone, en líneas generales, un proyecto para la utilización de bibliotecas digitales como herramienta de apoyo al trabajo de los estudiantes y como complemento de una biblioteca tradicional, en una empresa de Sudamérica que mantiene una universidad corporativa como recurso para el desarrollo de su capital intelectual; promueve la interacción con otras universidades; y a través de la misma y de otras actuaciones, legitíma ante la sociedad su rol de empresa comprometida con la responsabilidad social. Concluye con un comentario sobre la importancia de la formación del profesional bibliotecario investigador, con el conocimiento de otros idiomas, además de su lengua materna, así como sobre la importancia de su capacidad para enfrentar nuevos desafíos, buscando siempre los conocimientos que más favorecen su área de actuación, no solo por la lectura de textos especializados, sino también mediante la interacción con profesionales de otras áreas por medio de grupos de estudios multidisciplinarios.

\section{INTRODUCCIÓN}

esde el surgimiento de la red de las redes, es decir, la Internet,
ue creado un nuevo espacio para la interacción humana, el ci-
berespacio o espacio cibernético, así denominado por Pierre Levy (1994). Un mundo electrónico paralelo, altamente democrático y solidario, donde empieza la formación de una base de conocimiento universal, lo cual se ha tornado cada vez más importante en los más diversos aspectos, principalmente el económico. 
El aumento exponencial del número de personas que utilizan dicho servicio, debido a la gran reducción de los costos de acceso y de los propios equipamientos, está tornando posible pensar en alcanzar grandes grupos de personas, con intereses comunes. Progresivamente, los recursos tecnológicos están proporcionando una formación profesional para las personas que no tendrían posibilidad de desprenderse de recursos para esta finalidad, debido a los problemas económicos, a la rigidez de utilización del tiempo y a la dificultad de locomoción en busca de su formación.

Pierre Levy afirmó, con énfasis, que el espacio cibernético está proporcionando la desterritorialización de los textos, de las mensajes, de todo tipo de documento, en suma, la desterritorialización de la biblioteca. Se considera como evidencia de lo que está ocurriendo el creciente interés en la creación de bibliotecas digitales, virtuales o electrónicas, para las cuales no se presentará concepto en este momento para que no se desvie el foco principal del texto.

La contribución que se pretende ofrecer a través del presente trabajo está enfocada a los conceptos de e-learning, web based trainning, computer based training, e-reading, blended learning tipos de cursos síncronos, asíncronos, multisíncronos, educación a distancia y asuntos correspondientes, síntesis de la práctica de enseãnaza a distancia en Brasil y el aprovechamiento de las tecnologías que viabilizan esta forma de aprendizaje, principalmente en los países en desarrollo, llevando a una reflexión acerca de las barreras lingüísticas que deben ser superadas en favor de una economía de mercado que se refleja favorablemente, tanto en los países en desarrollo como para los ricos.

Dentro de este contexto es abordada la contribución del bibliotecario como profesional que por su formación académica está preparado para el gerenciamento de la información, y por lo tanto, podrá ejercer una interacción de forma relevante con profesionales de saberes diversificados para dar el soporte necesario a la formación de 
esa base de conocimiento universal, proporcionada por la riqueza de posibilidades de la red mundial de computadoras con su backbone ${ }^{2}$ principal, proveedores de backbones, proveedores locales de servicio $^{3}$ y usuarios finales. ${ }^{4}$

\section{RECURSOS PARA LA BÚSQUEDA DEL CONOCIMIENTO}

La búsqueda del conocimiento ha sido una de las grandes preocupaciones de la humanidad y por eso se han desarrollado diversos recursos, destacándose en la actualidad los siguientes: e-learning, web based trainning, computer based training, e-reading, blended learning, cursos síncronos, cursos asíncronos y cursos multisíncronos.

A continuación se presentan una serie de conceptos acerca de estos recursos:

\section{Educación a Distancia (EAD)}

Los conceptos acerca de este asunto son muchos y variados por lo que fueron seleccionados tres, tomados como base de reflexión en este contexto.

Educación a Distancia es un punto intermediario de una línea continua donde en un lado se encuentra la relación profesor-alumno y en el otro la educación autodidacta, abierta, en la que el alumno no necesita de la ayuda del profesor (Cirigliano, 1983).

2 backboneé es el punto central de la red, con capacidad para transmitir grandes volúmenes de dados, utilizando canales de alta velocidad, podiendo alcanzar una amplitud nacional, regional o estadual.

Backbone principal de la internet se encuentra en EEUU, viene siendo mantenido por empresas como la "America Online", "Sprint" y "MCI".

3 provedor local de servicio, un lazo de la red que paga para conectar su computadora a un backbone.

4 usuarios finales, contratante de un proveedor local de servicio para obtener el derecho de conexión durante algunas horas al mes. 
Educación a Distancia es una forma sistemáticamente organizada de autoestudio donde el alumno se instruye a partir del material que le es presentado; donde la guía y la supervisión del proceso educativo son llevados a cabo por un grupo de profesores. Esto es posible efectuarlo a distancia a través de la aplicación de medios de comunicación capaces de vencer la distancia, la que en ocasiones es grande. Lo opuesto de la educación a distancia es la educación directa o educación cara a cara, un tipo de educación que proporciona el contacto directo entre los profesores y los alumnos (García Aretio, 1994).

Enseñanza a Distancia es un método de instrucción en el que las conductas docentes ocurren en forma indepediente, de manera que la comunicación entre el profesor y el alumno se pueda realizar a através de textos impresos, medios electrónicos, mecánicos o otras técnicas (Moore, 1996).

\section{E-LEARNING}

En Brasil, el término e-learning ha servido para designar modelos de aprendizaje en los cuales son utilizados recursos electrónicos y otros medios diversos. En este contexto aquí son presentados tres conceptos que sirven para reflexionar acerca de la visión que se tiene en determinado momento respecto al asunto en estudio.

E-learning es una modalidad de enseñanza a distancia que posibilita el autoaprendizaje con la utilización de recursos didácticos sistemáticamente organizados, presentados en distintos soportes tecnológicos de información, utilizados aisladamente o combinados, propagado a través de la Internet (www.aprendervirtual.com.br)

E-learning es la utilización de tecnologías de la Internet para integrar un amplio conjunto de soluciones que mejoran el conocimiento y el desempeño (Rosenberg, 2002).

E-learning es la utilización de tecnologías de la Internet, como web, e-mail, conferencia, entre otras, para el entrenamiento y la capacitación profesional. Estas herramientas normalmente son agrupadas y gerenciadas en una plataforma de enseñanza y aprendizaje que permite monitorar todas las acciones de los entes involucrados. Estas 
plataformas reciben el nombre de Learning Management System (LMS) y son utilizadas por grandes corporaciones e instituciones de enseñanza, como universidades y centros de Investigación (http://www.mundi.com.br/e_learning/)

Con el crecimiento de la banda ancha en la web, el e-learning está siendo distribuído cada vez más vía web y menos vía CBT; sin embargo, soluciones como CD y DVD en muchas ocasiones son las más apropriadas para cursos con video, simulaciones más complejas, etc.

En inglés son usadas las siglas WBT y CBT para diferenciar el aprendizaje vía web (Web Based Training) de aquel sin conexión a la web, vía CD-ROM o DVD (Computer Based Training). Cada vez más se utiliza la terminología e-learning de forma general para designar el aprendizaje que contiene un elemento significativo de la tecnología. Nuevos términos pasan a ser utilizados en función de esta nueva metodología de aprendizaje, tales como: síncrono, asíncrono, multisíncrono, aprendizaje híbrido, apostilla on-line.

Síncrono designa el curso que es suministrado en vivo, por ejemplo, vía webcast (donde una cámara filma al profesor y las imágenes son convertidas en formato digital e inmediatamente transmitidas vía web para todos los alumnos participantes en el curso).

Asíncrono es cuando el material del curso es colocado en la web o en un CD-ROM/DVD y posteriormente el alumno trabajará con aquel en el momento que mejor le convenga.

Multisíncrono es el curso que combina la síncronia con la asíncronia en la comunicación intermediada por la computadora la que pone el alumno delante de una nueva temporalidad, la temporalidad multisíncrona. A distancia, vía Internet o en redes locales, la multisíncronia amplía las posibilidades de comunicación, permitiendo que esta ocurra de una forma más elástica, como si se "extendiera" sobre la temporalidad síncrona cotidiana.

Aprendizaje híbrido o blended learning designa el aprendizaje donde varias tecnologías y metodologías son utilizadas en conjunto. La hibridez puede ser tanto en la presentación del curso (vía tecnología y vía presencial) como en las tecnologías/medios utilizadas (por ejemplo, un curso vía web asíncrono + vía videoconferencia + más libros + CD-ROM). 
Apostilla on-line o e-reading, un término que surgió para caracterizar aquellos cursos de e-learning que prácticamente no utilizan ningún recurso de multimidia o interactividad. El contenido es a través de textos largos y algunos gráficos.La información que hoy circula con abundancia a través de las redes de computadoras se encuentra mayoritariamente en texto ya sea en páginas web o en mensajes de correo electrónico, en charlas o en programas de mensajes instantaneas. Es el texto que corre por las venas de la Internet o de la Intranet, a veces ilustrado por imágenes, fotos, o animaciones, pero fundamentalmente texto.

\section{SÍNTESIS DE LA EDUCACIÓN A DISTANCIA EN BRASIL}

Según los autores consultados, no existen registros precisos acerca de la creación de EAD en Brasil. Alves (2001) menciona que elJornal do Brasil (Periódico de Brasil) inició sus actividades en 1891 con un anuncio ofreciendo profesionalización por correspondencia para mecanógrafo.

Con el objetivo de ofrecer una síntesis sobre la educación a distancia en Brasil, son presentados a continuación algunos hechos sobresalientes:

- 1904, la implantación de las "Escuelas Interamericanas", considerada como marco histórico;

- 1923, la fundación de la Radio Sociedad Río de Janeiro por un grupo liderado por Henrique Morize y Roquete Pinto, lo que inició la educación por la radio;

- 1936, donación de la emisora para el Ministerio de Educación y Salud;

- 1937, creación del Servicio de Radiodifusión Educativa del Ministerio de Educación.

- 1939, fundación del Instituto Radio Técnico Monitor, en São Paulo, para estudios en el área electrónica.

- 1941, fundación del Instituto Universal Brasileño, promoviendo la formación profesional de nivel elemental y medio. 
- 1946, fundación de la Universidad del Aire por el Servicio Nacional de Aprendizaje Comercial (SENAC).

- 1967, inicio de las actividades de EAD por la Fundación Padre landell de Moura, con metodología de enseñanza por correspondencia y radio.

- 1989, creación de la Red Brasileña de Educación Superior Abierta y a Distancia - READ.

- 1994, celebración del Seminario Internacional de Nuevas Tecnologías en la Educación y en la Formación Continuada, iniciativa de la Universidad de Brasilia.

Según Alves (2001), las redes de EAD tienen como gran desafío el control de calidad de los cursos ofrecidos y la constante capacitación de los profesionales e instituciones que contribuirán para legitimar esta iniciativa frente a la sociedad.

El aprovechamiento de las tecnologías de la información constituyen altrnativas estratégicas para la gestión del capital intelectual en la Era del Conocimiento. La nueva economía, basada en el conocimiento, está llevando al surgimiento de nuevas organizaciones y la necesidad de adaptación de los propósitos de las universidades tradicionales para que éstas puedan aprovechar a las ventajas de las tecnologías emergentes, así como nuevos medios en la promoción del aprendizaje. Esta es la opinión de Hanna (1998).

Con el desarrollo de las tecnologías que utilizan nuevos medios para transmitir las informaciones y procesar el aprendizaje, las universidades precisan incorporar cambios en lo que hacen y como lo hacen, buscando en alianzas y sociedades la solución para superar los desafíos contemporáneos. La proliferación reciente de las universidades corporativas que enfatizan programas de enseñanza virtual (e-learning), ya es una clara y eficaz respuesta a esa necesidad.

En el mundo académico, la enseñanza a distancia permite que las personas asistan a las clases de universidades online. Instituciones de grande relevancia, como Stanford y Harvard ya ofrecen cursos enteros vía Web, a través de e-learning. Algunas organizaciones no gubernamentales, en Brasil, poseen un sistema altamente sofisticado de bajo costo y de fácil utilización, conocido como AlterNex, que une 
por medio de computadora a las organizaciones y a las personas que tienen un aparato denominado MODEM (MOdulador/DEMolulador).

A mediados de la década de los 70, la Universidad de Brasilia (UnB) inició una de las primeras experiencias universitarias de educación a distancia en Brasil. Fue motivada por el éxito británico de la Open University. La Universidad de Brasilia pretendía ser la Universidad Abierta de Brasil. Adquirió todos los derechos de traducción y publicación de los materiales de la Open University y empezó a producir algunos cursos en el área de ciencia política. En 1986, la UnB promovió un curso sobre la Constitución, la cual estaba siendo elaborada, organizó grupos de estudios y llevó el debate constitucional a más de 100.000 participantes del curso en todo el país. La educación a distancia empezaba a cumplir su papel democratizador del saber. Actualmente, la Universidad de Brasilia posee un Centro de Educación Abierta Continuada y a Distancia-CEAD.

Dentro de las ventajas del aprovechamiento de las tecnologías de la información en la educación, se observa:

- Viabilidad para la educación continua, descentralizada y dinámica;

- Aceleración de las actividades de formación e incentivo a la autoformación;

- Optimización de resultados y mayor posibilidad de evaluación;

- Aumento de la retención del contenido;

- Creación de facilidades para la formación de las competencias y habilidades;

> Reducción de costos.

De acuerdo con las informaciones transmitidas a través del sitio: E-Learning Brasil, fueron identificadas 374 organizaciones que ya utilizan el e-learning en el país (Información obtenida el 20/06/2004 en http://www.elearningbrasil.com.br/news/brasil/index.asp.) 


\section{DIFICULTADES PARA EL DESARROLLO DE LA ENSEÑANZA A DISTANCIA EN BRASIL}

En Brasil, los problemas más significativos que han impedido el progreso y la masificación de la modalidad de educación a distancia han sido:

- programas poco vinculados a las necesidades reales del país y organizados sin alguna vinculación exacta con los programas del gobierno;

- una visión administrativa y política que desconoce los potenciales y las exigencias de la educación a distancia, haciendo que esa área siempre sea administrada por personas sin una calificación técnica y profesional;

- organización de proyectos piloto sin la adecuda preparación para su continuidad;

- organización de proyectos piloto solamente con la finalidad de probar metodologías.

- falta de criterios de evaluación de los programas y proyectos;

- falta de divulgación de los proyectos e inexistencia de canales de interferencia social en los mismos;

- inexistencia de una memoria sistematizada de los programas desarrollados y de la evaluaciones realizadas (cuando existían);

- discontinuidad de los programas sin alguna presentación de cuentas a la sociedad, a los gobiernos y a las entidades financiadoras;

- falta de estructuras institucionales para la gerencia de los proyectos y la presentación de cuentas de acuerdo a sus objetivos;

El e-learning se presenta como la gran solución para el futuro; sin embargo, se deben considerar con atención dos aspectos; el primero es la credibilidad que regule la legitimidad de lo que se quiere emprender; el segundo, es la necesidad de un intercambio con organizaciones internacionales para que ocurra una correcta orientación acerca de los mejores recursos tecnológicos utilizables. 


\section{E-LEARNING Y EL BIBLIOTECARIO}

Las bibliotecas siempre colaboraran con la educación a distancia y con su continuidad, facilitando el acceso a las diferentes fuentes de información. Antaño, la colaboración era prestada atendiendo a las consultas locales por teléfono o hasta por correo. Hoy, el profesional se encuentra delante del lector virtual con las mismas necesidades, utilizando sólo soportes distintos para sus informaciones. Ante esta nueva realidad, la función de los bibliotecarios y los servicios ofrecidos por las bibliotecas han sufrido profundos cambios, debido a la explosión de información y, principalmente, al uso intensificado de los recursos tecnológicos.

Tiffin \& Rajasingham (1995) consideran a las bibliotecas como puntos vitales de las instituciones de enseñanza y en la educación a distancia es de gran relevancia el acceso a ellas. En el mundo están creciendo las bibliotecas digitales que permiten la obtención (download) del texto integro de los libros y artículos de revistas. En Brasil, iniciativas como la Biblioteca del Estudiante Brasileño de la Universidad de São Paulo y el Programa de Información y Comunicación para la Investigación - PROSSIGA están haciendo accesibles textos literários en portugués y textos técnico-científicos, en forma pública y gratuita.

A partir de esto, el bibliotecario, con su formación académica de gestor y organizador de la información, es el profesional por excelencia para interactuar con los profesionales de las tecnologias de información y con otros expertos de áreas específicas, formando un grupo interdisciplinar, con el objetivo de proporcionar a los e-learners el acceso a una biblioteca electrónica o virtual que atienda a sus expectativas de información.

Una biblioteca proyectada con este perfil, deberá incluir en su sitio (bomepage) información y acceso a servicios como:

$\checkmark$ Alerta bibliográfico;

$\checkmark$ Acceso a su acervo;

$\checkmark$ Acceso a bases nacionales y extranjeras;

$\checkmark$ Préstimo interbibliotecario;

$\checkmark$ Nuevas adquisiciones;

$\checkmark$ Intercambio bibliográfico; 
$\checkmark$ Orientación y entrenamiento para accesar a bases de dados;

$\checkmark$ Orientación para normalización de documentos;

$\checkmark$ Mercado editorial;

$\checkmark$ Permuta de facturas e intercambio;

$\checkmark$ Selección interactiva;

$\checkmark$ Listas de discusión;

$\checkmark$ Informes sobre las novedades y links interesantes.

Para una empresa de esta magnitud, el profesional deberá poseer conocimientos de al menos dos idiomas de alcance internacional. Un gran problema, existente principalmente en los países en desarrollo, es la barrera lingüística. En este sentido, los traductores electrónicos, cada vez más perfeccionados, encontrarán un excelente mercado y estarán contribuyendo de modo decisivo para el desarrollo científico y tecnológico del conocimiento universal.

\section{REFERENCIAS BIBLIOGRÁFICAS}

ALVES, Joao Roberto Moreira (2001). Educação à distância e as novas tecnologias de aprendizagem.

http://www.engenheiro2001.org.br/programas/980201a1.zip. [Consultado: 15 de Mayo, 2004].

CIRIGLIANO, Gustavo F. J. (1983). La educación abierta. Buenos Aires: El Ateneo.

DINIZ, Patrícia (1998). Biblioteca do futuro: Sem paredes e barreiras físicas as bibliotecas ampliam suas fronteiras e democratizam a informação.

http://www.cg.org.br/gt/gtbv/artigo02.htm [Consultado: 9 de Septiembre, 1998].

GARCIA ARETIO, Lorenzo (1994). Educación a distancia boy. Madrid: Universidad Nacional de Educación a Distancia. 
E-learning do Brasil.

http://www.elearningbrasil.com.br/news/brasil/index.asp. [Consultado: 15 de Mayo, 2004].

HANNA, D. (1998). Higher education in a era of digital competition: emerging organizational models Journal of Asynchronous Learning Networks, 2(1). [Consultado: 15 de Mayo, 2004].

MOORE, Michel G. y Kearsley, Greg (1996). Distance education: A systems view. Belmont (USA): Wadsworth Publishing Company.

ROSENBERG, MARC J. (2002). E-Learning. São Paulo: Makron Books.

TIFFIN, John y Rajasingham, Lalita (1995). In search of the virtual class: Education in a information society. London : Routledge. 


\title{
Calidad y e-learning
}

\author{
Viviana Fernández Marcial
}

\begin{abstract}
RESUMEN
La importancia del e-learning como sistema de formación en la sociedad de la información, así como las deficiencias y errores cometidos en el desarrollo de proyectos de e-aprendizaje, han conducido al desarrollo de estudios e iniciativas relacionadas con la mejora de la calidad. Con ello se han establecido criterios, indicadores, estándares y sistemas de calidad. Los procesos de acreditación de la calidad se configuran como una importante tendencia en la gestión de la calidad en el e-aprendizaje. Algunas actuaciones en este sentido así lo confirman. Pero también existe una amplia gama de iniciativas orientadas al establecimiento de estándares de calidad y de guías de recomendaciones y/o evaluación de la calidad en el contexto de la formación virtual. El presente trabajo revisa diversas iniciativas relacionadas con la calidad en el e-aprendizaje desarrolladas, fundamentalmente, en el ámbito de la Europa Comunitaria.
\end{abstract}

\section{INTRODUCCIÓN}

auge e importancia del e-learning, como elemento motriz en la sociedad de la información en lo que se refiere al ámbito educalivo, señala la necesidad de establecer criterios, normas y sistemas de calidad que garanticen, en un espacio globalizado de formación, los niveles de competitividad y excelencia demandados por los clientes y la sociedad.

Calidad en el entorno e-learning se puede definir como la adecuación de los recursos, métodos y herramientas utilizados en el proceso de formación virtual a las necesidades y expectativas de los estudiantes y de la sociedad con el fin de garantizar la optimización 
del proceso de aprendizaje y la utilización práctica y efectiva de los conocimiento y habilidades. Esta definición implica que para alcanzar los niveles de calidad esperados, es necesario una clara orientación al cliente, una adecuación a las demandas y condiciones del entorno y una visón integrada y sistémica de los diversos elementos que conforman la gestión del sistema de e-aprendizaje.

No es infrecuente que la calidad de un producto o prestación se asocie con el costo o con la calidad de uno de los aspectos que lo conforman. En el caso puntual del e-learning, la existencia de una plataforma tecnológica con una alto nivel de prestaciones y con una avanzada tecnología se identifica con un alto nivel de calidad. Diversos son los ejemplos que podrían enmarcarse en este enfoque. El caso del consorcio Fathom puede servir de ilustración (Kearney, 2003). Esta entidad, integrada por instituciones de gran prestigio, como por ejemplo, la Columbia University, la British Library, la Cambridge, el British Museum, decidió no continuar con el aprendizaje virtual. Kearney apunta que los factores desencantes de esta situación son diversos y algunos de los más probables son la utilización de una costosa infraestructura tecnológica, que no pudo ser amortizada, y la aplicación del sistema de aprendizaje a través del autoestudio, modelo pedagógico que en muchos casos se identifica con el sistema de tomar en cuenta la motivación y las necesidades de los estudiantes en formación virtual, sin desarrollar una adecuada planificación del proceso de aprendizaje y sin tener estudiantes.

Otro ejemplo que confirma la necesidad de desarrollar actuaciones para la mejora de la calidad en el e-learning se puede apreciar en el estudio realizado en el año 2002 por Massy. Esta investigación, impulsada por la European Training Village, se realizó sobre una muestra de 433 profesionales procedentes de diversos sectores vinculados con la enseñanza en Europa, en particular de la Europa Comunitaria a la que pertenecían el $82 \%$ de los encuestados, sobre la situación de la calidad en el e-learning. En este estudio se encontró que el $61 \%$ de los encuestados mencionaron la calidad de la oferta de formación virtual como baja o insuficiente. Tan sólo el 1\% estimó que los programas de e-learning podían considerarse como excelentes. 
Los problemas derivados de una inadecuada concepción de la calidad en el e-learning son de diversa naturaleza. Sin embargo, la consecuencia más crítica es la insatisfacción de los estudiantes que redunda en el abandono mediato o inmediato de los cursos, provocando con ello una situación negativa en la imagen y sostenibilidad del proyecto de formación virtual. La causa general que conduce a esta situación se puede encontrar en la disonancia entre tres elementos, la calidad esperada, la calidad percibida y la calidad realizada. Cuando un proyecto e-learning desarrolla una concepción de la calidad ajena a las verdaderas expectativas y necesidades de sus clientes y carece de una visión sistémica, entonces se producen, inevitablemente, situaciones como las antes referidas.

\section{CONDICIONANTES DE LA CALIDAD EN EL E-APRENDIZAJE}

$\mathrm{Al}$ abordar la problemática de la calidad en el e-learning es necesario considerar las características y rasgos de este sistema de enseñanza. El e-aprendizaje es, ante todo, un sistema de formación que presenta una alta complejidad. Esta complejidad deviene, por una parte, de los múltiples factores que lo integran. Estos factores son mayores que en un proceso formativo tradicional, puntualmente por la participación de las tecnologías en el desarrollo del mismo y por la gestión de la formación en un contexto verdaderamente global. Así se pueden identificar diferentes dimensiones. A saber: la dimensión pedagógica; la dimensión tecnológica; el diseño de las interfaces; la evaluación del proyecto e-learning; la gestión de la plataforma tecnológica; los recursos complementarios a la formación; la dimensión ética que incluye desde la gestión de la diversidad hasta los aspectos legales y los factores socio-políticos; la dimensión institucional, esto es, los servicios de apoyo al estudiante y las gestiones de tipo administrativa académica (Bradul, 2003).

Por otra parte, esta diversidad de competencias pedagógicas, tecnológicas y de servicio han de integrarse en una cadena de producción, siendo complejo en sí el engranaje óptimo entre todos los elementos que intervienen. Otros elementos condicionan la percepción 
y la concepción de la calidad en el entorno de la formación virtual. Así se pueden citar los siguientes (Snook, 2003):

- El estudiante, por lo general, trabaja de forma aislada sin el apoyo necesario para solventar problemas o dificultades, por lo que la percepción de un error se multiplica.

- El costo de la formación virtual es, por lo general, superior al de la formación tradicional.

- El e-aprendizaje está integrado por un número elevado de procesos que incluyen desde la producción del material audiovisual hasta la etapa de difusión del proyecto, las probabilidades de cometer un fallo en algunos de estos procesos es alta.

- Los gestores del e-aprendizaje, en muchos casos provienen de la enseñanza tradicional cuyos métodos trasladan al sistema virtual, lo cual conduce al uso de enfoques erróneos desde el propio diseño.

- La inexperiencia de los gestores de proyectos de formación virtual provoca la necesidad de contratar a terceros. La definición de tareas, especificaciones y estándares por parte de los gestores, así como la ausencia de unos criterios adecuados de contratación y evaluación de propuestas, redunda en una deficiencia en la calidad de los proyectos.

- La formación virtual demanda del e-formador un compendio de conocimientos y habilidades, desde habilidades didácticas y de comunicación hasta la elaboración del material audiovisual. Estos requisitos no siempre alcanzan los niveles óptimos en cada profesional. Por otra parte, es necesario el trabajo en equipo para subsanar esta situación y con ello aumenta la complejidad del sistema.

Estas afirmaciones se pueden matizar con los siguientes planteamientos:

- Se requieren nuevas formas y habilidades de comunicación por parte de los alumnos y de los profesores, y en general, es necesario por ambas partes abandonar los enfoques y prácticas de la formación tradicional. 
- En este nuevo sistema de aprendizaje es necesario, aún con más énfasis, considerar la motivación como factor clave del proceso de enseñanza-aprendizaje.

- Es necesario superar la infrautilización o el uso inadecuado de las nuevas tecnologías de la información. Ello atañe tanto al alumno como al profesor. Esta alfabetización tecnológica debe concebirse desde una perspectiva pedagógica.

- Se impone en el ámbito educativo un nuevo modelo didáctico orientado al desarrollo de habilidades y competencias que ha de trasladarse al contexto virtual

- Se identifica la formación virtual con el estudio autoorganizado, carente de la necesaria interactividad entre los integrantes del sistema.

Las deficiencias o fallos en los proyectos de e-aprendizaje se pueden eliminar y evitar en la medida que estos se gestionen conforme a indicadores, normas y sistemas de calidad.

\section{CRITERIOS E INDICADORES DE CALIDAD}

La definición de indicadores de calidad en el e-learning ha sido abordada por diferentes autores. Destaca en este sentido, la variedad de elementos y la categorización de los mismos. Le Préau (2002) clasifica los criterios de calidad en cuatro categorías. El nivel técnico que se identifica con los conocimientos y competencias de los e-formadores, el correcto funcionamiento técnico de los materiales, entre otros; el nivel pedagógico valora elementos tales como la personalización y flexibilidad de los contenidos, los métodos de enseñanza y evaluación utilizados, la comunicación entre estudiantes y profesores, entre otros; en el nivel de servicio se valoran, por ejemplo, la disponibilidad de tutores $y$ profesores para solventar dudas $y$ dificultades de los alumnos, la actualización regular de los contenidos, la existencia de un espacio de intercambio de información entre estudiantes y profesores. Finalmente, el nivel global representa aquellos criterios de calidad que se consideran en cualquier sistema de aprendizaje, tales como, la información sobre el programa de 
estudio, la definición adecuada de los objetivos, el reconocimiento de los esfuerzos realizados por los alumnos.

Otra interesante definición de indicadores la realiza Sígales ${ }^{1}$ quien refiere a cinco aspectos. Estos son:

- Calidad de la oferta formativa, entendiendo por ello la variedad y pertinencia de los programas con relación a sus clientes.

- Calidad de la organización y la tecnología, esto es, la idoneidad de ambos elementos con los segmentos de estudiantes y puntualmente, la adecuación de la plataforma tecnológica para garantizar los procesos de comunicación.

- Calidad de los materiales, la que implica la calidad tanto en el contenido como en la forma de los materiales de estudios, incluyendo los recursos de información complementarios.

- Calidad de la docencia, la cual depende del correcto desarrollo del proceso de selección, del apoyo institucional a la labor pedagógica y de la existencia de una adecuado sistema de acreditación.

Algunos autores han definido indicadores de calidad centrados en algún aspecto del e-learning. Así por ejemplo, Torres y Ortega (2003) ${ }^{2}$ proponen un conjunto de indicadores de calidad referentes a las plataformas tecnológicas, agrupados en cuatro categorías. A saber:

- Calidad técnica que implica la adecuación de la infraestructura tecnológica a los objetivos del proyectos, la facilidad de navegación, la complejidad de la interfase, entre otros aspectos.

- Calidad organizativa y creativa, relacionada con los aspectos creativos y organizativos que permite desarrollar la plataforma tecnológica, lo cual implica su flexibilidad para implementar

1 Esta propuesta de Sígales aparece en el artículo La calidad en las experiencias virtuales de educación superior de Albert Sangrá, disponible en la dirección www.uoc.edu/web/esp/uoc/0106024/sangra.html

2 En este trabajo, los autores realizan una sistematización de los diferentes principios de la calidad didáctica, conductuales, cognitivos y constructivitas. Torres y Ortega plantea que la calidad didáctica radica no en el uso de una tendencia didáctica puntual, sino en la adecuada utilización y combinación de estos. 
enfoques y metodologías diversas, la posibilidad de presentar la información mediante índices y mapas conceptúales, la capacidad de presentación y utilización óptima de los materiales multimedia, entre otros.

- Calidad comunicacional, se identifica con las posibilidades de la plataforma para implementar herramientas de comunicación síncronas y asíncronas entre profesores y alumnos, entre alumnos, y en general, entre todos los participantes en el proyecto.

Estos ejemplos de definición de indicadores están expresados en forma lineal y una muestra de indicadores ponderados aparece en el estudio antes referido de Massy (2002). En este estudio se identificaron los criterios de calidad más significativos para evaluar la calidad del e-aprendizaje, los que en orden de importancia son: las funciones técnicas carentes de problemas para todos los usuarios; un diseño pedagógico adaptado a las tipologías de los usuarios, sus necesidades y el contexto; unos contenidos actualizado y actuales; un alto nivel de interactividad. Los criterios e indicadores de calidad relacionados hacen referencia al producto. Pero para que un proyecto e-learning posea unos estándares de calidad, es necesario una gestión de los proyectos basados en normas y sistemas de calidad.

NORMAS Y SISTEMAS DE CALIDAD DE CALIDAD EN EL

\section{E-LEARNING}

Para iniciar una incursión en este apartado es conveniente citar las iniciativas de normalización de tipo tecnológico, ya que si bien estas propuestas no nacen como iniciativas de calidad, en la práctica han de considerarse como tal, pues garantizan los niveles que incidirán en la calidad global de un proyecto de e-learning. Algunas de las más significativas son, por ejemplo, las actividades desarrolladas por la IEE (Institute of Electrical and Electronics Engineers) y puntualmente las del LTSC (Learning Technology Standards Committee) que ha creado la norma 1484, la cual contiene las especificaciones para la implantación, mantenimiento y la interoperabilidad de plataformas virtuales. 
Otra propuesta de interés es la Dublín Core Metada Initiative que ha elaborado un conjunto de estándares para la normalización de metadatos para la creación de materiales educativos. Las actuaciones del Global Learning Consortium han dado como resultado un conjunto de especificaciones técnicas para disponer los contenidos pedagógicos y los metadatos basados en XML, creando el IMS Resource Metadata. Otra iniciativa reseñable es la ADL/SCORM (Advamce Distributed Laerning/Sharable Content Objetc Reference Model), orientada a la reutilización de productos pedagógicos por diversas plataformas.

Finalmente, destaca la propuesta de la ISO/IEC JTC1 SC36 (International Organization for Standarization/International Electrotechnical Committee, Joint Technical Committee, SubCommittee 36). Esta iniciativa se centra en la normalización de las nuevas tecnologías de la educación, abordando aspectos tales como la navegación en los entornos e-learning, la transferencia de programas, la seguridad de los sistemas, los metadatos.

Las disímiles propuestas de normalización del e-learning pueden ser clasificadas de formas diversas, pero quizá una forma efectiva de catalogarlas es en dos bloques. En uno, aquellas que se manifiestan como un conjunto de recomendaciones para el aseguramiento de la calidad en la e-formación; en otro, aquellos sistemas que conducen al reconocimiento público de la calidad por una autoridad competente en procesos de acreditación y certificación del e-learning.

\section{Guías de evaluación y buenas prácticas}

Diversas iniciativas se presentan como sistemas que permiten asegurar la calidad. El proyecto MECA-ODL representa un buen ejemplo de éstos (Fundació Universitat Empresa, 2000). Este proyecto, realizado bajo el programa QUAL-E-LEARNING, ha desarrollado una guía metodológica que establece un conjunto de estándares para todos los procesos implicados en un proyecto de e-formación. Así, incluye indicadores para las etapas de concepción del proyecto, de análisis de las condiciones del entorno, del diseño del proyecto, de definición de contenidos, de producción del proyecto, de distribución y promoción 
del mismo y del proceso de evaluación. Cada una de estas etapas se despliegan en subcriterios que sirven de marco de referencia para los creadores de contenidos, los distribuidores y los propios usuarios. Esta guía se conforma como herramientas metodológica en la medida que no es sólo una relación de criterios y subcriterios, sino porque además, define la forma y metodología de evaluación para cada apartado. MECA-ODL es una herramienta desarrollada y completa no sólo porque valora todos los procesos implicados en un proyecto educativo virtual, sino también por el nivel de profundidad de los aspectos tratados y por el profuso desarrollo metodológico.

Otra propuesta de interés, aunque menos completa que la anterior, la propone la Nortbern Ireland eLearning (NieL). Una de las actividades de esta entidad, fundada en el año 2002, se encamina a la creación de una guía para el aseguramiento de la calidad (Stein, 2003). Esta guía se estructura en seis apartados que se configuran como los agentes claves de la e-formación. En primer lugar aparecen los factores técnicos que miden la adecuación de las tecnologías al tipo y objetivos del curso, incluyendo la calidad del ancho de banda. En segundo lugar aparecen los factores de tipo académico, los que valoran la adecuación de la forma y contenidos del curso a los objetivos de formación que se propone.

Existen dos factores relacionados pero con enfoques diferentes, los factores correspondientes a los formadores y los relativos a la enseñanza. En ambos casos se valoran la motivación, formación, habilidades y responsabilidad de los e-formadores para acometer un proyecto docente, pero un enfoque analiza estos elementos desde la perspectiva del docente y otra desde el punto de vista de la organización. Es decir, se puede analizar si los e-formadores poseen el nivel de conocimientos y habilidades adecuadas y en otra dimensión se valora como la organización garantiza que los docentes tengan el nivel adecuado. Los factores relacionados con los procedimientos valoran como los criterios de calidad se integran en los diferentes procesos. Finalmente, la gestión operacional y administrativa constituye el último de estos factores y se refiere a las estructuras y procedimiento de naturaleza administrativa y logística que permiten garantizar el buen funcionamiento de un curso. 
Esta guía no se puede considerar tan completa como la anterior, pero tiene como aspectos destacables que establece un sistema de evaluación de los diferentes apartados en donde se combina lo cuantitativo y lo cualitativo; utiliza una interesante categorización de los criterios; y utiliza para cada criterios evaluado u ítem en el que valora el proceso de evaluación del mismo, manifestando así una clara orientación a la mejora continua.

DITRA $^{3}$ es un programa de la Unión Europea que se orienta a la creación de estándares en las diferentes etapas de creación y prestación de programas de e-aprendizaje. El Distance Trainers Profile recoge estas indicaciones recomendables para el diseño, prestación y evaluación de la formación virtual. Cada proceso se divide en varias tareas que se desarrollan en un tercer nivel. La guía está orientada a los e-formadores y desarrolla de forma detallada las diferentes tareas, pero quizá, lo más significativo de esta guía es la definición de los conocimientos y habilidades necesarias para el desempeño de las mismas. Aspecto novedoso con relación a otras herramientas.

El E-Learning Competency Centre ${ }^{4}$ utilizando un ejemplo fuera del contexto europeo, ha elaborado una guía para la creación de programas e-learning desde una perspectiva de calidad (ECC, 2002). Los aspectos incluidos en esta guía son los siguientes:

- Contenido, lo cual se valora desde la precisión, suficiencia, claridad, adecuación y organización del mismo.

- Usabilidad, en la que inciden las características de la interfase, la navegación, la tecnología y el apoyo al estudiante.

- Diseño de las instrucciones, esto es en cuanto a la presentación del curso, las actividades prácticas, el sistema de autoevaluación, las variedad de las técnicas de presentación de contenidos(simulaciones, gráficos, animaciones), el nivel de interactividad, la adecuación de las actividades a las necesidades individuales de los estudiantes, entre otros.

3 www5.vdab.be/vadab/europe/ditra/profile/intro.htm

4 El ECC pertenece al National Institute of Education de Singapur. 
Esta guía, muy útil por los aspectos que evalúa, adolece de presentar aspectos muy detallados y otros desarrollados de forma más genérica.

\section{Modelos de acreditación y certificación de la calidad}

El UK IT Training (ITTT) ha desarrollado un sistema de aseguramiento creando tres módulos de estándares (Snook, 2003). Estos se han publicado en el código de prácticas para los proveedores de $e$ learning. Esta modalidad es la bases del sistema de aseguramiento y permite que las entidades de e-formación aseguren la calidad de sus actuaciones. LA ITTT ha creado, además, un conjunto de estándares orientados a los e-estudiantes. En este documento se definen los aspectos que puede esperar un estudiante de un proceso de e-aprendizaje.

En el E-Learners Charters se valoran elementos tales como la facilidad de uso de la plataforma, el fomento de colaboración y comunicación entre los estudiantes, así como la aceptación de la diversidad cultural, religiosa, social. Como parte del proceso de acreditación, esta entidad ha creado un conjunto de estándares para la preparación del material e-learning. Estos estándares hacen referencia tanto a aspectos de contenido como a los aspectos técnicos tales como la navegabilidad y la usabilidad.

Otra interesante iniciativa es el proceso de certificación de profesionales del e-learning. El Certification e-Learning Profesional (CeLP) está orientado a todos los profesionales vinculados con este sistema de aprendizaje: desarrolladores, tutores, e-profesores. gestores y consultores. Este certificado desarrolla un herramienta de competencias a través de un proceso de formación en habilidades y conocimientos que desembocan en un proceso de certificación.

El ODL QC Standards 5 es una iniciativa desarrollada por el Open and Distance Learning Quality Council. Este conjunto de estándares se desarrollan en una guía dividida en diez categorías que abarcan un

5 www.odlqc.org.uk 
amplio abanico de funciones que incluyen desde los objetivos del curso, los contenidos, la publicidad, el procedimiento de admisión, el apoyo a la enseñanza, los centros de e-learning, hasta la relación con los proveedores y la satisfacción de los alumnos. El uso de este conjunto de estándares permite el acceso a un proceso de acreditación.

En otro nivel, más complejo y avanzado, se pueden citar dos importantes iniciativas. Por una parte la etiqueta OPQF y por la otra, la Baol Quality Mark. La OPQF (Office Professionnnel de Qualification des Organismes de Formation) es una organización francesa que en el año 2001 lanzó un proyecto de creación de un sello de calidad destinado a las empresas de e-learning (Even, 2004). Este sello de calidad se estructura sobre la base de cinco criterios: las competencias de los formadores, tutores y planificadores; los métodos de gestión de los empresas de e-formación (selección de los productos, análisis de costes, etc); el diseño pedagógico y el nivel de uso de las técnicas y materiales; la descripción exhaustiva de las acciones de formación; y un análisis de las modalidades de evaluación de las prestaciones y de medición de la satisfacción del cliente.

En esta panorámica de sistemas de calidad, requieren especial atención las actuaciones de la Bristish Association for Open Learning, en particular lo que se refiere a la creación de la Baol Quality Mark (BAOL). Este sistema de calidad, Baol Quality Mark,, supone un modelo de calidad muy logrado en la medida en que se establece sobre los principios de la gestión total de la calidad, basándose en el modelo europeo de excelencia de la E.F.Q.M ${ }^{6}$ (European Foundation Quality Management). Así, tal como su modelo de referencia, éste se estructura en nueve criterios agrupados en dos bloques. Agentes facilitadores, es decir, aquellos elementos en la gestión que facilitan o sirven de base para excelencia. Dentro de estos elementos se encuentra la gestión, la política y estrategia, la gestión de las personas, los recursos y los procesos. Por otro lado, en el apartado resultados

6 www.efqm.org 
se encuentran los criterios relacionados con los indicadores y categorías de rendimiento y que, al igual que el modelo de excelencia europeo, considera diversos factores.

El Baol Quality Mark, establece la siguiente adaptación: satisfacción del cliente, satisfacción en las personas de la organización, impacto del e-learning y resultados. Este modelo permite el proceso de acreditación de la calidad que conduce a la obtención del sello de calidad $^{7}$ Quality Mark, con una vigencia de 3 años, a partir de los cuales es necesario realizar una actualización del la evaluación.

\section{LA UNIÓN EUROPEA Y SU PAPEL EN LA IMPLEMENTACIÓN DE LA CALIDAD EN EL E-LEARNING}

Desde que en el año 2001 la Comisión Europea lanzó la iniciativa E-learning, diversas han sido las actividades orientadas a fomentar el desarrollo de este tipo de formación en el contexto comunitario y de desarrollar e implantar una filosofía de calidad y mejora continua en el e-learning. Así, en el año 2002, la Unión Europea desarrolló un estudio sobre 150 proyectos creados al amparo del programa Leornardo Da Vinci con el fin de valorar los puntos fuertes de la e-formación. Como resultado de este estudio se elaboraron una serie de recomendaciones (Attwell, 2002) de gran interés para el desarrollo de proyectos de e-aprendizaje que pueden ser tomados como punto de referencia.

Estas recomendaciones reflejan los principios de la excelencia, mostrando como se concibe el e-learning. Algunas de las recomendaciones delineadas son:

a) Una adecuada y clara compresión, y por tanto, orientación al e-aprendizaje; conocer cuál es su naturaleza, su alcance, objetivos, con vistas a evitar el desarrollo de proyectos que bajo este titulo

7 La International Council Distance Education (ICDE), multinacional de la educación desarrollará en los próximos años un sello de calidad internacional en el $e$ learning (www.icde.org) 
inicien actividades de formación mal enfocadas. (Principio de excelencia: Visión estratégica).

b) Desarrollar los proyectos con una clara orientación a los e-estudiantes. Ello incluye, por ejemplo, realizar un diagnóstico previo al desarrollo del proyecto para determinar las expectativas de los estudiantes y adaptar los estilos y contenidos. (Principio de excelencia: Orientación al cliente).

c) Adoptar, de común acuerdo con las entidades implicadas en la gestión de un proyecto, la filosofía del mismo, desde la etapa de diseno, de forma que sea transparente y consensuada la metodología, los enfoques, los objetivos del proyecto. (Principio de excelencia: Desarrollo de Alianzas).

d) Formación de los profesores y entrenadores, tanto en tecnologías como en aspectos didácticos y metodológicos. Ello se fundamenta por varias razones, una porque el docente destinado a la docencia universitaria o académica no posee las destrezas para enfrentar cursos de formación profesionales (on-job-courses) y aún cuando este problema se puede eliminar, el uso de las tecnologías en el proceso de aprendizaje requiere conocer y aplicar nuevos usos, además de modificar el enfoques de su uso en los métodos docentes. (Principio de excelencia: Desarrollo e implicación de las personas).

e) Desarrollar los proyectos centrados en una orientación pedagógica y comunicativa. La orientación pedagógica es un enfoque transversal que debe estar presente en todos los procesos y que se debe conformar como una estrategia. Así por ejemplo, si bien el factor técnico juega un papel crucial en el e-aprendizaje, lo importante no es utilizar los últimos progresos en IT sino aquellos que pedagógicamente se justifiquen en función de los objetivos y los estudiantes. Por otra parte, los programas de e-learning requieren del concurso de diversos profesionales que deben trabajar en grupo, por lo que es necesario elaborar estrategias y procesos de comunicación efectivos. (Gestión por procesos y hechos).

f) Evaluar el proyecto e-learning es una tarea vital. La evaluación del proyecto juega una importante función en el desarrollo del mismo ya que permitirá su mejora. La evaluación debe realizarse de forma continua y efectiva, desde el primer momento y no sólo al concluir 
el mismo; deben evaluarse diversos aspectos, desde los tecnológicos a la gestión; debe ser claramente definida la responsabilidad de este proceso; y debe combinar diversos enfoques, globales y regionales. (Principio de excelencia: Aprendizaje, innovación y mejora continuos).

g) Ampliar y orientar el e-aprendizaje hacia nuevos segmentos de clientes, pasando de los grupos tradicionales a nuevos grupos ${ }^{8}$. Para ello es necesario desarrollar nuevas competencias pedagógicas. (Principio de excelencia: Aprendizaje, innovación y mejora continuos).

h) Los proyectos de e-learning tienen que ser competitivos y sostenibles. Los contenidos deben adaptarse a las necesidades del mercado, ser actualizados y no debe caer en el error de una simple plataforma tecnológica sin más utilidad. (Principio de excelencia: Orientación hacia los resultados).

Otras actuaciones que vinculan la calidad y el e-learning en el ámbito comunitario son:

- Creación del European Quality Obscrvatory (EQO)9 ${ }^{9}$. Este observatorio europeo de la calidad en el e-learning tiene como atribuciones fundamentales la creación de una herramienta conceptual (EQO Model) que permita la armonización de los conceptos de calidad en el e-learning y que facilite los procesos de acreditación de la calidad y el desarrollo de un espacio web

8 Sobre la necesidad de ampliar nuevos mercados se han pronunciado diferentes autores. Una interesante propuesta la ha planteado Jan Gejel, quien define que existe un mercado potencial de personas en Europa que no participan en el e-aprendizaje. A partir de esta realidad define un conjunto de estrategias basadas en principios de calidad para atraer a estos segmentos definidos por el autor como nonlearners. Esta información se puede consultar en el European E-learning Qualily Forum (cedcfop.conununityzero.com), mensaje del 20 de Julio de 2003 titulado Quality issue sfor the weak learners.

9 www.eqo.info 
que contenga la información necesaria para la comunidad e-leaming en términos de calidad, el EQO Quality Portal (EQP).

- QUAL-E-LEARNING. ${ }^{10}$ Este proyecto, desarrollado por cinco entidades de cuatro países europeos y que se desarrolló entre junio 2003 y octubre 2004 , tiene como objetivo crear un manual de buenas prácticas para el e-learning, utilizando como punto de partida el análisis de diversos proyectos.

- SEEL. Suporting Excellence in e-Learning. ${ }^{11}$ Esta iniciativa pretende sistematizar y observar las iniciativas regionales y locales relativas a la calidad en el e-learning en los países miembros de la Unión.

- SEEQUEL. Sustainable Environment for the Evaluation of Quality in E-Leaming. Este proyecto tiene como fin desarrollar un espacio que sirva de foro (European eLeaming Quality Forum $)^{12}$ y laboratorio para la aplicación de la cultura de la calidad en el entorno e-learning. Con ello se ofrece un espacio de puesta en común, intercambio y debate de experiencias prácticas, así como de las mejores prácticas.

La multitud de propuestas y enfoques existentes sobre calidad en el e-learning ha motivado que la U.E. haya desarrollado, a través del Observatorio Europeo de la Calidad, una herramienta denominada EQO Model. Esta herramienta no es un sistema de implementación de la calidad ni de acreditación. Es un modelo conceptual orientado a la descripción, análisis y comparación de los diversos niveles de enfoques de calidad en el e-learning y que reconoce la utilidad de cada uno de los enfoques de calidad existentes. (EQO, 2004).

10 www.qual-elearning.net

11 www.qwiki.info/projects/seel

12 cedefoo.communityzero.com/eLearning_forum 


\section{CONCLUSIONES}

La calidad en el e-learning es de naturaleza multifactorial, en la que inciden factores de tipo técnico, pedagógicos y de servicios. El logro de la calidad depende, por tanto, de la adecuada gestión de cada uno de los elementos que integran el e-aprendizaje. Para ello es necesario utilizar indicadores de calidad, pero especialmente, abordar la mejora de la formación virtual mediante el uso de sistemas de calidad que garanticen la implantación de los principios de la excelencia. En este hecho radica la sostenibilidad y la garantía de futuro del e-learning.

\section{REFERENCIAS}

Attwell, Graham et al (2002). E-learning in Europe: Results and recommendations.

http://bildungplus.forum-bildung.de/files/e-learning.pdf

BAOL (2002). The development, implentation and use of the BAOl Quality Mark : A report to the Department for Education and Skills.

http://www.british-learning.com/home.htm

Bradul, Khan (2003). A framework for E-learning. http://www.bookstoread.com/framework/

ECC(2002). Quality criteria for E-learning courseware. http://www.ecc.org.sg/cocoon/ecc/website/qualitycriteria2.pdf

EQO(2004). European Quality Observatory: The Eqo Model: version 1.2 (Draft version).

http://www.eqo.info/files/EQO-Model-1.2.pdf

Even, Natalie(2004). Normes et démarches qualité pour la e-formation : Etar des lieux de normes, de standards et de projects. http://ressources.algora.org/reperes/economie/tel/normes_ et_qualite.pdf 
Fundació Universitat Empresa (2000). MECA-ODL: Guía metodológica para el análisis de la calidad de la formación a distancia en Internet.

http://www.adeit.uv.es/mecaodl

Kearney, Nick (2003). Un modelo de costes asequibles para el elearning. http://www.elearningeuropa.info

Massy, Jane (2002). Quality and e-learning in Europe: survey report 2002.

http://www.elearningage.co.uk/docs/qualitysummary.pdf

Préau, Le (2002). Quel modèle qualité pour la e-formation ?: Les normes qualité existantes répondent-elles au besoin des acteurs de la e-formation?

http://www.preau.ccip.fr/images/etudes/etude_modele_qualite. pdf

Snook, Adrian (2003). Quality in e-learning: a critical issue. http://www.trainingfoundation.com

Stein, Gerogina (2003). Putting the e into learning \& teaching: quality assurance guidelines.

http://www.elearningfutures.com/documents/NIeLQuality\% 20Assurancetool.doc

Torres Toro, Sebastián y Ortega Carrillo, José Antonio (2003). Indicadores de calidad en las plataformas de formación virtual: una aproximación sistemática.

http://www.ugr.es/ sevimeco/revistaeticanet/Cultura\%20eval/ Calidad\%20en\%20el\%20eLearning.doc 


\title{
Principles of Classification for Writing Hyperdocuments
}

\author{
Maria luiza de Almeida Campos \\ Hagar EsPanHa GOMEZ
}

\begin{abstract}
Hypertext has introduced a new technology in document structure that makes non-linear reading possible, but is not involved with semantic content. Principles for organization of subject content were established in the fields of Faceted Classification and of Concept Theory. They constitute sound theoretical and methodological bases for planning and writing hyperdocuments for educational purposes. Faceted Classification method consists, on the one hand, in identifying general or facet concept classes within which are specific mutually exclusive classes and, on the other, in principles for their organization and relationships. Concept Theory provides orientation for the organization of node content. These are the main points for the organization of documents/information. Such theories provide conditions for coherent nodes and contribute to avoide cognitive overload.
\end{abstract}

\section{GENERAL CONSIDERATIONS}

utenberg's invention made possible greater distribution of texts, thus providing greater access to sources of knowledge records. However, while causing many transformations relating to access, it did not bring any significant modification in books which refer to the support of information. According to Roger Chartier, the printed book depends greatly on primitive forms, as it imitates pages, writing, appearances, in the same way that previously 
book pages were sewn. From this point of view, his invention does not produce 'the book'. (CHARTIER, 1997, p. 134).

Nowadays, an even greater revolution than that of Gutenberg is taking place and it is altering not only techniques of text reproduction, but also structures and forms of support that enable a particular form of communication to readers with electronic documents.

The technology known as Hypertext has brought about alterations in writing, with consequences for the production of educational documents. It makes possible the building of hyperdocuments, a product that requires new forms of writing and affects the process of traditional linear reading.

The production of non-linear texts using hypertext technology also requires a complex structure named hyperstructure, consisting of graphs pointing to nodes which are chunks of information, and of arches which link these chunks (CONKLIN, 1987, p. 31). The main feature is its ability to link content concepts within a document or within several ones. In essence, hypertext is a

computer based medium for thinking and communication. The thinking process does not build new ideas one at a time, starting with nothing and turning out each idea as finished pearl. Thinking seems rather to proceed on several fronts at once, developing and rejecting ideas at different levels and on different points in parallel, each idea depending on and contributing to the others. (CONKLIN, 1987, p. 32)

Hypertext materializes and emphasizes the associative and nonlinear reading process and this requires a rethink of the processes related to the arranging of ideas and how they affect modes of writing, i.e., new processes for new forms of writing. In this context, we will investigate a type of text named hyperdocument.

\section{THE HYPERDOCUMENT}

Hypertext technology brings together processes of both writing and reading in non-linear form. When writing a text on a sheet of paper, the author follows a linear process where logical chains of reasoning must have a beginning, a middle and an ending. Attempts to 
adapt this to the reading process cover thousands of years, but this process is naturally non-linear. How often does a reader need to search other documents to help, for instance, with the definition of a term, with the historical context of the topic presented in a document, with the identification of the school of thought of the author?

With the technology of hypertext the author presents readers with many possibilities of reading directions. In hyperdocuments these possibilities evidence the conceptual dimension employed in their construction. Every possible 'navigation' is conditioned to this conceptual dimension because of its nature as a closed hyperdocument developed within a field of knowledge, with explicit linking between nodes.

In addition to all this, technological possibilities have also brought about, in this specific case, discussions related to the construction of hyperdocuments and the search for the solution of problems inherent to this new object; they are cognitive overload and disorientation.

Cognitive overload may occur when authoring a hyperdocument as well as when reading it. For the author, it can be seen as a mental overload, because he/she needs to name nodes and to define semantic relations among them. For the reader, this overload occurs as a result of the need to make frequent choices and different ways to track. Disorientation occurs when reader feels lost, i.e. he does not know where he is in the network, or does not know how to get to some other place that he knows or thinks that exists in the network, losing track of the route he followed (CONKLIN, 1987, p. 38).

The readability of a document means the mental effort required for the process of its construction. So, if we wish to increase the readability of a hyperdocument, we must help readers in the construction of their mental models, strengthening those factors that support this process and weakening those that hinder it. This is done by strengthening coherence and hindering cognitive overload (THURING et al, 1995).

To assure coherence at node level one needs to rethink the processes of writing presented in the structure of the text within the conceptual node. As hypertext is a new textual means of information, one needs to think about a new rhetoric and style when producing a 
text. Some authors are developing research in this direction (LANDOW, 1987; MOULTHROP, 1992), but it is important to consider writing issues at the moment when the conceptual node is being written.

What is being done to a great extent is the conversion of texts produced for linear reading using hypertext. Generally, this is not the best option to warrant coherence at the node level (NILSEN, 1993).

Interpretative action is an issue to be thought of in the role of both author and reader. In this respect, linguistic phenomena ${ }^{1}$, according to French authors on discourse analysis, may facilitate or not the meanings in textual construction.

A text is a unit of meaning which in discourse analysis is seen as the materiality of the speech. One needs to think of the conditions of text production, in this case, the text as a hyperdocument.

Hypertextual writing opens up a new authoring process. When writing a hypertext the author must master both the subject which he/she wishes to write on and this new intellectual technology. A hyperdocument possesses a new speech materiality which does not use pencil and paper and linear thinking in its form of writing, but explores technological possibilities of man-machine interface as well as possibilities of the very speech construction and order within a knowledge domain.

Authors should limit the fragmentation of text, which characterizes hyperdocuments, in order to achieve coherence between nodes. This aspect seems to be endemic in hyperdocuments and as result one has information segmented in disjointed nodes presented in separate windows. This fragmentation may lead to lack of significant context, so giving the impression that a hyperdocument is an aggregate of pieces of information loosely joined together instead of a coherent whole (THURING et al.).

1 Linguistic phenomena such as polyphony, presupposition, negation, direct and indirect speech, words within inverted commas, metaspeech, paraphrases, irony, imitation, pastiche. (Maingueneau, 1998) 
A means of reducing this impression is the explicit representation of relationships between nodes. Besides that, it is fundamentally important that the author has consistent guidelines when planning the text and the browsing/reading possibilities.

\section{PlanNing OF HyPERDOCUMENTS FOR LONG DistanCE TEACHING}

The planning of hyperdocuments aims to establish a text structure to create mutually exclusive nodes. This is a measure that may avoid disorientation. Therefore, it must be conceived within a systemic approach which naturally provides a priori indications for some kinds of relationship useful to browsing.

The planning may also consider the different levels of the information needs of readers whom the educational hyperdocument is devised for, thus avoiding the problem of cognitive overload, i.e., giving the reader the possibility of easily finding the information on the desired level, being it only an indication or detailed information on the concept $\mathrm{t}^{2}$ he/she is searching for.

The structure of the hyperdocument consists, then, of establishing conceptual units/nodes and relationships aiming at consistency and coherence in the document as whole. At a certain point, hyperdocuments can be compared to a system of concepts. An underlying classificatory action exists, as relationships between nodes are created from a network of associations.

In hyperdocuments, a node is characteristically a knowledge unit, a concept that corresponds to the smallest unit of information in the subject field considered. This is one of the elements that allow the reader to track his/her way through the text. One of the first issues relating to the nature of hyperdocument node contents is the use of a verbal tag appropriate for a given subject content. If not appropriate

2 Concept is the term used here, as each node is a concept (Rumbaugh et al. 1994) 
it can lead the reader to cognitive overload and it may damage his/her understanding of the text. ${ }^{3}$

The theory of Faceted Classification provides basic principles for mutually exclusive chunks of texts and for logical relations. One of these principles, that of exclusiveness, means that one must be sure that all the characteristics of a class of concepts be analyzed. In other words, a given concept should belong to that class and to no others. A node must be built in this way, as a cohesive whole, so that it may have different further uses.

As each node is a conceptual unit, one finds in the Theory of Concept the elements to guide the development of the content of the fragments of text.

In short, we may state that the planning of the hyperdocument consists of identifying general and specific classes as well as generic and semantic relationships between them, according to principles of Faceted Classification. For the development of the content of each concept/node, the Theory of Concept provides the elements.

\section{Theoretical Principles FOR Writing HyPERDOCUMENTS}

\section{Faceted Classification}

The Theory of Faceted Classification was developed by Shiyali Ramamrita Ranganathan in the thirties, to make clear the principles he adopted when developing the Colon classification, the scheme he devised to arrange books in the Madras' University Library, in India (RANGANATHAN, 1967) .

3 This may seem inconsistent within the field of discourse analysis, but it is necessary to make clear that the hyperdocument is being analyzed from the perspective of the author preparing a teaching text and not of the reader .The author has "to fight" to ensure that his message is understood. It is up to the reader to interpret it from his/her own viewpoint and this is not a constraint for the author as he/she pursues the principle of univocity, for he/she writes aiming at a virtual reader. 
Ranganathan's theory consists of classification of ideas into Facets, which are general classes within a field of knowledge. These are, in turn, manifestations of fundamental categories, which are valid for any field of knowledge.

He identified five fundamental categories: Personality, Matter, Energy, Space and Time. They are, in fact, means to guide thinking when structuring any field of knowledge and they are an easy way to analyze its constituent concepts. This method is deductive as it provides the bases for the identification of general classes within which are chains and arrays of concepts of the field of knowledge analyzed.

In a hyperdocument, categorization is very important when building conceptual nodes. Modular writing brings together chunks of information, and then, it is necessary to select these chunks. For example, if a certain node deals with the properties of milk, the industrial process must be in another node in oder to archieve logical coherence when distributing the contents among the different nodes. This coherence must already be envisaged when preparing the hyperdocument, through the analysis of the selection of contents. As one knows, these contents result from a logical perspective of classification and their relationships within a category or among different categories.

The Classification Research Group of England has identified categories that most frequently occur and which are, in fact, a breakdown of the five fundamental categories of Ranganathan (VICKERY, 1966, p. 46-47). They were developed for the construction of thesauri but they fit equally when authoring hyperdocuments:

Things, Entities

Naturally occurring

Products

Mental constructs

Input to the System

Parts, components, structure

Organs

Materials, constituents

Attributes (examples)

Minerals, Animals, Plants, Soils

Bridges, Engines, Fiber

Equations, Rectangles, Formulae

\author{
Beam, Wheel, Wing \\ Heart, Seed \\ Metal, Glass, Nitrogen
}


Qualities, properties

Processes, behavior

Operations

Experimental
Mental
Cohesion, Color, Solubility

Vibration, Inflammation

Cutting, Breeding

Calculation, Reasoning

Operating agents - any thing or entity can act as an agent

Place condition

The content of the facets together their specific classes can be considered as fragments of text - the concepts - which are hierarchically related. The analysis of each fragment may reveal other kinds of relationships.

The above categories may be seen as a guideline for the analysis of a given topic of a subject field.

\section{Theory of Concept}

The Referent-Oriented Analytical Concept Theory provides a sound basis for the determination and understanding of the concept for information representation/retrieval. Dahlberg developed her theory in the seventies, aiming at building terminologies in the field of Social Sciences (DAHLBERG, 1978). In this same period, she explained the relationships between Concept Theory and Classification Theory (DAHLBERG, 1978a). Later on, she used her theory in the field of verbal documentary languages, specifically for building thesauri (DAHLBERG, 1980). In this paper those principles of the theory that are useful when authoring hyperdocuments must be emphasized.

According to Dahlberg, a concept is a "knowledge unity, comprising verifiable predications about a selected item of reference, represented in a verbal form" (DAHLBERG 1983, p. 17). Concept Theory is 'referent-oriented' because 'it presupposes that each concept refers to something and it is called 'analytical' because, by predicating the referent and thus generating and identifying its concept characteristics, a concept is constructed in an analytical mode' (id. p. 18).

Dahlberg's Concept Theory may prove useful to ensure consistency within a node and among them.

Another issue in modeling nodes is how to separate "chunks of information" so that they can be further interlinked by the reader when 
navigating through the document. If in the beginning it was possible to identify themes dealt with in hyperdocuments as a whole and to define what we call the structure of the work using principles of Faceted Classification, now it is necessary to establish criteria to relate contents consistently.

Each node contains information on a general concept which represents a concept class. So, when defining the scope of a content to be dealt with in a conceptual node one must first of all explore all the elements that contribute to the understanding of what a concept is and what are its constituent elements are. In hyperdocuments, a node needs to be worked this way, as a cohesive whole, so that one may use it later in different ways. These elements are present in conceptual definition, according to Dahlberg's Theory of Concept.

Dahlberg considers three kinds of definition, namely: nominal, ostensive and conceptual. The latter one provides elements to establish links/relations among fragments of text. It may be subdivided into generic definition, one that produces hierarchical relations; partitive definition, one that produces whole-part relations; definition by negation, which is rare and produces relationship of opposition; and definition by function, which produces a functional relationship.

In writing hyperdocuments it is fundamental to understand the nature of relations. They must be governed by classificatory principles; connection among nodes without principles based on logical and ontological relationships leads to links that may be inappropriate. So, the following kinds of relations may guide authors of hyperdocuments.

Hierarchical relation - A relationship that makes possible the organization of a line of reasoning where ideas are interconnected by logical succession. This means that this relationship represents a sequence of ideas of the same nature, forming logical chains and arrays of concepts. For instance the concept 'thesaurus' and kinds of thesaurus, such as 'multilingual', 'monolingual', 'microthesaurus', among others.

Partitive relation - A relationship that provides the organization of nodes in ontological coordination. It presents the elements or parts that constitute an object or the stages of a process. Similar to the hierarchical relationship, the partitive relation establishes a certain 
precedence among nodes of this kind and this is useful for documents with teaching objectives. For example, in a document on thesauri, the node that deals with planning implies several parts such as subject delimitation, target public, survey of sources of terms, forms of presentation, etc., and these constitute partitive relations.

Functional-Sintagmatic Relation - This is a relationship that establishes links between conceptual nodes of a different nature, not considered as parts or stages of a process. For example, a concept denoting a process or operation leads to concepts that supplement them, as in the following sequence: production - product - producer - consumer. The adoption of principles to identify how to relate concepts of different natures, will render hyperdocuments that will not give the impression of a mere aggregate of information 'loosely' gathered. On the contrary those relationships are built under a logical, coherent perspective.

\section{FURTHER CONSIDERATIONS}

A tutorial for thesaurus construction was developed according to the theories presented here and may be accessed at http://www.conexaorio.com/biti/tesauro. Figure 1 shows the scheme produced in the planning/classificatory process.

Browsing is the space of the reader. The objective of hypertext technology is browsing. The theories proposed here contribute to some extent to browsing that the author can offer students in a didactic sequence. But they are not the only ones.

The reader must find orientation as he/she browses, accepting or not the options offered. Even this may not suit the reader. So, other mechanisms should be offered, such as a map which is indeed the systematic plan identified when building the system of concepts, which provided the development of conceptual nodes. This plan provides the basis for an alphabetic index as well.

It must be emphasized that these two types of index -alphabetic and systematic- are relevant devices to avoid becoming lost or disoriented. The alphabetic index is useful when the reader already knows 
the topic that he/she wishes to access. The systematic approach gives the reader the overall plan of the hyperdocument and provides access to topics not necessarily previously thought of by the reader.

It is believed that the theories described here should be discussed with subject specialists so that consistent and coherent content can be present in future hyperdocuments for distance learning.

\section{REFERENCES}

CONKLIN (1987) Hypertext: an introduction and survey. IEEE Computers, sep., p. 17-41.

DAHLBERG, I. (1978) A Referent-oriented analytical concept theory of interconcept. International Classification, v. 5, n. 2, p. 142-150.

DAHLBERG, I. (1978a) Ontical structure and universal classification. Bangalore, Sarada Ranganathan Endowment. 64 p.

DAHLBERG, I. (1983) Terminological definitions: characteristics and demands. In: Problèmes de la définition et de la synonymie en terminologie. Québec, GIRSTERM, p. 13-51

LANDOW, George P. (1987) Relationally encoded links and the rhetoric of hypertext. Hypertext '87 Proceedings, p. 331-338.

MaIgueneau, Dominique (1998) Termos-Chave da Análise do Discurso. Belo Horizonte: Editora UFMG.

MOULTHROP, Stuart (1992) Toward a rhetoric of informating texts. The Fourth ACM Conference Hypertext, p. 171-180.

NILSEN, J. (1993) Hypertext EHypermedia. New York, Academic Press.

RANGANaTHAN, S. R. (1967) Prolegomena to library classification. Bombay, Asia Publishing House. 640 p. 
RUMBAUgH, J., BLAHA, M., PREMERLANI, W. et al. (1994) Modelagem e projetos baseados em objetos. Rio de Janeiro: Campus.

THÜRING, M.; HANNEMANN, J.; HHAKE, J. M. (1995) Hypermedia and cognition designing for comprehension. Communications of the ACM, v. 38, n. 8, p. 57-66.

VICKERY B.C.. (1966) Faceted classification schemes. New Brunswick, N.J., Rutgers State University. 


\title{
Interoperability with E-Learning Process: Capabilities of Digital Libraries in Supporting Course Websites as a New Domain of E-Services
}

\author{
AHMED TAHA
}

\begin{abstract}
As learning has become an increasingly central concern to the knowledge-encompassed society, an array of information technologies has been introduced particularly in the educational settings and mainstream to foster the peaceful transition from papyrus education into web-based or online learning. It is strongly believed that the Web nowadays has become a wonderful vehicle for delivering e-learning materials, and has significantly increased the ranges of access to a plethora of scholarly information sources within ICT-rich environments resulting in the shift of the educational paradigm from teacher-oriented to learner-centric. Should the networked library have to view e-learning as a new domain of information service? The strong capabilities of the digital library in providing scholarly information have made interoperability with the e-learning process a highly urgent requirement. This paper sketches the outlines of the proposed plan of the United Arab Emirates University (UAEU) Libraries to tackle the challenges that the new elearning paradigm poses, and explores how to support the linkage of e-resources with course website curricula. The benefits and potentials are discussed and reflected within the realm of good opportunities for fruitful collaboration in the knowledge-based society.
\end{abstract}




\section{INTRODUCTION}

$\mathbf{T}$ advent of Web-based IT applications into ever greater areas of societal activities and settings has provided an impetus for fundamental changes. One changing paradigm is the role of distance e-learning in different levels of the educational system. In the ideal learning spectrum, university education forms the knowledge foundation for professional understanding and the development of new skills of in-depth information acquisition, which is the hallmark of talented learners. In this intellectual sphere, e-learning has sprung up in universities and private businesses across the world benefiting from the dynamic advancements in information and communication technologies (ICTs). In the Web-based economy, e-learning interventions are rapidly affecting the organisation's response to the need for continuous workforce training and development while reducing training-related costs (Wentling et al., 2000).

The main advantages of distance e-learning are availability, reduced cost, flexibility and integration. E-learners are able to take their ecourses often at their own pace and when they have time, without disruptions to their daily life. Moreover, travel costs and lost workdays are saved if e-learners have the opportunity to follow necessary continuing education from their workplaces. With the inception of computer technologies in the 1980s and the rapid developments in communications technologies in the 1990s, the potential for improving the quality and effectiveness of e-learning has grown. This has resulted in the development of a wide variety of learning technologies and the incorporation of a number of new elements into e-learning such as multimedia and hypermedia (Beller \& Or, 1998).

Effective online education is a blend of pedagogy, technology, and organizational support. The rapid development of the Web from a text-only medium to an expanding multimedia communication system has increased and diversified the delivery mechanisms of quality distance learning. The term e-learning covers course websites, and 
audiovisual instruction; it also includes virtual classrooms and digital collaboration and uses. E-learning has come to the fore in many important areas such as: higher education, vocational training in business and industry, government and military, and public continuing education.

The emergence and adoption of web portal systems in the past few years by most learning institutions has led to a greatly enhanced networked e-learning environment for non-traditional learners to pursue further education at their convenience. While considerable research has been conducted into the role of libraries in supporting distance and off-campus learning over the past decades, this paper focuses specifically on how the digital library interoperates with the course-website learning process within the networked e-information service environment at UAEU.

\section{RELATED LITERATURES}

Web-based instruction has ushered in a new era of e-learning networks. As a new paradigm of the educational system, a growing body of research literature has accumulated. E-learning library services have also been tackled by many scholars and researchers in recent years. Benbunan-Fich and Hiltz (1999) have critically discussed the use of computer-mediated communication systems (CMCS) in distance education; they also have focused on the convergence of technological and institutional factors involved in the promotion of e-learning. Jorgensen (2002) has highlighted the overall evolution and significance of the asynchronous learning network, and explored how online courses can be used to foster a rich collaborative e-learning environment and virtual classroom, whereas Cannon (2002) has outlined the potential catalytic role of the digital library in supporting the e-learning process. Slade (2004) has comprehensively reviewed the related works conducted to date on the topic of library support for distance learning programmes and identified some priorities for future research. 
Web-based library e-services have been approached from different angles. Kinder (2002) has addressed the central role of the digital library in instructional liaison with distance e-learners. Germain and Bobish (2002) have outlined approaches by which librarians can incorporate and develop a functional web-based tool. Herget (2003) has provided evidence for successful and productive hybrid concepts in e-learning, which are largely based on digital library resources. Ngimwa (2004) has demonstrated the African Virtual University experience in using digital library e-services to enhance quality of distance e-learning, whereas the research study of Rieger et al. (2004) at Cornell University library has confirmed the strategic importance of the digital library presence within the virtual learning environments. Markland (2004) has discussed some current thinking and perspectives evidenced in the literature and research on the integration of digital libraries and online information resources into online learning environments.

\section{THE RISE OF DISTANCE LEARNING}

The rise of distance learning has resulted from the so-called push and pull factors: advances in knowledge technologies have created user demand for e-literacy and continuing education through distance learning, while extensive usage of information and communication technologies has led to further development in ICT and related applications. Distance e-learning was put into practice with the dawn of industrial expansion in the early $19^{\text {th }}$ century in some European countries (e.g. Great Britain, France, and Germany) and the USA. Although distance learning is neither a recent nor a new educational phenomenon, the advent and adoption of sophisticated information technologies into learning settings often creates this impression (McGorry, 2003). As far as the history of distance learning is concerned, it can be divided-into four generations of distance learning technologies. 
The time-frame of the first generation is from 1830 to 1920 and the technologies employed were printed materials (correspondence classes). The second generation (1921-1980) was characterised by the use of multiple audio-visual technologies, but not yet computers (print, fax, radio and instructional television). The third generation (1983-1995) integrated -further advances in computer, CD-ROM-, and space telecommunication technologies to launch two-way interactive instruction. Internet and Web-based classes represent the latest e-learning technologies in the 1990's and twenty-first century. The extensive use of computer-aided learning technologies and the Internet are the common features for this period. The fourth generation is characterised by two-way interactive real-time capabilities of audio and video, desktop conferencing and video available on demand (Prasolova-Førland, 2000).

Table-1

Milestones of Distance Learning Technologies

\begin{tabular}{||c|l||}
\hline Period Span & \multicolumn{1}{|c|}{ Features of Technologies Employed } \\
\hline $\begin{array}{c}\text { Pre-correspondence education } \\
\text { (1700s- 1820s) }\end{array}$ & $\begin{array}{l}\text { Some societal activities in Great Britain involved in supporting } \\
\text { those not enrolled in formal schools to continue their education } \\
\text { (printed textbooks). }\end{array}$ \\
\hline $\begin{array}{c}\text { Correspondence education } \\
\text { (1830s-1920) }\end{array}$ & $\begin{array}{l}\text { The advent of postal service systems in 1866 supported the de- } \\
\text { livery of teaching materials to remote learners. In 1886, Penn- } \\
\text { sylvania State University was the first higher institute to } \\
\text { maintain mail-based distance learning in an organised manner. }\end{array}$ \\
\hline $\begin{array}{c}\text { Audiovisual based instruction } \\
\text { (1921-1980s) }\end{array}$ & $\begin{array}{l}\text { Instructional radio and TV blended to give a strong boost for the } \\
\text { distance learning system to be a part of the educational pro- } \\
\text { cess, and motivated more people to enrol in distance learning } \\
\text { (visualising teaching materials). }\end{array}$ \\
\hline $\begin{array}{c}\text { Computer and telecommunica- } \\
\text { tions technology } \\
\text { (1980s-1995) }\end{array}$ & $\begin{array}{l}\text { ICT has spread -distance learning to geographically remote ar- } \\
\text { eas to help effectively in illiteracy eradication in heavily popu- } \\
\text { lated countries such as China. ICT integrated TV, video, and } \\
\text { computer connections to launch two-way interactive instruction. }\end{array}$ \\
\hline $\begin{array}{c}\text { Web-based instruction } \\
\text { (1995-present) }\end{array}$ & $\begin{array}{l}\text { The Internet introduced a new paradigm of online/virtual learn- } \\
\text { ing environments and expanded the capabilities of learning } \\
\text { centres to reach off-campus learners. }\end{array}$ \\
\hline \hline
\end{tabular}




\section{WIRED HIGHER EDUCATION IN UAEU}

The United Arab Emirates has been investing heavily in the educational sector and related activities, as it strongly believes that a robust educational system is a key to future prosperity in the forthcoming Web-based society whose hallmark is its consciousness of the importance of information literacy (Taha, 2004). To maintain this trend, UNESCO introduced the International Computer Driving Licence (ICDL) programme in all United Arab Emirates educational settings (UAE 2004). ICDL provides the basic computer knowledge necessary to use the Web and the word processing packages.

Higher education was introduced to the educational system by the opening of the UAE University in 1977 as the first national university, modelled on the American university system. UAEU paved the way for establishing a series of High Colleges of Technology (HCT) in 1988 to provide more innovative, technically-oriented education. By the turn of the twentieth century, five private universities had found their way into the higher education sector. Such an expansion in university education has sparked strong interest in providing off-campus education based on Web technologies. Most of these universities are currently providing some form of e-learning courses.

UNDP has highlighted United Arab Emirates as the most advanced e-learning country in the Arab world, which is especially manifested in the ICT infrastructure of Dubai Internet City and Dubai Village of Knowledge; both have attracted many e-learning providers to be based at these locations. For instance, eTQM is the world's first online school providing TQM e-learning http://www.etqm.net. UK eUniversities (UKeU) and other Australian universities are currently providing accredited web-based e-learning programmes in UAE. HCT made a crucial step in blending technical education with the needs of the labour market through the Centre of Excellence for Applied Research and Training (CERT), which employed the latest ICT-based elearning (UAE 2004). 


\section{UAE University: from Papyrus to Course Websites}

In 2002, the UAEU introduced course management software (CMS) to launch the e-Blackboard ${ }^{\mathrm{TM}}$ portal http://blackboard.uaeu.ac.ae for providing integrative course websites. CMS incorporates a wide range of teaching and learning tools into a web-based interface. UAEU's $e$-Blackboard ${ }^{\mathrm{TM}}$ portal offers a suite of features to facilitate some key administrative process such as group communication and self-learning assessment.

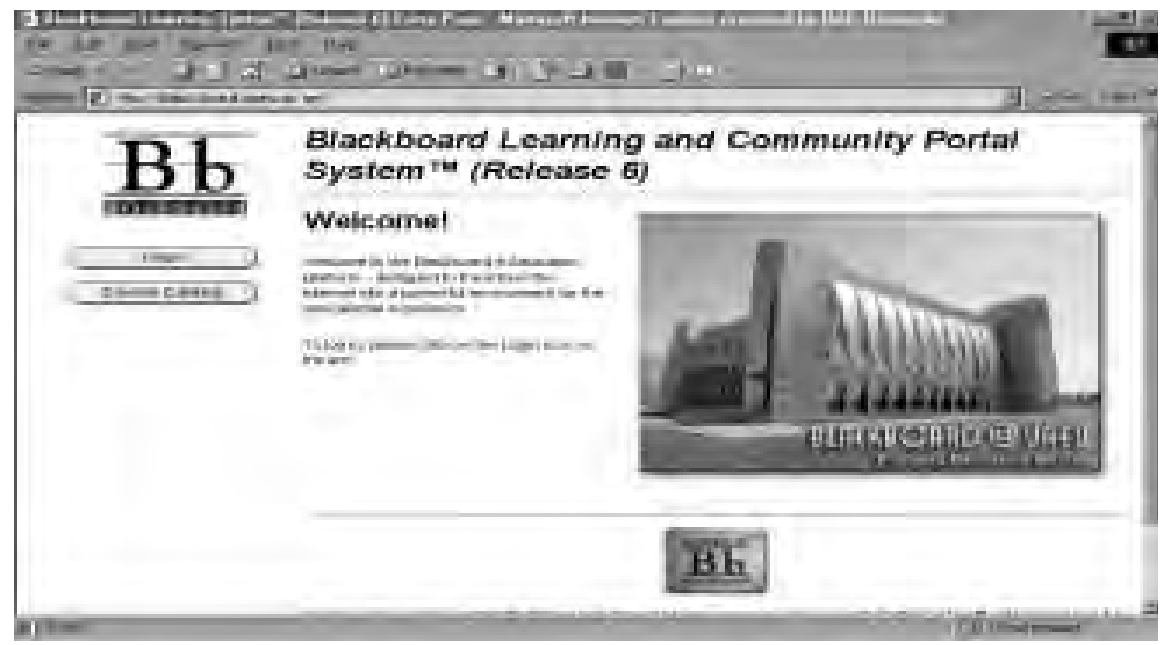

Fig. 1

UAEU e-Blackboard ${ }^{\mathrm{TM}}$ portal

Selim (2003) has conducted an empirical study on UAEU student acceptance of course websites as a teaching and learning tool in the UAEU. The course website acceptance model (CWAM) has been used to measure students' adoption of and satisfaction with the web-based courses delivered by the College of Economics and Business. The study revealed four major critical factors for CWPU:

- Course-work interactivity allowed students to engage conveniently in instruction, 
- Online components (e.g. multimedia modules) encouraged students to accomplish their assignments on time,

- Friendly use of the course website materials, and

- Increased academic productivity students through using interactive tools.

The drawback of this study is the fact that it ignores the crucial role of e-literacy and library e-services in encouraging acceptance and efficient use of course websites components (Taha, 2003).

The student's e-Blackboard ${ }^{\mathrm{TM}}$ account usually includes course syllabi, lectures, assignments, outlines, supporting materials, and links to cited websites. It also offers e-communication facilities for group discussion, for online contact with supervisors, and for promoting the exchange of ideas and documents betweens virtual classmates. Therefore, CMS creates a kind of "invisible college".

Fig. 2

Student Account in UAEU e-Blackboard ${ }^{\mathrm{TM}}$ Portal

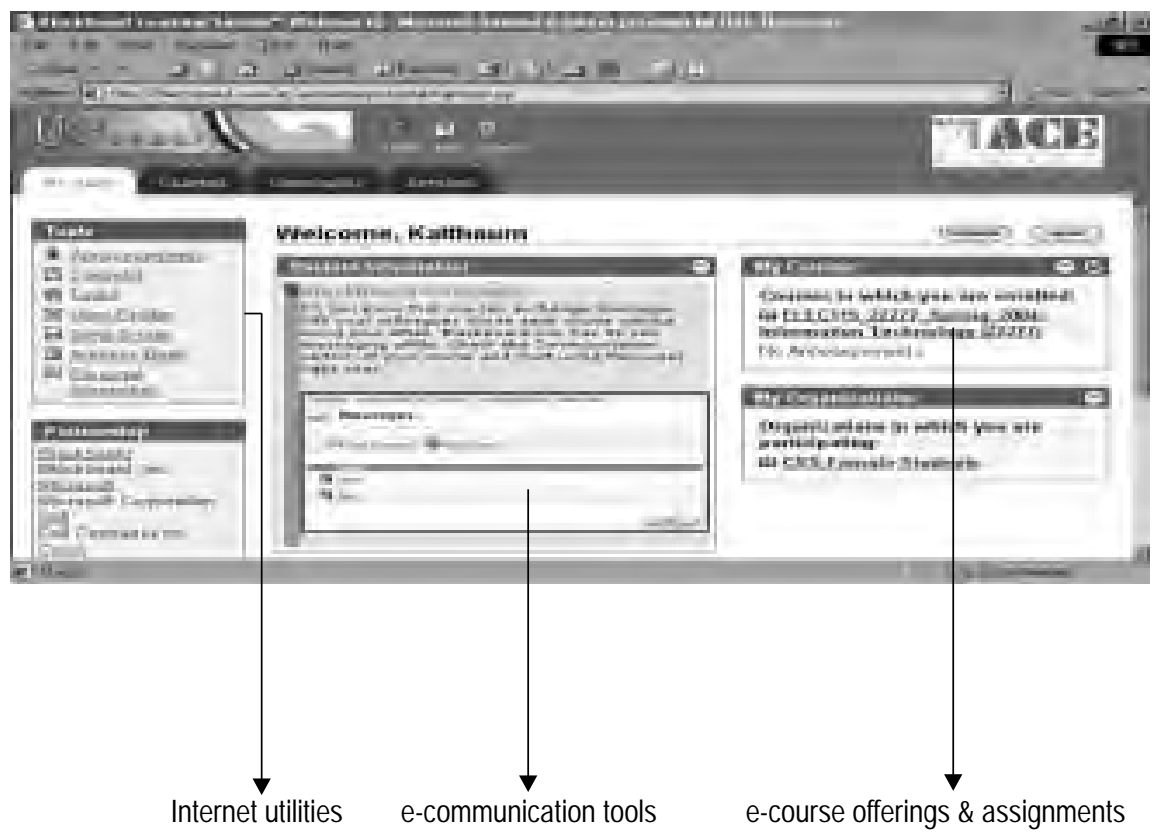


On the other hand, the UAEU Library is rich in e-collections; its web portal at http://www.libs.uaeu.ac.ae provides options to reach and search a range of e-services and e-resources. The integration of $E Z$ Proxy $^{\mathrm{TM}}$ http://ezproxy.uaeu.ac.ae into e-services has greatly expanded permanent access to library database holdings from anywhere, and has equipped the library with strong capabilities to provide timely and effective access to scholarly information, which would virtually support the e-learning process (Taha 2004).

Fig. 3

EZProxy ${ }^{\mathrm{TM}}$ Databases Menu (15 Textual and 20 Bibliographic)

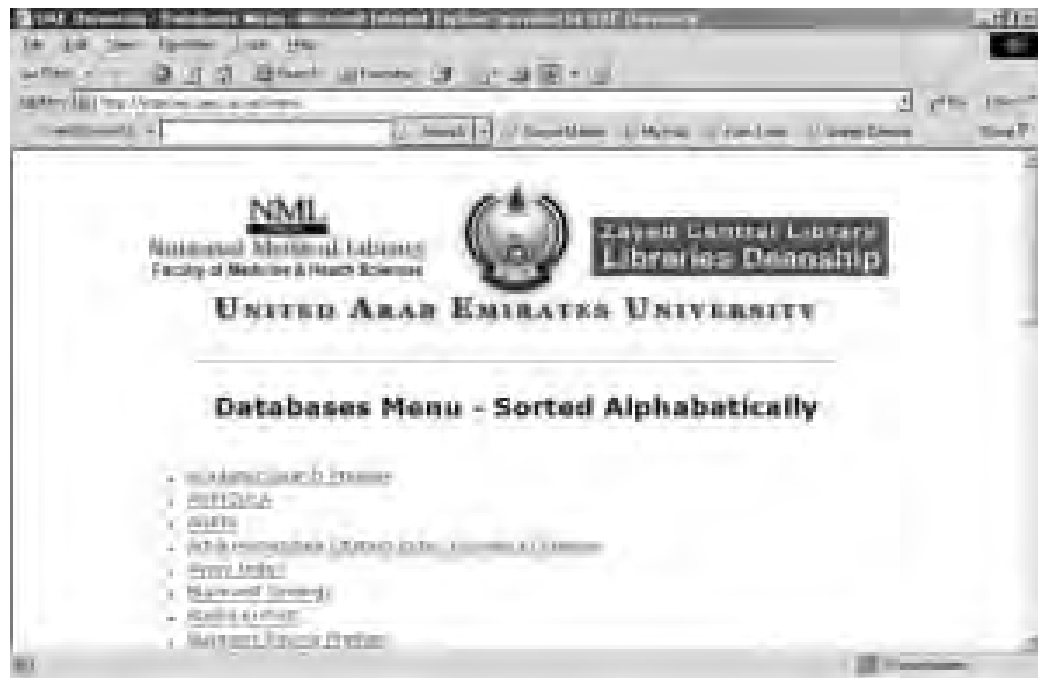

\section{TYPES OF DISTANCE E-LEARNING}

Distance e-learning generally involves two teaching modes: i- Asynchronous education tools support communication and collaboration between instructors and learners, which takes place across time and space; and are usually provided via the Internet, Web-based virtual classes (CMS, e.g. e-Blackboard) and, computer-based training modules; ii- Synchronous tools support communication and collaboration 
at the same time by means of using an interactive distance learning network (IDLN) set. IDLN allows the instructor to be seen and heard by the audience; the audience feedback is latent since they communicate only via e-massages. In many cases both synchronous and asynchronous teaching modes are used during the different phases of a course (Prasolova-Førland, 2000).

\section{E-LEARNING-DIGITAL LIBRARY INTEROPERABILITY MODEL}

The ubiquity of the Internet along with the increasing availability of Web-based technology in library settings has significantly enhanced off-campus access to e-resources. The term distance learning library services (DLLS) refers to those library services in support of college, university, or other post-secondary courses and programmes offered away from a main campus by means of electronic transmission. The phrase is inclusive of courses in all post-secondary programmes designated as extension, extended, off-campus, extended campus, distance, distributed, open, flexible, franchising, virtual, synchronous, or asynchronous (ACRL 2000).

The proposed model aims at delineating the potential interplay between the digital library and the e-learning process within the networked environment. The main ingredients of the model are concisely explained as follows (see Fig. 4):

\section{Functional Roles of the Digital Library}

- Virtual reference desk (VRD) assistance and e-mail enquiry service

- Reliable and secure access to library academic e-resources e.g. databases

- Web-based OPAC services

- Library research consultation services (expert subject)

- E-literacy programmes to develop e-learning information search skills

- Acquisition of core e-collections specifically meeting e-learning needs. 
Fig. 4

A Model Depicts Digital Library Support e-Learning Process in Networked Environment

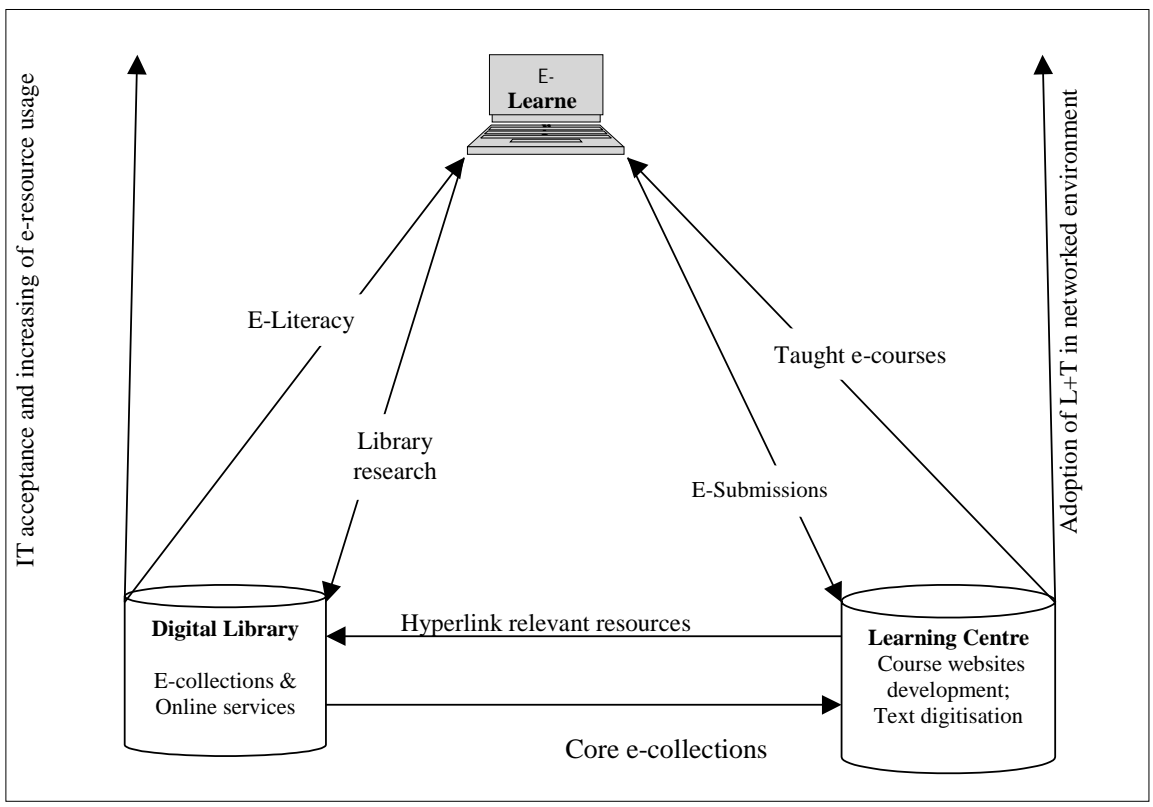

- Prompt document delivery using electronic transmission

- Promotion of library e-services to the e-learning virtual community.

\section{Functional Roles of the Learning Institution}

- Development of innovative web-based e-courses using multimedia effects and simulation

- Integration of a variety of core e-collections such as digital resources, formats, new contents, etc., that are related to the ecourses

- Hyperlink the e-courses with the library e-reference resources such as e-books and e-journals, as well as with the web-based open-access resources

- Digitisation of textbooks and other learning resources

- Possible permanent updating of e-course contents 
- Integrated web portal design provides friendly access with efficient browsing and research abilities

\section{Functional Roles of Expert e-Librarian}

The proposed model would have an expert e-librarian as:

- Knowledge explorer to locate and retrieve required academic information from different sources for support of e-courses

- Editor to accumulate and compile related information in easyto-read fashion

- Consultant to assess information quality and help in Web-based e-course

- Innovator to look for improving efficiency of information delivery

- Educator to assist in promoting e-literacy among e-learners

- Information therapist to assist in obtaining relevant and usable information in a convenient way, e.g. relieve computer-search anxiety

\section{DISCUSSION AND CONCLUSION}

The provision of digital library services to support e-learning is an area of growing recent concern for academic libraries worldwide. The strong capabilities of the digital library in providing off-campus e-information services have made the interoperability with the elearning process a highly urgent requirement. UAE University is positioning itself well to support e-courses through a range of electronic resources and other online services. The e-collection wealth of the library would usher in a new paradigm of interoperability with exponential growth in the number and variety of e-courses provided by the UAEU programmes.

Rapid advances in digital technologies have resulted not only in a proliferation of the amount of information available to students, but also in the packaging of that information in an increasing variety of digital formats. It is within this context that the expression of $e$ literacy has achieved its current popularity. The term embodies a 
challenge to the library to mandate a new paradigm for training elearners to make effective use of course website materials and to receive the full benefit of the rich knowledge resources available.

In an age where a growing number of students do not see an appreciable difference between what is offered by library e-services and web search engines, the seamless linking of course website and networked library becomes even more crucially important. To maintain the momentum of e-learning in the UAE, the university libraries should view e-learning as a new domain of e-services by means of linking e-resources with course websites. The potential future developments for support web-based curricula would lead to:

> improvement of the link between library e-collections and eservices with course website materials

- development of full e-literacy and search skills programmes

- liaison between expert librarians with teaching staff involved in the development of course website curricula

- more emphasis on handheld and wireless devices, to increase accessibility.

In this study, the following assumptions are taken into account:

- Knowledge is constructive information.

- Learning is more effective if the 'learner' is provided with a strong incentive to take responsibility for self-learning.

- Learner's motivation is a strong determinant of the outcomes of the success of the online learning.

- Encouragement of instructors, faculty and the like to incorporate ICT into their classrooms is a success indicator of online learning.

- The constant emergence of new computer technologies will lead the distant education concept to further evolve and change.

\section{Acknowledgements}

I am truly indebted to Prof. Abdulla Al-Dabbagh, Head of the English Department, for his thorough proofreading and revision. This work would not have been accomplished without the encouragement and patient care provided cordially by my wife Muzna and the 
beloved twins Amr and Omran. To all of them my sincere appreciation. This work is dedicated to my late parents, Taha and Mariam, who nurtured my professional career so carefully.

\section{REFERENCES}

ALA. ACRL (2000). Guidelines for distance-learning library services- Available: http://www.ala.org/acrl.html (viewed 7/7/2004)

Alley, L. and Jansak, K.E. (2001). Ten keys to quality assurance and assessment in online learning. Available:

http://www.worldclassstrategies.com/papers/keys.html (viewed 13/6/2004)

Beller, M. and Or, E. (1998). The crossroads between lifelong learning and information technology: a challenge facing leading universities. Available:

http://www.ascusc.org/jcmc/vol4/issue2/beller.html (viewed 17/7/2004)

Benbunan-Fich, R. and Hiltz, S.R. (1999). Educational applications of CMCS: solving case studies through asynchronous learning networks. Available:

http://www.ascusc.org/jcmc/vol4/issue3/benbunan-fich.html (viewed 25/6/2004)

Cannon, N. (2002). Yahoo! Do you Google? Virtual reference overview. The Reference Librarian, 77, 31-37.

Distance learning- an overview. Available:

http://www.pbs.org/als/dlweek/history/index.html (viewed $25 / 6 / 2004)$

Germain, C.A. and Bobish, G. (2002). Virtual teaching library instruction via the Web. The Reference Librarian, 77, 71-88. 
Herget, J. (2003). Digital environment for e-learning: a concept for excellence in knowledge transfer. Presented at: Toward a UserCentred Approach to Digital Libraries Conference, 8-9 Sept. 2003, Espoo, Finland.

Jorgensen, D. (2002). The challenges and benefits of asynchronous learning networks. The Reference Librarian, 77, 3-17.

Kinder, R. (2002). Instructional services for distance education. The Reference Librarian, 77, 63-70.

McGorry, S.Y. (2003). Measuring quality in online programmes. Internet and Higher Education, 6, 159-177.

Ngimwa, P. (2004). Using digital libraries to enhance quality of learning in distance education - the experience of the African Virtual University in Nairobi. In: Proceedings of the International Conference on Digital Libraries (Vol. 2, pp. 636- 640), New Delhi: ICDL-TERI.

Prasolova-Førland, E. (2000). Distance learning: overview and design issues. Available:

http://www.ucalgary.ca/ srmccaus/ekaterina-essay2000.htm (viewed 14/7/2004)

Rieger, O.; et al. (2004). Linking course websites to library collection and services. Journal of Academic Librarianship, 30, 205-211.

Selim, H.M. (2003). An empirical investigation of student acceptance of course websites. Computers E Education, 40, 343-360.

Slade, A.L. (2004). Research on library services for distance learning: an international perspective. Journal of Library \& Information Services in Distance Learning, 1, 5- 43.

Taha, A. (2003). Networked information for support graduate research at UAE University - information access, scholarly use, and research rigour. Presented at: Toward a User-Centred Approach to Digital Libraries Conference, 8-9 Sept. 2003, Espoo, Finland. 
Taha, A. (2004). 'Digitally yours': UAEU Libraries -proposed strategic plan to meet the challenges of digital dilemma- visions and aspirations. In: Proceedings of the International Conference on Digital Libraries (Vol. 1, pp. 208-215). New Delhi: ICDL- TERI,

UAE. Ministry of Information \& Culture, 2004. Social development. In: UAE Yearbook 2004 ed. (pp. 217-244), Abu Dhabi: The Ministry.

Wentling, T.L.; et al. (2000). The future of e-learning- a corporate and academic perspective [report], UIUC: Knowledge and Learning Systems Group, 28p. 


\title{
E-aprendizaje en el Posgrado en Bibliotecología y Estudios de la Información de la Universidad Nacional Autónoma de México
}

\author{
Filiberto Felipe Martínez Arellano \\ Adolfo Rodríguez Gallardo
}

\section{RESUMEN}

El incremento en la utilización de las computadoras y de Internet, así como la existencia de nuevas opciones de comunicación, distribución y recuperación de la información, han cambiado las peculiaridades de la educación, particularmente las correspondientes a la educación a distancia. La bibliotecología, al igual que otras disciplinas, ha adoptado el uso de este nuevo tipo de educación, en donde el elemento central es el aprendizaje interactivo mediante el uso de medios electrónicos por lo que éste ha empezado a ser conocido como e-aprendizaje. En esta nueva opción educativa existen una serie de retos para trasladar los procesos y actividades de aprendizaje del aula tradicional a un ambiente electrónico. El presente documento muestra las características principales del espacio de aprendizaje electrónico, desarrollado por el Centro Universitario de Investigaciones Bibliotecológicas de la Universidad Nacional Autónoma de México, para apoyar la impartición a distancia del Programa de Posgrado en Bibliotecología y Estudios de la Información en sedes foráneas. Asimismo, la forma en que se han apoyado los roles del profesor y del alumno en un ambiente de aprendizaje electrónico.

a utilización de las tecnologías de la información y la comunicación (TICs) en diversos campos y actividades de la sociedad actual muestra una gran expansión y la educación no podía ser la excepción. Tanto en los países desarrollados como en los denominados 
en vías de desarrollo, las características de la educación están cambiando substancialmente debido a la incorporación y utilización de la digitalización y las TICs en los procesos de enseñanza-aprendizaje. El incremento en la utilización de las computadoras y de Internet, así como la existencia de nuevas opciones de comunicación, distribución y recuperación de la información tales como las listas de discusión, el correo electrónico, el chat y los recursos electrónicos de la Web, han cambiado las peculiaridades de la educación, particularmente las correspondientes a la educación a distancia. La utilización de estos nuevos medios tecnológicos permite a los estudiantes localizar e interactuar con materiales y recursos educativos en formas que previamente no habían sido posibles.

Las universidades y las instituciones de educación superior están haciendo uso de la tecnología para que sus programas de educación a distancia lleguen a un mayor número de estudiantes, ya sea dentro de su propio campus o en sitios fuera de éste como sus casas o sus lugares de trabajo. Ciertamente, un gran número de instituciones educativas están haciendo accesibles sus cursos a través de Internet. Un estudio llevado a cabo por el National Center for Education Statistics (2004) de los Estados Unidos de Norteamérica para estimar el número de instituciones que impartían educación a distancia, considerando a ésta como los cursos ofrecidos en forma remota fuera del campus a través de audio, video (en vivo o pregrabado), o con tecnologías de cómputo (en forma asíncrona o síncrona), encontró que durante el año académico 2000-2001, un 56 por ciento $(2,320)$ de las instituciones de educación superior de ese país ofrecían esa modalidad educativa y otro 12 por ciento (510) estaban planeando ofrecerla en los próximos tres años. Por otro lado, actualmente más de 70 millones de personas ya reciben educación a través de Internet y en un futuro próximo, la formación de profesionales en distintas disciplinas será efectuada de ese modo. (El e-aprendizaje, 2004).

Por otro lado, Frey, Alman, Barron y Steffens (2004) señalan que en un estudio llevado a cabo en septiembre de 2002 para obtener información de los profesores acerca del uso de la Web para sus cursos se encontró que: 
- 50 -75 por ciento de los profesores usaban la Web para apoyar sus clases tradicionales.

- 50-75 por ciento de los profesores utilizaban la Web para apoyar sus cursos de educación a distancia.

- 25-50 por ciento de los profesores utilizaban la Web para distribuir la totalidad de sus cursos dentro del campus.

- 25-50 por ciento de los profesores utilizaban la Web para distribuir la totalidad de sus cursos a distancia.

Ciertamente, Internet y la World Wide Web ofrecen un gran potencial para el aprendizaje por lo que las características de la educación a distancia han cambiado drásticamente en la última década. La integración de las tecnologías basada en las telecomunicaciones ha permitido que muchas instituciones implementen programas educativos de este tipo.

\section{EDUCACIÓN A DISTANCIA Y E-APRENDIZAJE}

La educación a distancia no es un concepto totalmente nuevo, pues ésta tiene una existencia de más de cien años. La distribución de los primeros materiales educativos, con los que la educación a distancia surgió, tuvo lugar a principios del siglo pasado, conjuntamente con la aparición del correo postal; posteriormente surgió la distribución de cursos a través de la radio alrededor de 1910, por televisión en la década de los 60s, por video en los 80 s y a través del CD-ROM en los 90s. El uso de la Web fue el siguiente paso en la evolución de la educación a distancia (Rodman, 2003).

De acuerdo con Padula Perkins (2002), la educación a distancia puede ser definida como "una metodología educativa no presencial, basada en la comunicación pluridireccional mediatizada, que implica amplias posibilidades de participación de estudiantes dispersos, con un alto grado de autonomía de tiempo, espacio y compromiso, y con una orientación docente, dada en el diseño, en la elección de los medios adecuados para cada caso (en virtud de los temas y con consideración de las posibilidades de acceso de los destinatarios a los mismos) y en las tutorías." 
Adicionalmente, para García Aretio (citado por Padula Perkins, 2002), la educación a distancia "[...] es un sistema tecnológico de comunicación masiva y bidireccional, que sustituye la interacción personal en el aula de profesor y alumno como medio preferente de enseñanza, por la acción sistemática y conjunta de diversos recursos didácticos y el apoyo de una organización tutorial, que propician el aprendizaje autónomo de los estudiantes."

Por otro lado, Williams (2003) menciona que el uso creciente de las computadoras y de la comunicación basada en Internet y los sistemas de distribución/recuperación de la información tales como las listas de discusión, el correo electrónico, el chat, el software para la discusión en grupo y las bases de datos existentes la web ofrecen a los educadores una variedad de herramientas con las que se promueven interacciones de aprendizaje de tres tipos: estudiante-instructor, estudiante-contenido y estudiante-estudiante. De esta forma, los profesores y los estudiantes tienen la oportunidad y las herramientas para interactuar y crear un ambiente interactivo de aprendizaje mediante el uso de la tecnología.

Este nuevo tipo de educación, en donde el elemento central es el aprendizaje interactivo mediante el uso de medios electrónicos, facilita la interacción espontánea de persona a persona y de experiencias colectivas, independientemente del tiempo y del lugar, y ha empezado a ser conocido como e-aprendizaje. La integración de las TICs, particularmente la Internet, dentro del e-aprendizaje, es considerada como una oportunidad para eliminar las barreras de espacio, tiempo y distancia, facilitando además el proceso de aprendizaje.

El e-aprendizaje involucra un proceso interactivo en el cual el que aprende recibe información del maestro, de otros estudiantes y de fuentes que incluyen material educativo. Asimismo, el que aprende responde a las preguntas, planteamientos y problemas del profesor y de sus compañeros. Las TICs ofrecen la oportunidad de crear ambientes interactivos de aprendizaje, completamente electrónicos, que apoyan la adquisición de conocimientos y habilidades. 


\section{VENTAJAS Y DESVENTAJAS}

Maddux, Ewing-Taylor y LaMont Jonson (2002) señalan que la educación a distancia, como muchas otras cosas relacionadas con las nuevas tecnologías, presentan una serie de ventajas y desventajas. Entre las primeras se encuentran y pueden apreciarse fácilmente las siguientes: la capacidad para llegar a un mayor número de estudiantes en lugares geográficamente remotos, en circunstancias que no requieren la asistencia a clases en horarios regulares; el potencial para llegar a muchos tipos de estudiantes calificados como no tradicionales; y la oportunidad de los estudiantes de trabajar y aprender dentro de un estilo y ritmo más acorde con sus capacidades mentales y físicas. Por otro, las desventajas de la educación a distancia no son tan evidentes; sin embargo, éstas se ponen de manifiesto a medida que se implementan este tipo de programas en distintos lugares con características particulares. Uno de los problemas más serios de esta opción educativa es el incremento en el número de cursos ofrecidos a través de este medio por distintas instituciones, lo cual hace necesario la evaluación de su calidad académica, pues en ocasiones, el surgimiento de éstos es motivado únicamente por razones comerciales, transformándose la educación en un bien y los estudiantes en clientes y por el supuesto de que se está a la vanguardia educativa por el uso de los instrumentos tecnológicos.

Un argumento en contra de los programas basados en computadora es que ofrecen a los individuos un aprendizaje aislado y como tal no proporcionan los componentes esenciales de una experiencia de aprendizaje efectivo y enriquecedor, tal y como ocurre en los grupos sociales, en donde los individuos interactúan, compartiendo e intercambiando información y experiencias, creando comunidades sociales en donde el aprendizaje tiene lugar en un ambiente de participación y no en forma individual. Al respecto, Browne (2003) menciona que por el contrario, con las ventajas que ofrecen las computadoras y la tecnología existen mayores oportunidades para las opciones del aprendizaje participativo. La perspectiva de un grupo o de una comunidad de estudiantes trabajando cooperativamente, ejercitando, verificando, solidificando y mejorando sus modelos 
mentales de pensamiento, a través de la discusión y el intercambió de información, es posible en ambientes virtuales.

Las tecnologías digitales ofrecen la oportunidad para que los estudiantes interactúen con otros a través de varios medios. En su nivel más elemental, el e-aprendizaje les ofrece a los estudiantes la oportunidad de una interacción asíncrona, a través del correo electrónico. Respecto al uso de éste, Mitra y Hall (2002) señalan que bajo ciertas circunstancias, el correo electrónico ofrece un modo de comunicación más abierto y libre que no impone a los estudiantes, resultando en una disolución del sistema jerárquico de comunicación, incrementando la interacción y relación estudiante-maestro. A medida que el uso del correo electrónico es complementado con otras opciones asíncronas como las listas y los grupos de discusión electrónicos, se promueve una mayor interacción, pues mas estudiantes y maestros pueden comunicarse e interactuar. El correo electrónico es el punto de partida para integrar formas más complejas de interacción en donde los estudiantes pueden intercambiar, aún en forma síncrona, sonido e imágenes.

El aprendizaje basado en medios asíncronos se ha convertido en un método popular para ofrecer mayores oportunidades de aprendizaje. Al no estar la comunicación e interacción entre el estudiante y el profesor sujetas a un tiempo y un lugar específicos, permiten una gran flexibilidad para todos los individuos involucrados en este ambiente; sin embargo, Wheler y Fournier (2001) señalan que junto con estas ventajas, también existen retos, siendo uno de ellos que el instructor debe aprender a interactuar dentro de este ambiente de aprendizaje, adquiriendo las habilidades necesarias para motivar la participación de los estudiantes a través de la distancia.

Cuando los e-estudiantes, particularmente los adultos maduros, son altamente motivados, prefieren esta opción de aprendizaje en la cual construyen sus propias representaciones internas de conocimiento mas que aceptar las del instructor. El reto para los educadores a distancia es establecer ambientes de aprendizaje cognocitivamente ricos que incorporen las características mas apropiadas y efectivas del aprendizaje que tiene lugar en el salón de clases, con nuevas formas para facilitar el proceso de construcción del conocimiento de 
los estudiantes a distancia, usando la tecnología para fomentar la espontaneidad y la interacción grupal y disminuir los sentimientos de aislamiento experimentados en ocasiones en las situaciones de aprendizaje a distancia. Uno de los retos de los programas de educación a distancia es la creación de comunidades de aprendizaje a través del uso de métodos basados en la tecnología (Small, 1999).

Padula Perkins (2002) señala que junto con la tutoría a los estudiantes, otro de los elementos esenciales dentro de esta modalidad educativa son los materiales de apoyo. El papel y lugar de las tutorías dentro de la educación a distancia puede ser analizados desde distintas perspectivas; sin embargo, junto con los materiales de aprendizaje integran el núcleo operacional del dialogo didáctico que caracteriza a esta opción educativa. Los textos, imágenes o sonidos, presentados como impresos, en casetes, soportes informáticos o en páginas Web, conforman un instrumento pedagógico irremplazable.

No obstante lo anterior, Reid (2003) señala que algunos involucrados en el sector educativo cuestionan el tiempo requerido para desarrollar y mantener materiales en ambientes de aprendizaje virtual; asimismo, otros cuestionan la falta de valoración del trabajo que involucra la elaboración de estos medios, mientras que otros más cuestionan sus implicaciones pedagógicas. No obstante lo anterior, el entusiasmo por estas nuevas tecnologías ha llevado a diversas instituciones educativas a transformar sus programas de educación a distancia en forma impresa a formatos digitales. En algunos otros casos se han desarrollado materiales específicos para la educación a distancia virtual.

Los programas de educación a distancia deben brindar una mayor cantidad de contenidos a través de materiales de aprendizaje que permitan disminuir la ausencia del salón de clases. En los programas de educación a distancia se deben incluir la mayor cantidad de posible de contenidos por medio de materiales elaborados específicamente para tal fin; sin embargo, no es posible abarcar todos los aspectos conceptuales a través de materiales de elaboración propia, existiendo la necesidad de incluir materiales de aprendizaje o bibliografías complementarias, lo cual constituye otro reto para las instituciones que ofrecen este tipo de programas y los estudiantes inscritos 
en ellos. Las organizaciones e instituciones educativas deben proporcionar la bibliografía existente en el mercado o los alumnos deberán adquirirla.

Por otro lado, muchos de los e-estudiantes toman cursos desde sus casas; sin embargo, las circunstancias en que tiene lugar su aprendizaje son complejas y variadas, lo cual puede influir en el proceso educativo. La lectura de materiales requiere de un lugar en el cual puedan trabajar libres de distracciones por largos periodos. Revisar un video o interactuar con un CD-ROM requiere el acceso a recursos y aparatos que podrían ser compartidos con otros habitantes de la casa, lo cual involucra negociaciones. Si un curso requiere el uso de materiales que no se poseen, ¿cómo pueden obtenerse esos recursos?. Adicionalmente a lo anterior, para una gran mayoría de los estudiantes independientes, el estudio no es la primera prioridad en su tiempo y atención. Muchos tienen un empleo o responsabilidades que son prioritarias. El contexto individual es un esquema particular por lo que cada estudiante tiene que determinar sus patrones de estudio, así como adecuar sus patrones de vida en el hogar y en trabajo a circunstancias y necesidades particulares (Kirkwood, 2003).

Scheer y Lockee (2003) señalan que al igual que en un ambiente de aprendizaje tradicional, en un ambiente de educación a distancia es importancia que los estudiantes cuenten con los servicios de apoyo que demandan el estudio independiente y tomar en cuenta los roles que tienen que jugar los estudiantes. Entre los servicios de apoyo se pueden mencionar: la orientación a los estudiantes para trabajar en un ambiente a distancia, acceso a recursos bibliográficos, asesoría académica, registro en línea de los cursos, asesoría individual, apoyo técnico, ayuda financiera y oportunidades para la interacción social. Asimismo, los estudiantes a distancia enfrentan una serie de problemas que requieren apoyo. Estos problemas involucran necesidades extracurriculares relacionadas con una gran diversidad de aspectos tales como empleo, estabilidad laboral, sobrecargas de trabajo, responsabilidades familiares, salud, e intereses y obligaciones. Es necesario enfatizar el apoyo para la administración del tiempo y el manejo del estrés que demandan los compromisos familiares y de trabajo de los estudiantes a distancia. 
Ciertamente, desarrollar un curso de e-aprendizaje es un gran reto pues implica identificar actividades y alternativas pedagógicas para reproducir la situación de aprendizaje en el aula dentro de un ambiente virtual. Respecto a este aspecto, Small (1999) señala que las tecnologías de la información son de gran utilidad para la enseñanza y el aprendizaje puesto que proporcionan un amplio rango de formas que facilitan la creación de ambientes interactivos de aprendizaje que llenan las rupturas de tiempo y espacio y maximizan la interacción que existe en los salones de clase tradicionales.

\section{UTILIZACIÓN DEL E-APRENDIZAJE EN BIBLIOTECOLOGÍA}

Al igual que en otras disciplinas, dentro de la bibliotecología y los estudios de la información, la educación a distancia y el e-aprendizaje representan nuevas alternativas para la formación profesional. El número de programas de educación a distancia basados en las TICs se ha incrementado notablemente en los últimos años. En un reporte estadístico de la Asociación de Educación en Bibliotecología y Ciencias de la Información (Association for Library and Information Science Education), correspondiente a 1990, se mostraba que 38 escuelas de los Estados Unidos de Norteamérica ofrecían alrededor de 408 cursos fuera de las instalaciones de sus campus, cerca del doble de los que habían sido ofrecidos el año anterior. Asimismo, solamente diez escuelas utilizaron alguna forma de telecomunicaciones para impartirlos. Sin embargo, en el reporte correspondiente al año 2000, cuarenta y cuatro escuelas ofrecían 489 cursos fuera de sus instalaciones y en veintiocho de ellos se habían utilizado alguna forma de telecomunicaciones. Por otro lado, en 1990, catorce escuelas indicaban cambios en sus ofertas educativas, principalmente en el incremento de sus contenidos y en el 2000, veintiocho escuelas indicaron cambios, particularmente en el numero de cursos ofrecidos a través de Internet (Barron, 2002).

Gregory (2003) menciona que la educación a distancia basada en la Web se está convirtiendo rápidamente en una de las alternativas preferidas, si no es que una de las formas predominantes en las 
escuelas de bibliotecología y ciencias de la información de los Estados Unidos, al igual que en muchas otras áreas de la educación superior. Los cursos impartidos pueden ser clasificados como asíncronos o síncronos, encontrándose entre los primeros aquellos que promueven un aprendizaje en cualquier lugar y a cualquier hora, sin ningún tiempo fijo de concurrencia para la interacción entre los instructores y los estudiantes, mientras que en los segundos existe una interacción en tiempo real, en menor o mayor grado, por medio de Internet o de chat. Algunos otros cursos son impartidos en una forma híbrida, incluyendo un número limitado de sesiones presenciales. Al respecto, Gregory (2003) también señala que los estudiantes están satisfechos con la calidad del aprendizaje de los cursos que reciben en forma asíncrona a través de la Web; sin embargo, expresan que la calidad de su educación podría ser mejorada incorporando algunos elementos de interacción en tiempo real. Dado que este tipo de educación se encuentra en una etapa de crecimiento y maduración, no debe ser olvidado que el desarrollo de los cursos ofrecidos a distancia necesita ser cuidado.

Frey, Alman, Barron y Steffens (2004), en una evaluación de la Maestría en línea en Bibliotecología y Ciencias de la Información, impartida en la Universidad de Pittsburg, comprobaron algunas de las ventajas y desventajas de la educación en línea. Encontraron que la interacción entre los estudiantes y entre éstos y el instructor eran componentes vitales para una exitosa experiencia de aprendizaje. Los participantes en este programa valoraron fuertemente la interacción en línea con sus instructores y con sus compañeros. El diseño del curso enriqueció el sentido de comunidad. Asimismo, valoraron la igualdad de oportunidades para todos los participantes. Al comparar la experiencia de sus cursos en línea con sus experiencias en cursos tradicionales, se mencionó que fue posible conocer mejor a sus compañeros en comparación con los cursos normales.

Los estudiantes valoraron el formato y horarios flexibles, considerándolos como convenientes. Los estudiantes también se sintieron altamente motivados; sin embargo, también existió ansiedad, la cual estaba relacionada con el proceso de evaluación. Por lo anterior, los estudiantes requerían una retroalimentación tangible por parte del 
instructor. En otras palabras, los estudiantes deseaban calificaciones para cada uno de sus trabajos. El requerimiento de retroalimentación en la evaluación fue uno de los comentarios mas frecuentes. También se encontró que dentro de sus expectativas estaban que las instrucciones e indicaciones de los cursos fueran claras y pertinentes y que el contenido fuese actualizado.

Por otro lado, existía la necesidad de que los estudiantes dominasen la tecnología antes de poder entrar al contenido del curso. Existió un sentimiento de satisfacción y autoconfianza después de que aprendieron a usar la tecnología. También solicitaron acceso para el uso de la plataforma de e-aprendizaje antes del inicio formal de los cursos. Finalmente, es importante mencionar que también encontraron que su papel de estudiantes fue secundario a sus roles como padres, hermanos y empleados, lo cual tenía que ser tomado en cuenta.

Como producto de este estudio, la Universidad de Pittsburg elaboró una serie de recomendaciones para la planeación y conducción de cursos en línea, las cuales fueron:

1. Establecer claramente las expectativas

- Proporcionar programas detallados con calendarios, criterios de evaluación, tareas, número de participaciones por semana, fechas límite de entrega y horarios de oficina.

- Evitar cambios en el curso una vez que este haya empezado.

- Establecer planes de contingencia para cuando falle la tecnología.

2. Incorporar diversas formas de retroalimentación durante el curso

- Usar formas específicas y consistentes de retroalimentación por parte del instructor y de los estudiantes.

- Evaluar los trabajos con criterios específicos, previamente establecidos.

- Proporcionar retroalimentación general y específica a los individuos, a los equipos y al grupo en general.

3. Proporcionar comunicación regular con los estudiantes y con el grupo

- Responder al correo electrónico dentro de un término de 24 a 48 horas (aunque sea un respuesta breve a una calificación o una nota que será ampliada con información más detallada). 
- Personalizar el ambiente de las clases.

- Utilizar un estilo de escritura amigable e informal.

- Hacer anuncios o actualizaciones semanales.

- Establecer horarios de oficina en línea durante la semana.

- Asegurar y demostrar a los estudiantes que las participaciones electrónicas están siendo leídas.

- Proporcionar información por teléfono, fax y correo ordinario.

- Limitar el tamaño de los grupos para permitir un manejo efectivo.

- Considerar el uso de ayudantes para monitorear los foros o grupos de discusión.

- Ser claro y sucinto en las instrucciones y explicaciones.

- Preparar a los estudiantes para trabajar en grupos o equipos pequeños proporcionándoles objetivos y roles.

- Requerir una participación regular para acreditar el curso.

- Establecer criterios claros de participación (número de participaciones por semana y extensión de las mismas).

- Motivar a los estudiantes a interactuar y no sólo colocar sus respuestas.

4. Proporcionarle al estudiante flexibilidad y control

- Utilizar correo asíncrono y foros de discusión para participar desde cualquier lugar y a cualquier hora.

- Dividir las actividades de aprendizaje en unidades o subunidades pequeñas y manejables que puedan se completadas en periodos relativamente cortos (los estudiantes constantemente estarán accesando y recorriendo el curso y necesitan puntos lógicos de comienzo y final).

- Permitir a los estudiantes la elección de trabajos, proyectos o tópicos de investigación.

- Incorporar señales dentro del texto en relación con la cantidad de trabajo que los estudiantes pueden esperar tales como "esta es una unidad grande", "este es un concepto muy importante", "proceda a la Lección 6."

- Permitir a los estudiantes acceder previamente al curso y enviarles el programa varias semanas antes de que éste comience. 
5. Incorporar estrategias que motiven a los estudiantes

- Indicarles porque un tópico o liga son importantes.

- Proporcionar información con ejemplos.

- Relacionar nuevos tópicos con los que previamente han sido discutidos o leídos.

6. Ofrecer variedad de formas de apoyo al estudiante

- Apoyo técnico.

- Apoyo para desarrollar sus habilidades de aprendizaje.

- Apoyo de sus compañeros.

- Apoyo administrativo de su departamento.

7. Mantener el foco del contenido dentro de cada unidad

- Proporcionar los objetivos y un esquema al comienzo de cada unidad.

- Limitar los hipervínculos solamente a unos cuantos seleccionando los mejores.

- Colocar ligas adicionales al final de las unidades para enriquecerlas.

- Resumir las puntos clave de las unidades y de las discusiones para concluirlas, resumir y reenfocar a los estudiantes a la unidad siguiente.

8. Establecer consistencia entre las unidades y el curso

- Mantener el mismo formato a través de todo el programa (por ejemplo, todas las actividades bajo el mismo encabezamiento del curso).

- Crear archivos pdf que se puedan imprimir para los artículos grandes.

- Usar los mismos encabezados en todas las unidades (objetivos, introducción, contenido o notas de lectura, exposiciones, lecturas, actividades, recursos opcionales, conclusiones).

9. Considerar las limitaciones de los adultos

- Mantener fuentes grandes para facilitar la lectura.

- Usar colores claros y subrayados.

- Usar una gran variedad de imágenes, gráficas y tablas.

- Considerar diferentes estilos de aprendizaje.

- Estar consciente de las discapacidades. 
10. Respetar el papel de los estudiantes y sus experiencias

- Asumir el papel de facilitador más que el de experto.

- Reconocer las diferencias en los antecedentes de los adultos.

- Aplicar los conceptos en la realización de tareas o solución de problemas.

- Usar un estilo de escritura en primera persona.

- Solicitar a los estudiantes, a manera de introducción, que incluyan sus antecedentes profesionales y alguna información personal.

POSGRADO EN BIBLIOTECOLOGÍA Y ESTUDIOS DE LA INFORMACIÓN DE LA UNAM

Los estudios de Maestría en Bibliotecología fueron establecidos en la Universidad Nacional Autónoma de México (UNAM) en 1972. A partir de entonces, la UNAM ha sido la única institución del país que ha impartido en forma continua estudios de Posgrado en Bibliotecología, y por lo tanto, la única opción para cursar este nivel de estudios en nuestra disciplina.

En la década de los 90 se planteó la necesidad de transformar integralmente este Posgrado debido a que el existente hasta entonces ya no respondía a las necesidades de la disciplina ni a las demandas del mercado laboral. Por lo anterior, un grupo de investigadores del Centro Universitario de Investigaciones Bibliotecológicas (CUIB) se dio a la tarea de elaborar un programa de Posgrado que habría de sustentar las nuevas demandas y tendencias de la disciplina. Este nuevo programa de Posgrado, aprobado por el Consejo Universitario en 1998, consideró la necesidad de abordar sistemáticamente todas aquellas cuestiones relacionadas con la disciplina por lo que se denominó Posgrado en Bibliotecología y Estudios de la Información. Una de características fundamentales de este nuevo programa de Posgrado fue la inclusión de los estudios de doctorado, además de los de maestría. 
Comité Académico. El Posgrado de Bibliotecología y Estudios de la Información cuenta con un órgano académico colegiado que se denomina Comité Académico, el cual está integrado por el Director de la Facultad de Filosofía y Letras o su representante; el Director del Centro Universitarios de Investigaciones Bibliotecológicas o su representante; un representante académico, elegido por los profesores de la Facultad de Filosofía y Letras y otro por los investigadores del Centro Universitario de Investigaciones Bibliotecológicas; cinco representantes tutores, elegidos por los miembros de cada una de las cinco áreas de especialización en que está dividido el programa; dos estudiantes electos por los alumnos inscritos en el programa, uno de doctorado y otro de maestría; y el Coordinador del Programa de Posgrado. En total, este Comité Académico está integrado por doce miembros que duran dos años en su cargo, con excepción de los directores, quienes duran cuatro años, correspondientes al periodo para el cual fueron elegidos.

Personal: El cuerpo de tutores y profesores de este Posgrado está integrado por el grupo de más alto nivel académico en el país en nuestra disciplina. La mayoría tiene doctorado y son miembros del Sistema Nacional de Investigadores, reconocimiento que por la calidad de la obra publicada (libros y artículos) hace el Consejo Nacional de Ciencia y Tecnología mediante la evaluación de pares. El nivel de maestría tiene 28 tutores, 18 con grado de doctor y diez con grado de maestría.

Objetivos: El Posgrado en Bibliotecología y Estudios de la Información (Universidad Nacional Autónoma de México, 2004) tiene los siguientes objetivos:

- "Formar cuadros de alto nivel académico, con una sólida formación que los capacite para investigar, generar y transmitir nuevos conocimientos orientados a diseñar los modernos sistemas de información apoyados en las nuevas tecnologías de información, los cuales son parte de la docencia y la investigación en las universidades, y otras instituciones educativas, así como en las actividades que realizan las organizaciones gubernamentales, las empresas, las industrias, etc. 
- Relacionar la investigación y la docencia en el ámbito de la Bibliotecología y Estudios de la Información con programas y proyectos nacionales en el campo de información, bibliotecas, organización y difusión documental e industria editorial y de la información.

- Realizar estudios encaminados a identificar prioridades de investigación y docencia a mediano y largo plazo.

- Generar proyectos que tengan por objetivo lograr la interacción sociedad - información y conocimiento, a través del estudio de las formas de uso y posibilidades de aprovechamiento de la información, el conocimiento y los recursos documentales en diversos tipos de comunidades.

- Impulsar investigaciones orientadas a conocer los fenómenos que inciden en la lectura, comprensión y utilización de la información y el conocimiento, a fin de proponer medios para mejorar la capacidad de los individuos para utilizar y aplicar la información en el desarrollo social, científico y tecnológico del país.

- Promover el cultivo de una cultura del conocimiento que permita establecer puntos de partida sólidos para llevar a cabo un trabajo de investigación, reflexión y docencia sobre la situación y perspectiva de la Bibliotecología y los Estudios de la Información.

- Vincular la investigación con programas de enseñanza en el área de Bibliotecología y estudios de la información.”

Actualmente, los cursos de la Maestría en Bibliotecología y Estudios de la Información se encuentran ubicados en las siguientes áreas:

- Información conocimiento y sociedad

$\checkmark$ Teoría de la bibliotecología y de la información

$\checkmark$ Educación en bibliotecología y estudios de la información

$\checkmark$ Educación en bibliotecología y estudios de la información: educación a distancia en bibliotecología

$\checkmark$ Información y sociedad 
$\checkmark$ Bibliotecas, colecciones y servicios especializados:

legislativas y gubernamentales, arte.

$\checkmark$ Bibliotecas, colecciones y servicios especializados: acervos fotográficos

$\checkmark$ Teoría de la evaluación

- Organización de la información documental

$\checkmark$ Análisis documental

$\checkmark$ Clasificación documental

$\checkmark$ Lenguajes documentales

$\checkmark$ Normalización de la información

$\checkmark$ Lingüística e información

$\checkmark$ Teoría de las bases de datos textuales

$\checkmark$ Seminario de lenguajes documentales: un análisis de contenido

- Tecnologías de la información

$\checkmark$ Automatización aplicada a los servicios de información

$\checkmark$ Telecomunicaciones y servicios de la información

$\checkmark$ Diseño de bases de datos bibliográficas

$\checkmark$ Sistemas operativos y plataformas

$\checkmark$ Políticas de información

$\checkmark$ Lenguajes de recuperación de información

$\checkmark$ Información y documentación electrónicas

$\checkmark$ Información y documentación electrónicas: lógica booleana

- Sistemas y servicios bibliotecarios y de información

$\checkmark$ Bibliotecología y estudios de la información en México

$\checkmark$ Recursos de información especializada en: humanidades, ciencias sociales, ciencia y tecnología.

$\checkmark$ Gestión de la información

$\checkmark$ Espacios y servicios de información

$\checkmark$ Economía y comercialización de la información

$\checkmark$ Análisis de costos

$\checkmark$ Evaluación estadística

$\checkmark$ Estudios métricos

- Usuarios de la información

$\checkmark$ Tecnología de la información y sociedad

$\checkmark$ Estudios de usuarios 
$\checkmark$ Educación de usuarios

$\checkmark$ Comunidades científicas e información

$\checkmark$ Comunicación científica

$\checkmark$ Comunicación y relaciones humanas

$\checkmark$ Comunicación y relaciones humanas: lectura y comunicación

Para obtener el grado de maestría, los estudiantes tienen que tomar ocho seminarios y cuatro cursos. Cuatro de los seminarios y un curso son obligatorios, correspondiendo cada uno de ellos a las cinco áreas anteriormente mencionados. Los seminarios y el curso obligatorio son:

$\checkmark$ Teoría de la bibliotecología y de la información (s)

$\checkmark$ Análisis documental (s)

$\checkmark$ Automatización aplicada a los servicios de información (c)

$\checkmark$ Bibliotecología y estudios de la información en México (s)

$\checkmark$ Tecnología de la información y sociedad (s)

Los cuatro seminarios y los tres cursos restantes pueden ser elegidos entre los 32 adicionales que se ofrecen en las distintas áreas.

Los estudiantes que ingresan a la maestría pueden tener como antecedente la Licenciaturas en Bibliotecología o en alguna otra área afín como son: Documentación, Ciencias de la Información o Archivonomía. En el primer caso, los aspirantes deben presentar una propuesta de tesis, la cual es discutida con dos tutores para evaluar sobre viabilidad, y en caso de ser aceptada, ingresa directamente a cursar los seminarios y cursos del programa. En el segundo caso, es decir, cuando un licenciado en otras áreas desea cursar la maestría, se le asignan seis cursos de prerrequisito, los cuales son los siguientes:

$\checkmark$ Fundamentos de la Bibliotecología,

$\checkmark$ Fundamentos de la organización documental,

$\checkmark$ Fundamentos de los servicios,

$\checkmark$ Desarrollo de colecciones,

$\checkmark$ Consulta I

$\checkmark$ Consulta II 
Al concluir satisfactoriamente estos cursos, el estudiante debe presentar una propuesta de tesis, la cual también es discutido con dos tutores, y en caso de ser viable es admitido en forma definitiva y entonces puede cursar las materias de la maestría.

Los estudiantes del Programa pueden ser de tiempo completo, los que deberán cursar tres materias por semestre, o bien, estudiantes de tiempo parcial quienes tiene una carga menor, correspondiente a dos materias por semestre. Los alumnos también pueden tomar materias en otro programa de posgrado impartido en la universidad, siempre y cuando así lo recomiende su tutor y lo apruebe el Comité Académico.

Una de las metas del Centro Universitario de Investigaciones Bibliotecológicas y de la Facultad de Filosofía de Letras de la UNAM, quienes son los responsables de este Posgrado, es el establecimiento de sedes foráneas del mismo en diversos estados de nuestro país. Por lo anterior, actualmente se han establecido dos sedes foráneas de este posgrado; una de ellas en la Universidad Autónoma de Yucatán, la cual cuenta con 15 estudiantes y donde está por terminar la primera generación, y la otra en la Universidad Autónoma de San Luis Potosí, la cual cuenta con 12 estudiantes. En este último caso, el programa se está coordinando con la Escuela de Bibliotecología e Información e incluye un convenio para la impartición de la maestría y posteriormente del doctorado. Ambos programas tienen como objetivo satisfacer la demanda de recursos humanos formados a alto nivel y preparar personal que en unos pocos años pueda ser independiente y capaz de impartir la maestría en sus lugares de origen.

En estas sedes se han empezado a impartir cursos en la modalidad de educación virtual. Para tal fin, el CUIB ha desarrollado una plataforma de e-aprendizaje, en la cual se han incluido las recomendaciones para la planeación y conducción de cursos de e-aprendizaje. El espacio de e-aprendizaje del CUIB incluye siguientes secciones, las cuales son descritas a continuación: 


\section{Presentación}

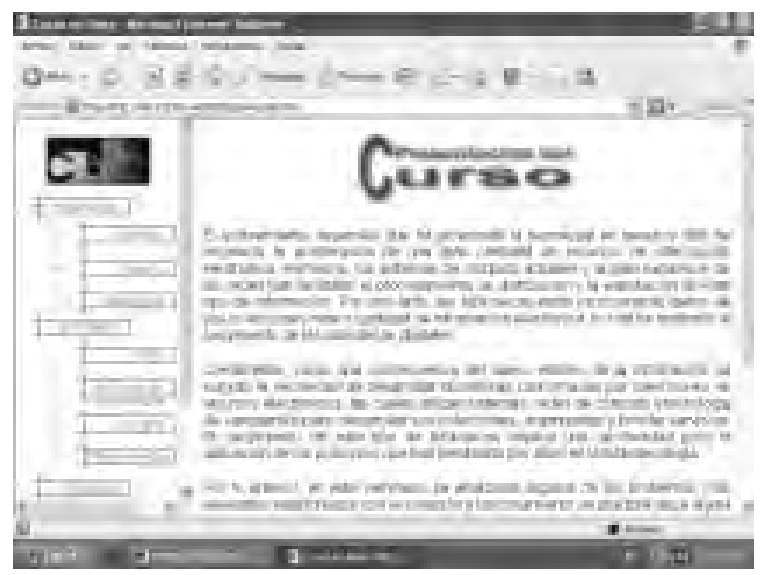

En esta sección del espacio de e-aprendizaje se ofrece un panorama general del curso o seminario, incluyendo lo que se espera de los alumnos y lo que se pretende lograr al final del mismo.

\section{Objetivos}

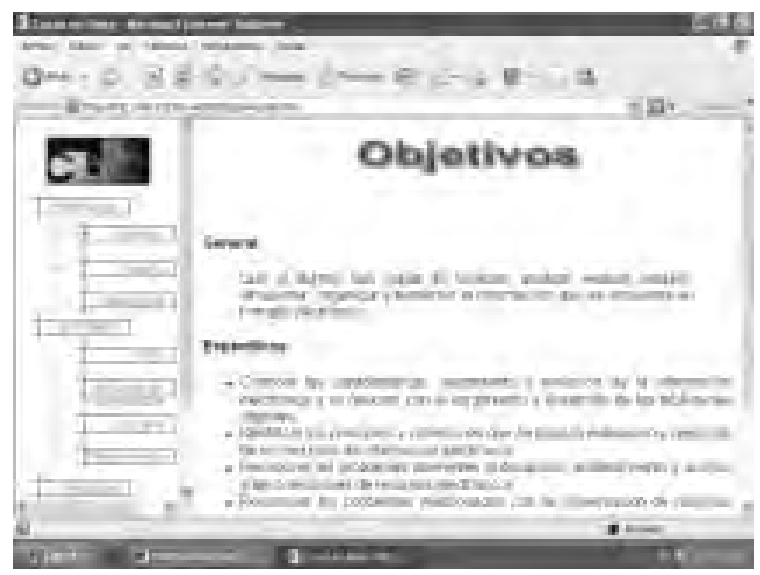

Esta sección incluye el objetivo general y los específicos del curso. Los objetivos específicos corresponden a cada una de las diferentes, unidades o bloques que integran el curso. 


\section{Temario}

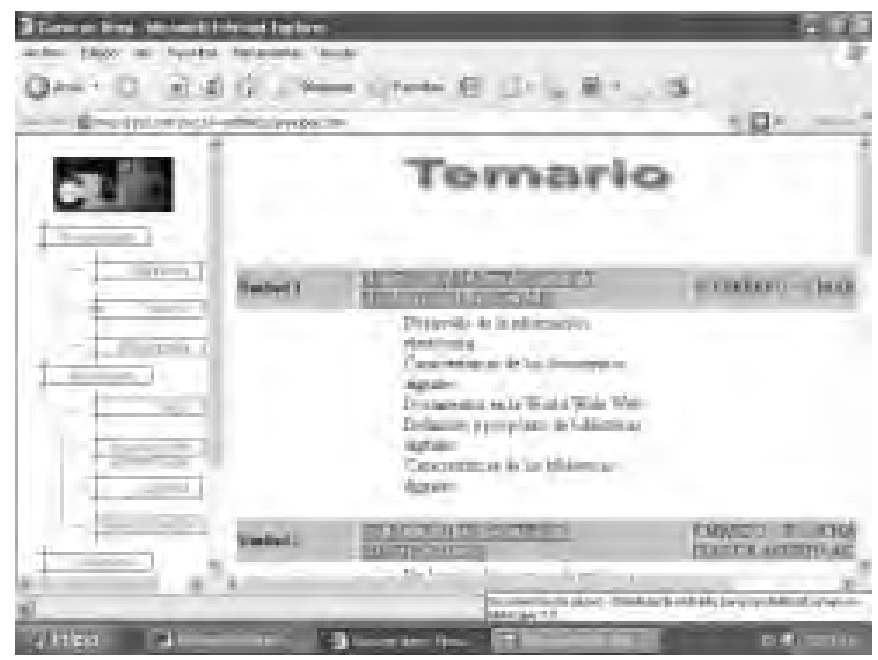

Aquí se le presenta al alumno el contenido del curso desarrollado por unidades, bloques, temas, etc., (El profesor determina la estructura de cada curso), las cuales son calendarizadas. Asimismo, cada una de las unidades es desarrollada y en ellas se incluye:

$\checkmark$ Objetivo. Este corresponde a cada uno de los objetivos específicos planteados para el curso.

$\checkmark$ Introducción. Una breve introducción al contenido de la unidad.

$\checkmark$ Contenido. Temas o tópicos que se abordarán en cada unidad.

$\checkmark$ Lecturas. Bibliografía que apoyará las actividades de aprendizaje de cada unidad.

$\checkmark$ Actividades de aprendizaje. Son determinadas por el profesor de acuerdo al contenido o naturaleza del curso y éstas pueden ser individuales y colectivas. Entre estas se encuentran los foros de discusión y la elaboración de ensayos. 


\section{E-aprendizaje en el Posgrado en Bibliotecología y Estudios ...}
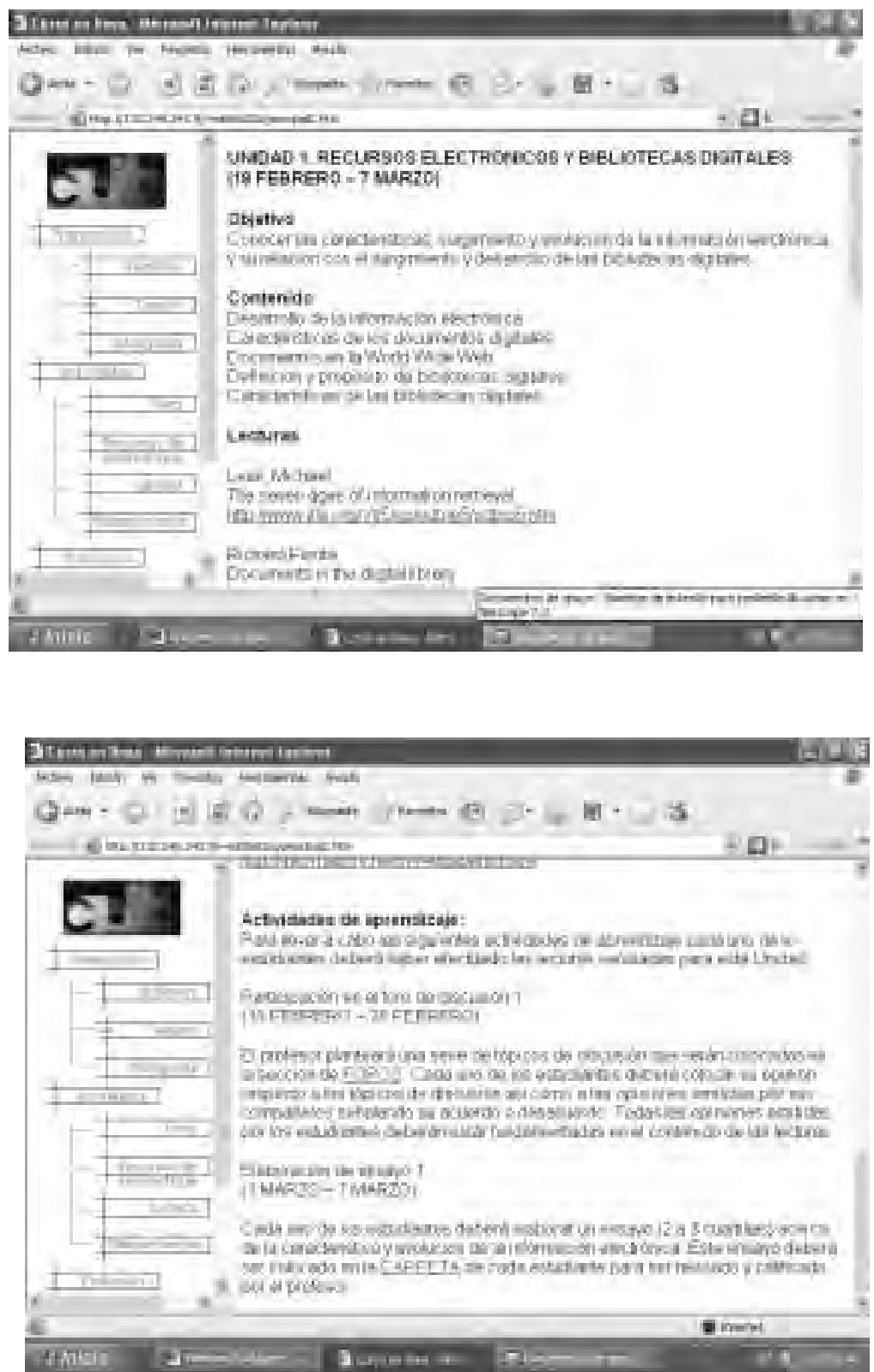


\section{Bibliografía}

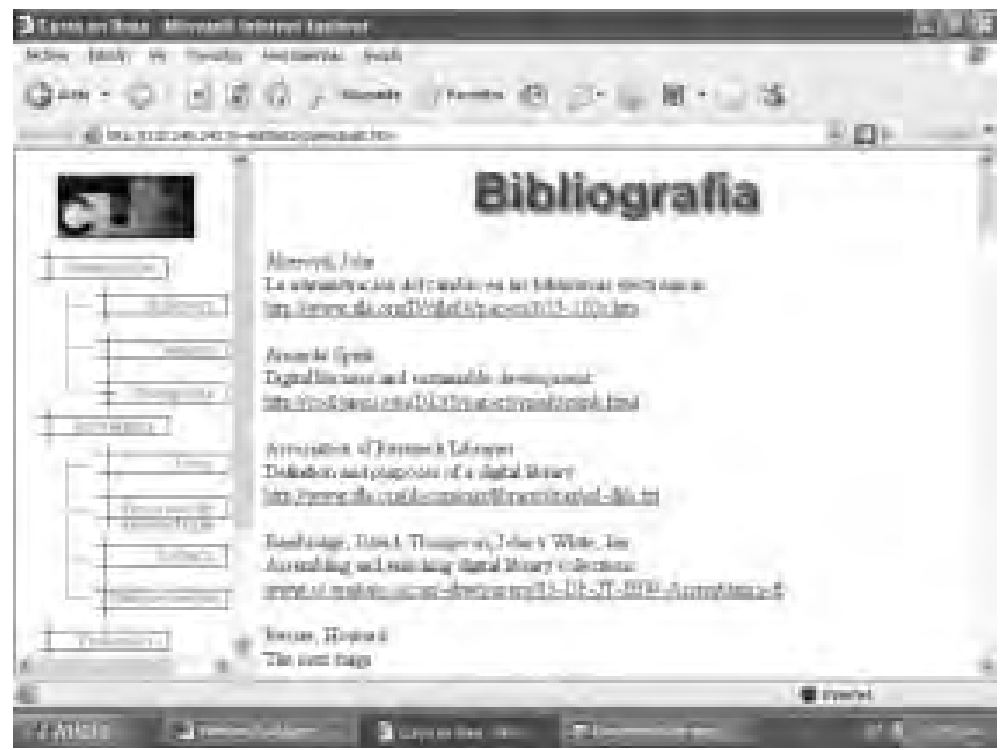

Aquí se incluyen las referencias bibliográficas de todo el curso y la manera de tener acceso a ellas. 


\section{Actividades de aprendizaje}

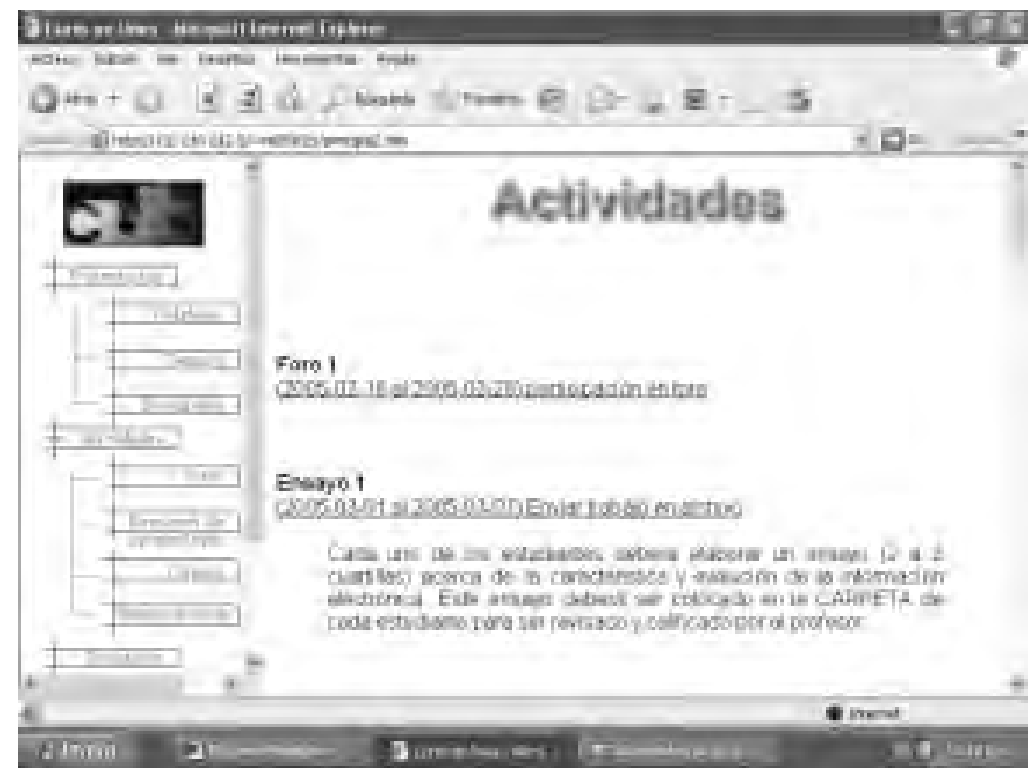

En esta sección se incluyen la totalidad de las actividades de aprendizaje para que el alumno pueda identificar aquellas que tiene que realizar en cada una de las diferentes unidades o bloques del curso, así como las fechas en que deberán ser desarrolladas. 


\section{Foros}
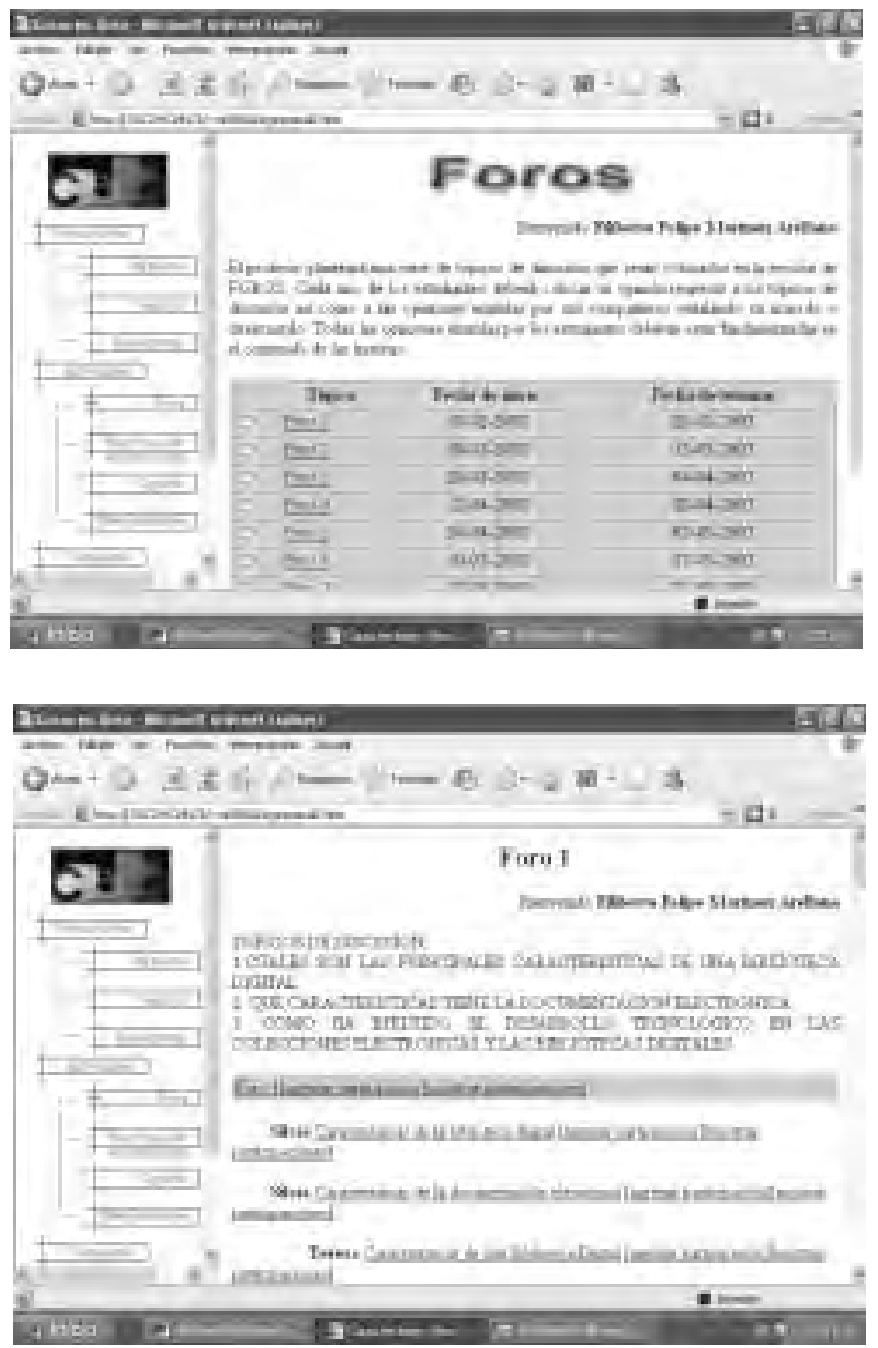

Esta es una de las secciones más importantes del espacio de aprendizaje ya que proporciona a los estudiantes una herramienta para interactuar con su profesor y con los demás miembros del curso o seminario, discutiendo y opinando sobre diversos tópicos plantea- 
dos por el profesor en cada unidad. La participación en los foros es asíncrona, pues las intervenciones de los estudiantes no están sujetas a un tiempo específico, sino que pueden tener acceso y participar en la discusión durante el tiempo que se establece para cada uno de los foros.

\section{Recursos de aprendizaje}

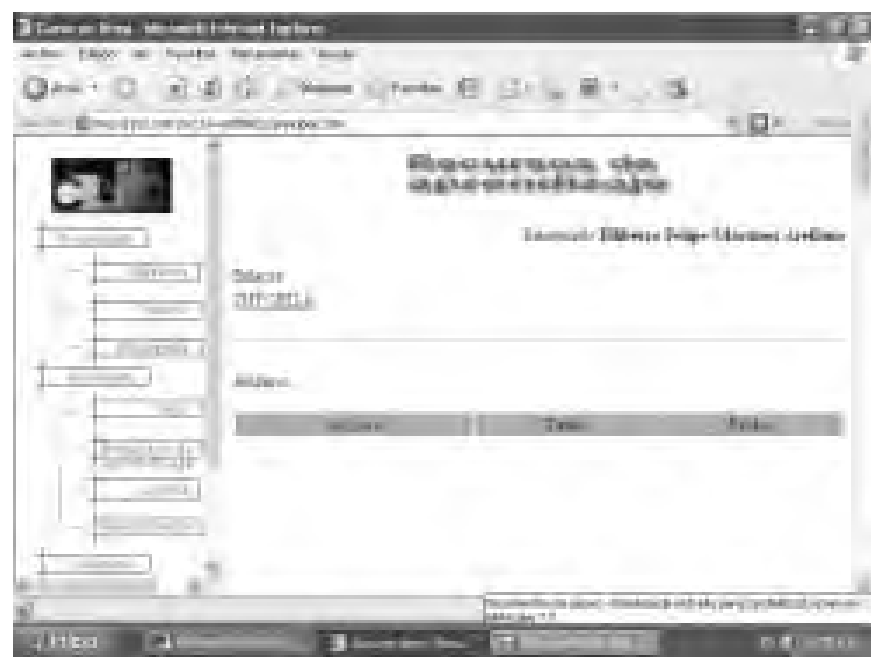

En esta parte se colocan los enlaces a bases de datos, bibliotecas virtuales, colecciones de publicaciones periódicas electrónicas, enciclopedias y diccionarios en formato digital, así como a otro tipo de recursos de utilidad para apoyar las actividades de aprendizaje de los alumnos y publicaciones electrónicas propias del profesor u otras. 


\section{Carpeta}

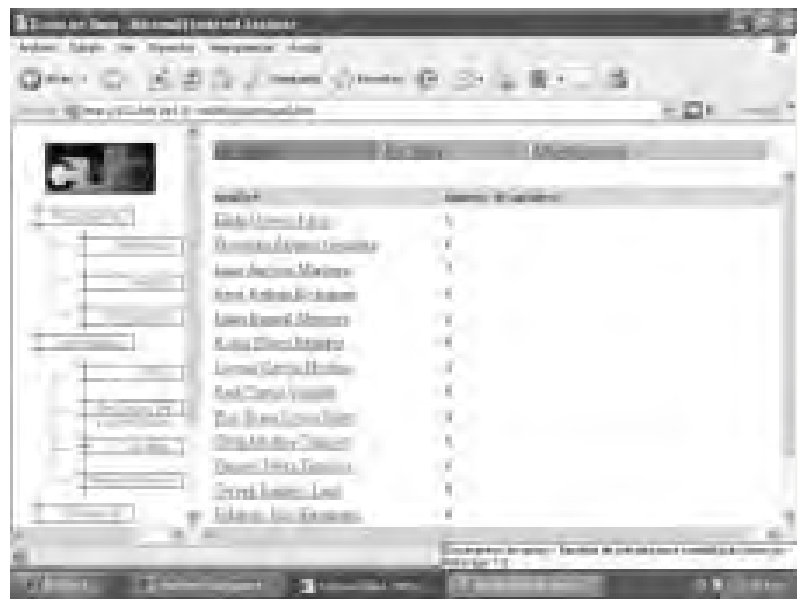

Este es el espacio destinado para que el alumno coloque los trabajos solicitados y el maestro los revise y brinde la retroalimentación necesaria. Los trabajos deben ser colocados durante el periodo previamente establecido, pues después que éste concluye, el sistema cierra automáticamente la posibilidad de colocar trabajos fuera del tiempo marcado para cada uno de ellos.

\section{Videoconferencias}

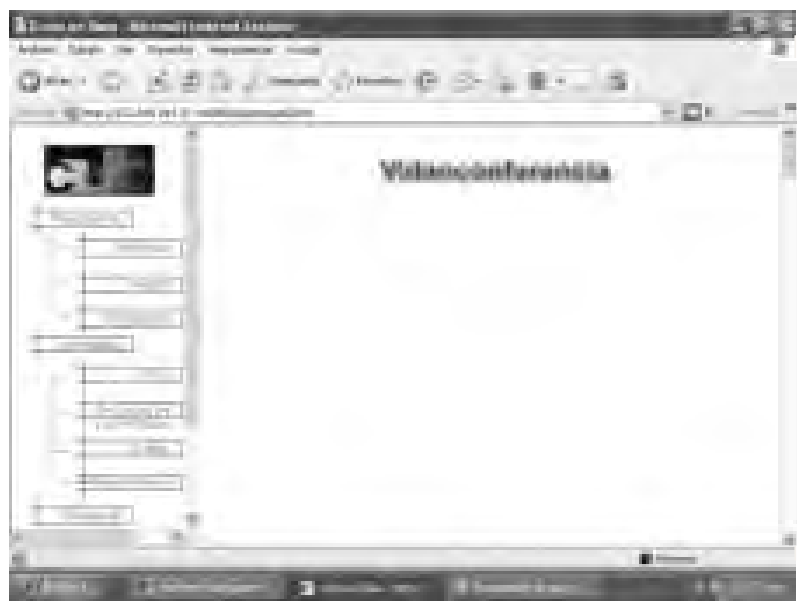


En esta parte son anunciadas y colocados algunos fragmentos de las videconferencias que tienen lugar dentro del curso o seminario. Estas tienen como finalidad que el profesor enriquezca el contenido del curso o seminario invitando a especialistas en los diferentes temas incluidos en el curso o seminario.

\section{Evaluación}

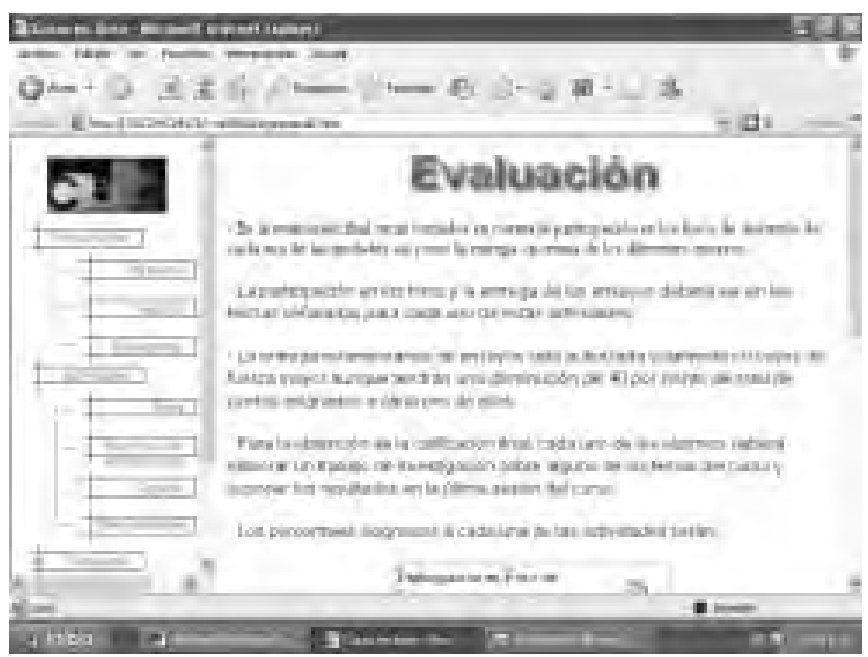

En esta sección se incluyen la valoración de cada una de las actividades de aprendizaje, la cual es necesario establecer desde el inicio del curso, Asimismo, se incluyen las condiciones de evaluación y las de acreditación del curso. 


\section{Alumnos}

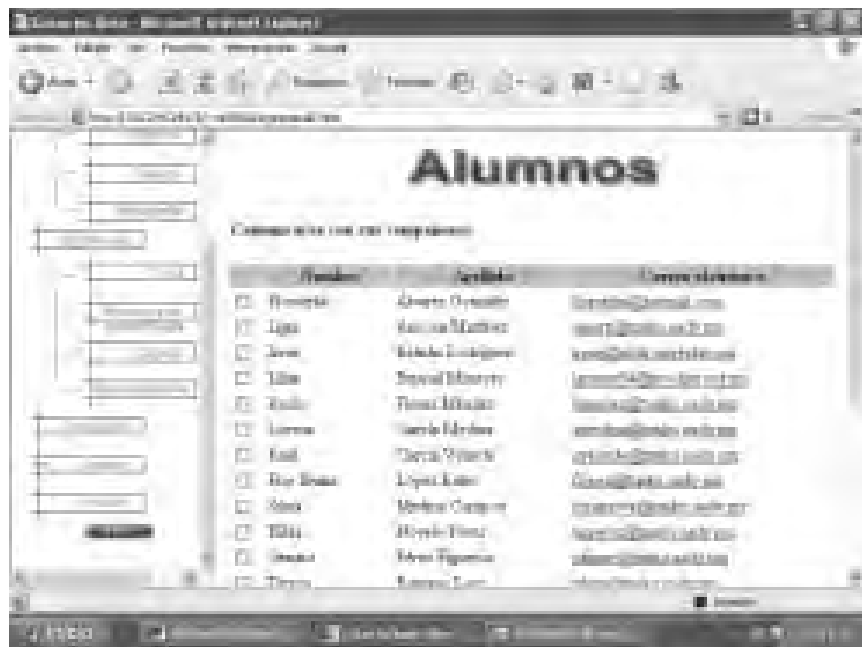

Esta sección del espacio de e-aprendizaje permite la comunicación de los alumnos con sus compañeros a través de correo electrónico, en forma individual o con un grupo de ellos, así como con su profesor. Asimismo, los alumnos pueden consultar en esta sección sus calificaciones en línea. 


\section{Profesor}
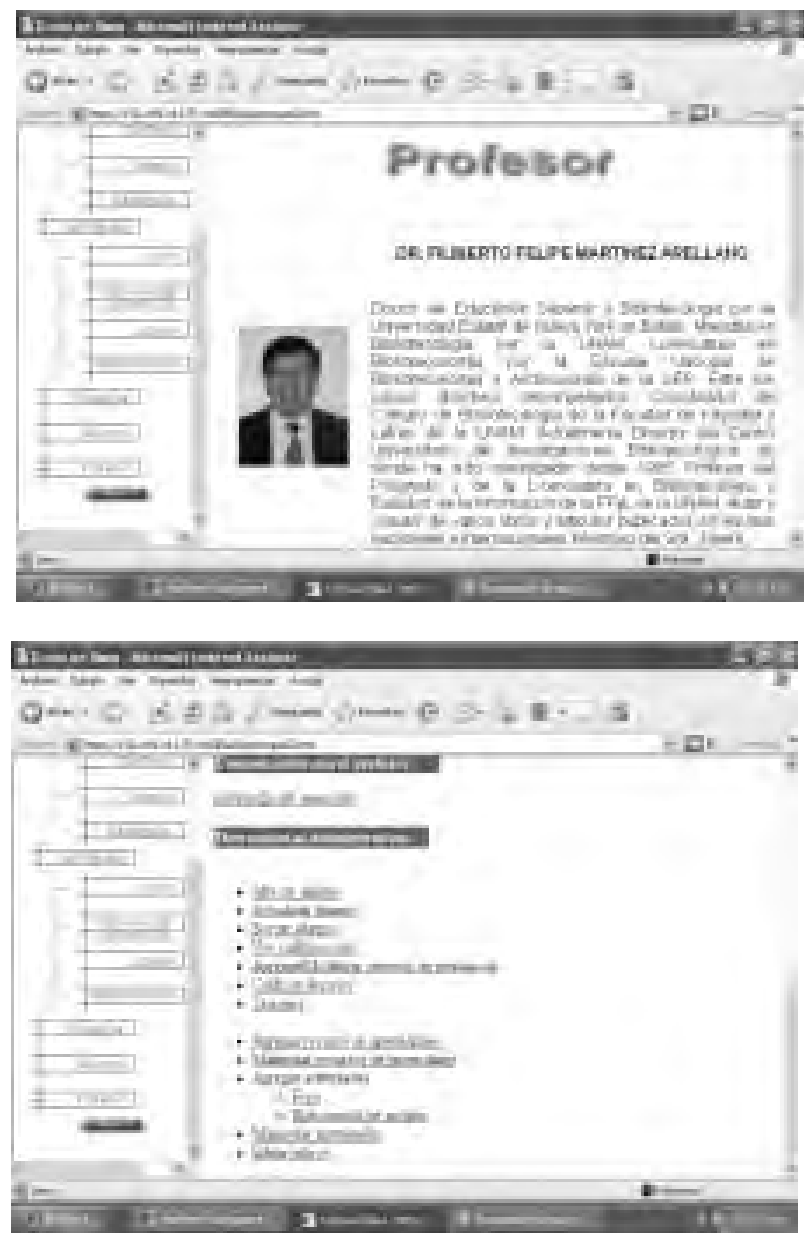

En esta parte los alumnos pueden encontrar una breve semblanza del profesor y comunicarse por correo electrónico con éste. Por otro lado, el profesor cuenta en esta sección con una serie de herramientas administrativas:

- Alta de alumno

- Actualizar alumno 
- Borrar alumno

- Ver calificaciones

- Agregar/Modificar criterios de evaluación

- Calificar alumnos

- Sesiones

- Agregar recurso de aprendizaje

- Manipular recursos de aprendizaje

- Agregar actividades

$\checkmark$ Foro

$\checkmark$ Elaboración de archivo

- Manipular actividades

- Editar rubros

Finalmente, es importante señalar que El Posgrado en Bibliotecología y Estudios de la Información ha impulsado el desarrollo e inicio de un programa de educación a distancia, basado en el uso de la plataforma del CUIB, en donde los tutores del programa desarrollen sus seminarios y cursos en una nueva forma. Se ha planeado el inició del Posgrado, totalmente en línea y en forma virtual, para agosto de 2005. Por el momento se está trabajando en la elaboración de los cursos y seminarios para esta nueva modalidad, aunque en la realidad son los mismos que se ofrecen en el sistema presencial. Se tienen ya terminados (mayo de 2005) los seis cursos de prerrequisito, además de siete cursos y seminarios de maestría y se está trabajando en siete más, esperado se concluyan en julio de este año. De esta forma, el Posgrado en Bibliotecología y Estudios de la Información se convertirá en una opción de e-aprendizaje en nuestra disciplina, la cual coadyuvará a la formación de profesionales en México y en América Latina, ya que en esta región existen muy pocas ofertas de educación bibliotecológica. Indudablemente, el inicio de la maestría en línea contribuirá a que la educación bibliotecológica llegue a todo el país y a otros países latinoamericanos. Esta nueva opción de e-aprendizaje, fortalecerá la bibliotecología mexicana y latinoamericana, pues al contar con mayor número de bibliotecarios, formados con un gran rigor académico, los servicios bibliotecarios que reciben los usuarios de esta región geográfica se verán fortalecidos. 


\section{CONSIDERACIONES FINALES}

Indudablemente, el surgimiento y desarrollo de las tecnologías de la información y comunicación TICs han generado nuevas opciones de comunicación, distribución y recuperación de la información, lo cual ha traído consigo la modificación de las características de la educación a distancia. La utilización de estos nuevos medios tecnológicos permite a los estudiantes localizar e interactuar con materiales y recursos educativos en formas que previamente no habían sido posibles.

En este nuevo tipo de educación, el cual ha empezado a ser denominado como e-aprendizaje, el elemento central es el aprendizaje interactivo mediante el uso de medios electrónicos, lo cual facilita la interacción espontánea de persona a persona y de experiencias colectivas, independientemente del tiempo y del lugar. Ciertamente, esta es una de las principales ventajas de esta opción educativa; sin embargo, también han sido expresado opiniones y puntos con relación a sus desventajas, mencionándose como una de las principales ser un proceso de aprendizaje aislado. No obstante lo anterior, la tecnología también ofrece diversas alternativas para lograr una disminución de estas desventajas.

Ciertamente, desarrollar un curso de e-aprendizaje es un gran reto pues implica identificar las actividades y alternativas pedagógicas para reproducir la situación de aprendizaje en el aula dentro de un ambiente virtual. Lo anterior implica que los profesores, además de poseer conocimientos sólidos en su disciplina y área de especialidad, deberán tener conocimientos y habilidades tecnológicas así como explorar opciones pedagógicas que les permitan desenvolverse adecuadamente en este nuevo entorno del e-aprendizaje.

Considerando que la tecnología puede apoyar los roles y actividades de los alumnos y del profesor en un ambiente de e-aprendizaje, el Centro Universitario de Investigaciones Bibliotecológicas (CUIB) de la UNAM ha desarrollado una plataforma electrónica para apoyar la impartición a distancia del Programa de Posgrado en Bibliotecología y Estudios de la Información, en la cual se reproduce el ambiente de aprendizaje del salón de clases tradicional en un entorno virtual. 
De esta forma, el Centro Universitario de Investigaciones Bibliotecológicas y la Facultad de Filosofía y Letras de la UNAM, han entrado en esta nueva fase de la educación a distancia y del e-aprendizaje en bibliotecología.

\section{REFERENCIAS}

Barron, Dan (2002). Distance education in Library and Information Science: a long road traveled. Journal of Education for Library and Information Science, 43(1), 3-5

Browne, Elizabeth (2003). Conversations in cyberspace: a study of online learning. Open Learning, 18(3), 245-259.

Gregory, Vicki L. (2003). Student perceptions of the effectiveness of Web-based distance education. New Library World, 104(10), 426-431.

Maddux, Cleborne D., Ewing-Taylor, Jacque y Lamont Johnson, D. (2002). The light and dark sides of distance education. Computers in the Schools, 19(3/4), 1-8.

National Center for Education Statistics (2004). Distance education at degree-granting postsecondary institutions: 2000-2001. http://nces.ed.gov/surveys/peqis/publications/2003017/ (Consultado, 25 de enero de 2005).

El e-aprendizaje (2004). http://tecnologia.monster.es/articulos/e_aprend/ (Consultado, 25 de enero de 2005).

Frey, Barbara, Alman, Susan Webreck, Barron, Dan y Steffens, Anne (2004). Student satisfaction with the online MLIS Program at the University of Pittsburg. Journal of Education for Library and Information Science, 45(2), 82-97.

Kirkwood Kirkwood, Adrian (2003). Understanding independent learners' use of media technologies. Open Learning, 18(2), 155-175. 
Mitra, Amanda y Hall, Amelia (2002). Distance education as a discursive practice: voice, discourse, and Pedagogy. Computers in the Schools, 19(3/4), 129-142.

Padula Perkins, Jorge Eduardo (2002). La cuestión bibliográfica en la educación a distancia. Educación y Biblioteca, 14(132), 54-58.

Reid, Peter H. (2003). The digital age and local studies. Oxford: Chandos.

Rodman, Ruey (2003). Cost analysis and student survey results of library support for distance education. Journal of the Medical L $i$ brary Association, 91(1), 72-88.

Sheer, Stephanie y Locke, Barbara (2003). Addressing the wellness needs of online distance learners. Open Learning, 18(2), 177-196.

Small, Ruth (1999). A comparison of resident and distance learning experience in Library and Information science graduate education.Journal of Education for Library and Information Science, 40(1), 27-47.

Universidad Nacional Autónoma de México (2004). Programa de Maestría y Doctorado en Bibliotecología y Estudios de la Información http://www.filos.unam.mx/POSGRADO/programa/biblio.htm (Consultado, 12 de Abril, 2004)

Wheeler, Justine y Fournier, Leslie (2001). Working in the asynchronous environment: two case studies. Journal of Library Administration, 32(1/2), 425-438.

Williams, Peter E. (2003). Roles and competencies for distance education programs in higher education institutions. The American Journal of Distance Education, 17(1), 45-57. 


\section{Autores}

\section{María Luisa de Almeida Campos}

Doutora em Ciencia da Infarcacao, UFRJ

Endereco: Rua Tiradentes 210, apt. 602

Ingá, Niterói, RJ Brasil

CEP: 24210510

Email: mlcampos@nitnet.com.br

\section{Hagar Espanba Gomes}

Livre Docente, UFF

Endereco Trav. Maria Elmina 37

Santa Rosa, Niterói, RJ Brasil

CEP: 24240-260

Email: hagarespanha@terra.com.br

Viviana Fernández Marcial

Doctora en Documentación

Universidad San Pablo CEU (Madrid)

Email: marcial.fhm@ceu.es

\section{Roberto Garduño Vera}

Doctor en Bibliotecología y Ciencias de la Información por la Universidad Complutense de Madrid, España.

Investigador Titular B de Tiempo Completo del Centro Universitario de Investigaciones Bibliotecológicas de la Universidad Nacional Autónoma de México.

Torre II de Humanidades, Piso 12, Ciudad Universitaria CP 04510, México, D.F.

Email: garduño@servidor.unam.mx

Filiberto Felipe Martínez Arellano

Doctor en Educación Superior y Bibliotecología por la

Universidad Estatal de Nueva York, Búfalo.

Director e Investigador Titular B del Centro Universitario de 
Investigaciones Bibliotecológicas de la Universidad Nacional Autónoma de México.

Torre II de Humanidades, Piso 11, 12 y 13, Ciudad Universitaria CP 04510, México, D.F.

Email: felipe@servidor.unam.mx

\section{Adolfo Rodríguez Gallardo}

Doctor en Pedagogía por la Universidad Nacional Autónoma de México.

Investigador Titular $\mathrm{C}$ de Tiempo Completo del Centro Universitario de Investigaciones Bibliotecológicas de la Universidad Nacional Autónoma de México.

Torre II de Humanidades, Piso 11, Ciudad Universitaria CP 04510, México, D.F. jadolfo@servidor.unam.mx

\section{Regina Santos Silva Tonini}

Master en Ciancia de la Información

Universidad de Brasilia Av. A.C.M., 1113, Ed. Universidade Corporativa 10. andar-Itagira-Salvador-Bahia-Brasil CEP 41.856.900.

Email: aymores@petrobras.com.br bibliotecarnne@petrobras.com.br rsstonini@uol.com.mx

\section{Abmed Taba}

Specialist in Research Information \& a-Access Services UAE University Libraries Deanship

P.O. Box 1441, Al-Ain

United Arab Emirates (UAE)

Fax: +(9713)-7666975

Email: Jazraby@mail2uae.com 

E-Aprendizaje en bibliotecología: perspectivas globales. La edición consta de 500 ejemplares. Coordinación editorial, Ignacio Rodríguez Sánchez. Formación editorial, Carlos Ceballos Sosa. Centro Universitario de Investigaciones Bibliotecológicas/ UNAM. Fue impreso en papel cultural ahuesado de 90 gr. en Desarrollo Gráfico Editorial, S. A. de C. V., ubicados en Municipio Libre 175, Nave Principal, Col. Portales, México D.F. Se terminó de imprimir en el mes de agosto de 2005. 